\title{
SAMHSA
}

\section{Driving After Drug or Alcohol Use: Findings from the 1996 National Household Survey on Drug Abuse}

\section{Office of Applied Studies}

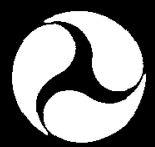

U.S. Department of Transportation

National Highway Traffic Safety Administration

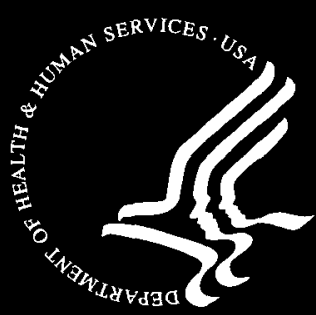

DEPARTMENT OF HEALTH AND HUMAN SERVICES Substance Abuse and Mental Health Services Administration 


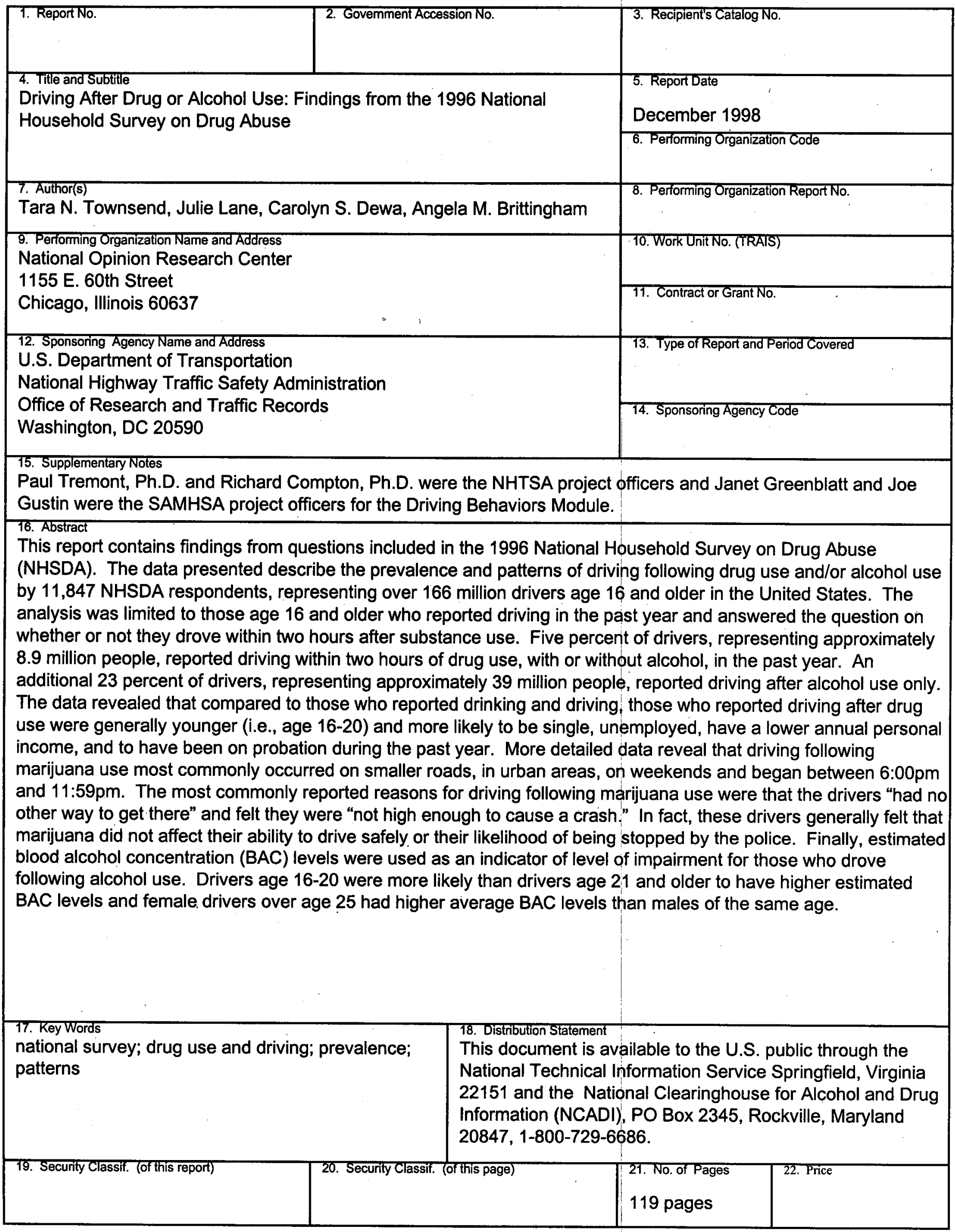




\section{OFFICE OF APPLIED STUDIES}

\section{Driving After Drug or Alcohol Use: Findings from the 1996 National Household Survey on Drug Abuse}

DEPARTMENT OF HEALTH AND HUMAN SERVICES

Substance Abuse and Mental Health Services Administration

DEPARTMENT OF TRANSPORTATION

National Highway Traffic Safety Administration 


\title{
ACKNOWLEDGMENTS
}

This publication was developed for the Substance Abuse and Mental Health Services Administration (SAMHSA) Office of Applied Studies (OAS) and the Department of Transportation (DOT) National Highway Traffic Safety Administration (NHTSA), by the National Opinion Research Center (NORC), under Contract No. 283-95-0002. Dean Gerstein was the Principal Investigator and Janet Greenblatt and Joe Gustin were the OAS Project Officers. The authors were Tara N. Townsend, Ph.D., Julie Lane, Ph.D., Carolyn S. Dewa, M.P.H., Ph.D., and Angela M. Brittingham, M.A.

\section{PUBLIC DOMAIN NOTICE}

All material appearing in this report is in the public domain and may be reproduced or copied without permission from the Substance Abuse and Mental Health Services Administration or the National Highway Traffic Safety Administration. Citation of the source is appreciated.

\section{OBTAINING ADDITIONAL COPIES OF PUBLICATIONS}

Copies may be obtained, free of charge, from the National Clearinghouse for Alcohol and Drug Information (NCADI) and the National Technical Information Service (NTIS):

National Clearinghouse for Alcohol and Drug Information (NCADI)

P.O. Box 2345

Rockville, MD 20847-2345

(301) 468-2600 1-800-729-6686 1-800-487-4889 (TDD)

National Technical Information Service

Springfield, VA 22151

\section{ELECTRONIC ACCESS TO PUBLICATION}

This publication can be accessed electronically through the Internet Worldwide Web connections listed below:

\author{
http://www.samhsa.gov http://www.health.org http://www.nhtsa.gov \\ ORIGINATING OFFICE: \\ SAMHSA, Office of Applied Studies \\ 5600 Fishers Lane, Room 16-105 \\ Rockville, MD 20857
}

December 1998 


\section{TABLE OF CONTENTS}

Page

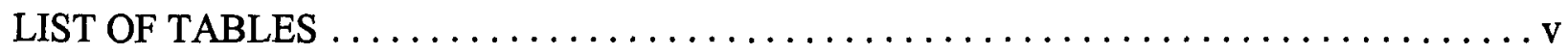

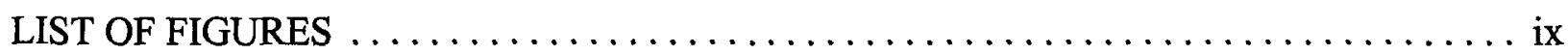

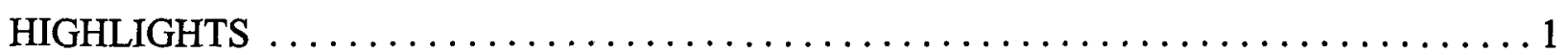

\section{CHAPTERS}

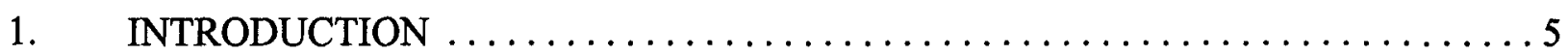

2. FINDINGS ON DRUG USE AND DRIVING BEHAVIORS FROM THE

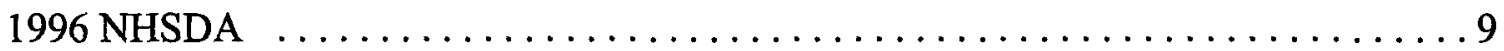

A. Demographic Characteristics ........................... 19

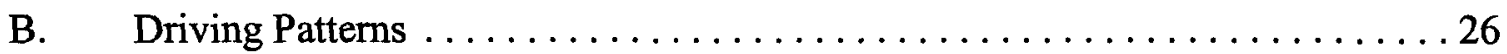

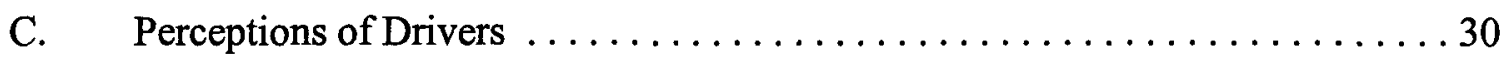

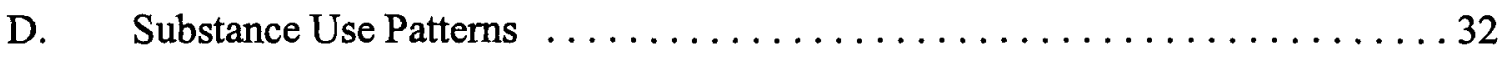

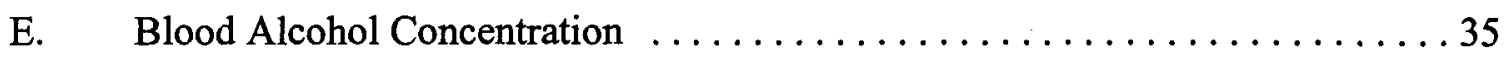

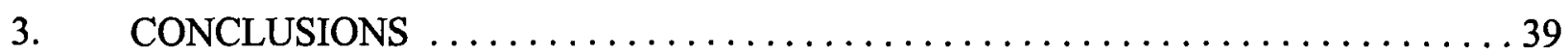

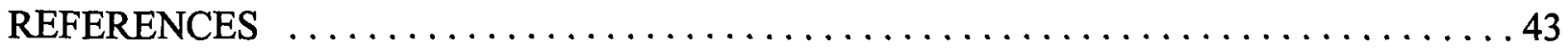

APPENDICES

A. DETAILED DATA TABLES $\ldots \ldots \ldots \ldots \ldots \ldots \ldots \ldots \ldots \ldots \ldots \ldots$

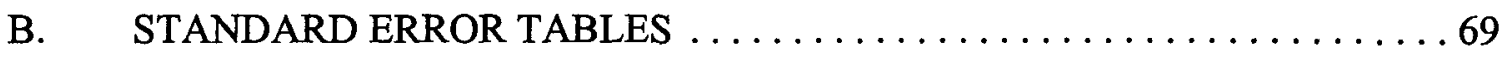

C. NHSDA METHODOLOGY AND LIMITATIONS OF THE DATA $\ldots \ldots .91$

Sample Design ................................ 91

Data Collection Methodology $\ldots \ldots \ldots \ldots \ldots \ldots \ldots \ldots . \ldots . \ldots 93$

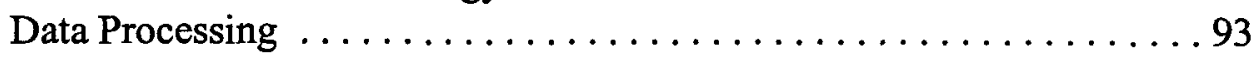




\section{TABLE OF CONTENTS (continued)}

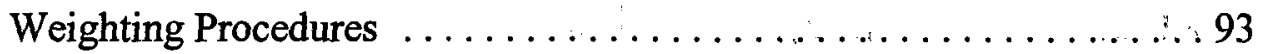

Limitations of the Data ........................ 95

References ...............................997

D. ESTIMATION OF BLOOD ALCOHOL CONCENTRATION (BAC)

LEVELS . . . . . . . . . . . . . . . . . . . . . . . . . . . 99

E. 1996 NHSDA DRIVING BEHAVIORS MODULE $\ldots \ldots \ldots \ldots \ldots \ldots \ldots$ 


\section{LIST OF TABLES}

Table 1a. Age, Gender, Racial/Ethnic, and Regional Distribution of Total Driving Population Age 16+ who Reported Driving in the Past Year, 1996 . . . . . . 47

Table 1b. Marital, Educational, Employment, and Personal Income Distribution of Total Driving Population Age 16+ who Reported Driving in the Past

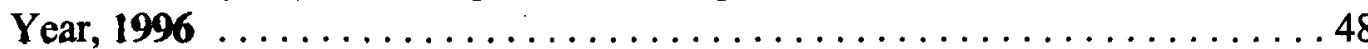

Table 2. Percentage of Drivers Age 16+ in Age, Gender, and Regional Groups who Drove Within Two Hours of Substance Use by Substance Used, 1996 . . . . . 49

Table 3a. Percentage of Drivers Age 16+ within Age, Gender, Racial/Ethnic, and Regional Groups who Drove within Two Hours of Substance Use in the Past Year by Substance Used, $1996 \ldots \ldots \ldots \ldots \ldots \ldots \ldots \ldots \ldots \ldots . \ldots \ldots$

Table 3b. Percentage of Drivers Age 16+ within Marital, Educational, Employment, and Personal Income Groups who Drove within Two Hours of Substance Use in the Past Year by Substance Used, $1996 \ldots \ldots \ldots \ldots \ldots \ldots \ldots . . . . .51$

Table 4. Percentage of Drivers Age 16+ within Age by Gender, Racial/Ethnic by Age, and Racial/Ethnic by Gender Groups who Drove within Two Hours of Substance Use in the Past Year by Substance Used, 1996

Table 5. Percentage of Drivers Age 16+ Arrested and Not Arrested and on Probation and Not on Probation in the Past Year who Drove within Two Hours of Substance Use in the Past Year by Substance Used, $1996 \ldots \ldots \ldots \ldots . . .53$

Table 6a. Age, Gender, Racial/Ethnic, and Regional Distribution of Drivers Age 16+ who Drove within Two Hours of Substance Use in the Past Year

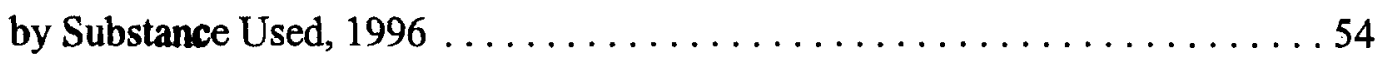

Table 6b. Marital, Educational, Employment, and Personal Income Distribution of Drivers Age 16+ who Drove within Two Hours of Substance Use in the

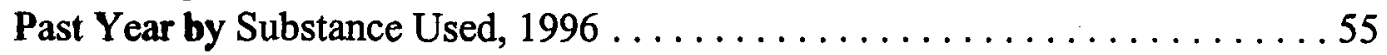

Table 7. Age by Gender, Racia//Ethnic by Age, and Racial/Ethnic by Gender Distribution of Drivers Age 16+ who Drove within Two Hours of Substance Use in the Past Year by Substance Used, 1996 56 


\section{LIST OF TABLES (continued)}

Table 8. Past-Year Arrest and Probation Status Distribution of Drivers Age 16+ who Drove within Two Hours of Substance Use in the Past Year by Substance Used, 1996

Table 9. Distribution of Size of Road Driven, Area Driven, Day of Week Driven, and Time of Day Driving Began on Most Recent Occasion of Driving within Two Hours of Marijuana Use for Drivers Age 16+ who Drove Following Marijuana Use in the Past Year by Age Group, 1996

Table 10. Distribution of Starting Point and Destination on Most Recent Occasion of Driving within Two Hours of Marijuana Use for Drivers Age 16+ who Drove Following Marijuana Use in the Past Year by Age Group, 1996

Table 11. Percentage of Drivers Age 16+ who Drove within Two Hours of Marijuana Use in the Past Year Reporting Reasons for Driving on Most Recent Occasion of Driving Following Marijuana Use by Age Group, 1996

Table 12. Distribution of Perceived Extent to which Marijuana Affected Ability to Drive Safely on Most Recent Occasion of Driving within Two Hours of Marijuana Use for Drivers Age 16+ who Drove Following Marijuana Use in the Past Year by Age Group, 1996

Table 13. Distribution of Perceived Likelihood of Being Stopped by the Police when Driving Following Marijuana Use Compared to when Driving on Other Occasions for Drivers Age 16+ who Drove within Two Hours of Marijuana Use in the Past Year by Age Group, 1996 . . . . . . . . . . . . . . . . . . . 61

Table 14. Distribution of Number of Days in Past Month Drove within Two Hours of Alcohol or Marijuana Use, for All Ages and within Age Groups, for Drivers Age 16+ who Drove Following Alcohol Use Only or Marijuana Use in the

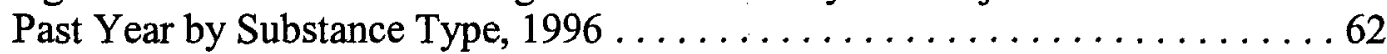

Table 15. Distribution of Level of Past-Month Alcohol Use or Past-Year Marijuana Use for Drivers Age 16+ who Drove within Two Hours of Alcohol Use Only or Marijuana Use in the Past Year by Age Group, 1996

Table 16. Distribution of Whether or Not Other Substances Were Also Used on Most Recent Occasion of Driving within Two Hours of Marijuana Use for Drivers Age 16+ who Drove Following Marijuana Use in the Past Year by Age

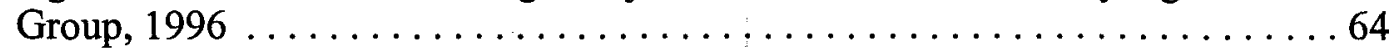

Table 17. Percentage of Drivers Age 16+ who Drove within Two Hours of Using Marijuana and Another Substance in the Past Year by Age Group, 1996 


\section{LIST OF TABLES (continued)}

Table 18. Distribution of Number of Drinks Consumed, Number of Hours between First and Last Drink, and Time between Last Drink and when Driving Began on Most Recent Occasion of Driving within Two Hours of Alcohol Use for Drivers Age 16+ who Drove Following Alcohol Use in the Past

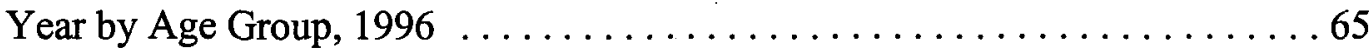

Table 19. Distribution of Estimated Blood Alcohol Concentration (BAC) Levels on Most Recent Occasion of Driving within Two Hours of Alcohol Use for Drivers Age 16+ who Drove Following Alcohol Use in the Past Year by Age within Gender, 1996 . . . . . . . . . . . . . . . . 66

Table 20. Average Estimated Blood Alcohol Concentration (BAC) Level on Most Recent Occasion of Driving within Two Hours of Alcohol Use for Drivers Age 16+ who Drove Following Alcohol Use in the Past Year by Gender and Age, 1996 


\section{LIST OF FIGURES}

Figure 2.1 Percentage and Number (in thousands) of Drivers Age 16+ who Reported Whether or Not They Drove within Two Hours of Substance Use in the

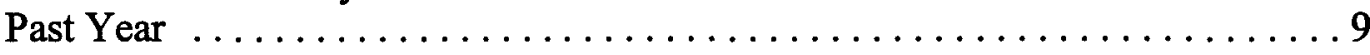

Figure 2.1a Percentage of Drivers Age 16+ who Drove within Two Hours of Drug Use in the Past Year by Drug Used . . . . . . . . . . . . . . . . 10

Figure 2.2 Percentage of Drivers Age 16+ within Age Groups who Drove within Two Hours of Substance Use in the Past Year by Substance Used . . . . . . . . . 11

Figure 2.3 Percentage of Male and Female Drivers Age 16+ who Drove within Two Hours of Substance Use in the Past Year by Substance Used . . . . . . . . . 11

Figure 2.4 Percentage of Drivers Age 16+ within Racial/Ethnic Groups who Drove within Two Hours of Substance Use in the Past Year by Substance Used . . . . 12

Figure 2.5 Percentage of Drivers Age 16+ within each Region who Drove within Two Hours of Substance Use in the Past Year by Substance Used . . . . . . . . 12

Figure 2.6 Percentage of Drivers Age 16+ within Marital Categories who Drove within Two Hours of Substance Use in the Past Year by Substance Used . . . . 13

Figure 2.7 Percentage of Drivers Age 16+ within Educational Levels who Drove within Two Hours of Substance Use in the Past Year by Substance Used . . . . 13

Figure 2.8 Percentage of Drivers Age 16+ within Employment Categories who Drove within Two Hours of Substance Use in the Past Year by Substance Used . . . . 14

Figure 2.9 Percentage of Drivers Age 16+ within Personal Income Levels who Drove within Two Hours of Substance Use in the Past Year by Substance Used . . . . 14

Figure 2.10 Percentage of Drivers Age 16+ within Gender by Age Groups who Drove within Two Hours of Substance Use in the Past Year by Substance Used . . . . 15

Figure 2.11 Percentage of Drivers Age 16+ within Racial/Ethnic by Age Groups who Drove within Two Hours of Substance Use in the Past Year by Substance Used

Figure 2.12 Percentage of Drivers Age 16+ within Racial/Ethnic by Gender Groups who Drove within Two Hours of Substance Use in the Past Year by Substance Used 


\section{LIST OF FIGURES (continued)}

Figure 2.13 Percentage of Drivers Age 16+ with and without Past-Year Arrests who Drove within Two Hours of Substance Use in the Past Year by

Substance Used

Figure 2.14 Percentage of Drivers Age 16+ on Probation and Not on Probation in the Past Year who Drove within Two Hours of Substance Use in the Past Year by Substance Used . . . . . . . . . . . . . . . . . . . . 18

Figure 2.15 Age Distribution of Drivers Age 16+ who Drove within Two Hours of Substance Use in the Past Year by Substance Used . . . . . . . . . . . . . 19

Figure 2.16 Gender Distribution of Drivers Age 16+ who Drove within Two Hours of Substance Use in the Past Year by Substance Used . . . . . . . . . . . 20

Figure 2.17 Racial/Ethnic Distribution of Drivers Age 16+ who Drove within Two Hours of Substance Use in the Past Year by Substance Used

Figure 2.18 Marital Distribution of Drivers Age 16+ who Drove within Two Hours of Substance Use in the Past Year by Substance Used . . . . . . . . . . 21

Figure 2.19 Educational Distribution of Drivers Age 16+ who Drove within Two Hours of Substance Use in the Past Year by Substance Used . . . . . . . . . . 21

Figure 2.20 Employment Distribution of Drivers Age 16+ who Drove within Two Hours of Substance Use in the Past Year by Substance Used . . . . . . . . . . 22

Figure 2.21 Personal Income Distribution of Drivers Age 16+ who Drove within Two Hours of Substance Use in the Past Year by Substance Used . . . . . . . . 22

Figure 2.22 Racial/Ethnic by Gender Distribution of Drivers Age 16+ who Drove within Two Hours of Substance Use in the Past Year by Substance Used . . . . 23

Figure 2.23 Past-Year Arrest Distribution of Drivers Age 16+ who Drove within Two Hours of Substance Use in the Past Year by Substance Used . . . . . . . . . . 24

Figure 2.24 Past-Year Probation Status Distribution of Drivers Age 16+ who Drove within Two Hours of Substance Use in the Past Year by Substance.Used . . . 25

Figure 2.25 Distribution of Size of Road Driven on Most Recent Occasion of Driving within Two Hours of Marijuana Use for Drivers Age 16+ who Drove Following Marijuana Use in the Past Year by Age Group . . . . . . . . 26 


\section{LIST OF FIGURES (continued)}

Figure 2.26 Distribution of Area Driven on Most Recent Occasion of Driving within Two Hours of Marijuana Use for Drivers Age 16+ who Drove Following Marijuana Use in the Past Year by Age Group ................. 26

Figure 2.27 Distribution of Day of Week Driven on Most Recent Occasion of Driving within Two Hours of Marijuana Use for Drivers Age 16+ who Drove Following Marijuana Use in the Past Year by Age Group ......... 27

Figure 2.28 Distribution of Time of Day Driving Began on Most Recent Occasion of Driving within Two Hours of Marijuana Use for Drivers Age 16+ who Drove Following Marijuana Use in the Past Year by Age Group ...... 27

Figure 2.29 Distribution of Starting Point on Most Recent Occasion of Driving within Two Hours of Marijuana Use for Drivers Age 16+ who Drove Following Marijuana Use in the Past Year by Age Group ............ 28

Figure 2.30 Distribution of Destination on Most Recent Occasion Drove within Two Hours of Marijuana Use for Drivers Age 16+ who Drove Following Marijuana Use in the Past Year by Age Group $\ldots \ldots \ldots \ldots \ldots \ldots \ldots . \ldots 28$

Figure 2.31 Percentage of Drivers Age 16+ who Drove within Two Hours of Marijuana Use in the Past Year Reporting Reasons for Driving on Most Recent Occasion of Driving Following Marijuana Use by Age Group . . . . . . . . 29

Figure 2.32 Distribution of Perceived Extent to which Marijuana Affected Ability to Drive Safely on Most Recent Occasion of Driving within Two Hours of Marijuana Use for Drivers Age 16+ who Drove Following Marijuana

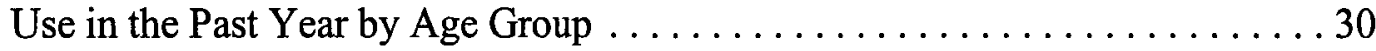

Figure 2.33 Distribution of Perceived Likelihood of Being Stopped by the Police when Driving Following Marijuana Use Compared to when Driving on Other Occasions for Drivers Age 16+ who Drove within Two Hours of Marijuana Use in the Past Year by Age Group ................... 31

Figure 2.34 Distribution of Number of Days in Past Month Drove within Two Hours of Marijuana or Alcohol Use for Drivers Age 16+ who Drove Following Marijuana Use or Alcohol Use in the Past Year by Age Group .......... 32 


\section{LIST OF FIGURES (continued)}

Figure 2.35 Distribution of Level of Past-Year Marijuana Use and Past-Month Alcohol Use for Drivers Age 16+ who Drove within Two Hours of Marijuana Use or Alcohol Use Only in the Past Year by Age Group ........ 33

Figure 2.36 Distribution of Whether or Not Other Substances Were Also Used on Most Recent Occasion of Driving within Two Hours of Marijuana Use for Drivers Age 16+ who Drove Following Marijuana Use in the Past Year by

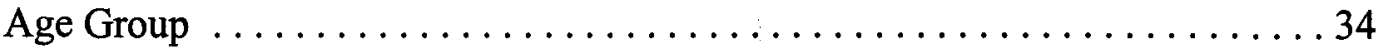

Figure 2.37 Percentage of Drivers Age 16+ who Drove within Two Hours of Marijuana Use in the Past Year Reporting Use of Other Substances when Driving Following Marijuana Use by Age Group .................... 34

Figure 2.38 Distribution of Number of Drinks Consumed on Most Recent Occasion of Driving within Two Hours of Alcohol Use for Drivers Age 16+ who Drove Following Alcohol Use in the Past Year by Age Group ............. 35

Figure 2.39 Distribution of Number of Hours between First and Last Drink on Most Recent Occasion of Driving within Two Hours of Alcohol Use for Drivers Age 16+ who Drove Following Alcohol Use in the Past Year by Age Group . . 36

Figure 2.40 Distribution of Time between Last Drink and When Driving Began on Most Recent Occasion of Driving within Two Hours of Alcohol Use for Drivers Age 16+ who Drove Following Alcohol Use in the Past Year by Age Group . . 36

Figure 2.41 Distribution of Estimated Blood Alcohol Concentration Levels on Most Recent Occasion of Driving within Two Hours of Alcohol Use for Drivers Age 16+ who Drove Following Alcohol Use in the Past Year by Gender . . . . 37

Figure 2.42 Average Estimated Blood Alcohol Concentration Level on Most Recent Occasion of Driving within Two Hours of Alcohol Use for Male and Female Drivers Age 16+ who Drove Following Alcohol Use in the Past Year by Age . 37 


\section{HIGHLIGHTS}

This report contains findings about drug use and driving using data collected in the 1996 National Household Survey on Drug Abuse (NHSDA). The 1996 NHSDA included questions developed through a collaborative effort between the Substance Abuse and Mental Health Services Administration (SAMHSA) and the National Highway Traffic Safety Administration (NHTSA). The questions were designed to examine past year prevalence and patterns of driving behaviors within two hours after substance use.

The data presented in this report come from in-home personal interviews with 11,847 NHSDA respondents, age 16 and older, representing over 166 million drivers in the United States. The 166 million drivers represent only those drivers who reported driving a motor vehicle on at least one occasion in the 12 months prior to their interview and reported whether or not they drove within two hours after drug and/or alcohol use. The primary purpose of this report is to present data on driving following drug use, an area in which previous research is limited. Data on driving after alcohol use are also presented for comparison purposes. In the following summary statements, 'driving after drug use' refers to 'driving within two hours after the use of drugs, with or without alcohol, in the past year'. 'Driving after alcohol use only' means 'driving within two hours after the use of alcohol without the use of drugs in the past year' unless otherwise noted. With these definitions in mind, the principal findings of this report are as follows:

- 28 percent (46.5 million people) reported driving within two hours after drug or alcohol use:

- 5 percent (9 million people) drove after drug use, with or without alcohol, and

- 23 percent (38 million people) drove after alcohol use only.

\section{Characteristics of Drivers Who Drove after Drug Use}

- Driving after drug use was more common among drivers who were:

- Young (13\% for those age $16-20$ vs. 5\% for those age 21 and older),

- Male ( $7 \%$ vs. $4 \%$ for females),

- Never married ( $11 \%$ vs. $3 \%$ for those who were married), and

- Unemployed ( $11 \%$ vs. $6 \%$ for those employed full-time). 
- Driving after drug use was more common among those who reported, in the past year, being:

- Arrested (18\% vs. $4 \%$ for those not arrested) or

- On probation ( $22 \%$ vs. $5 \%$ for those not on probation).

- Marijuana was the illicit drug used most often by drivers who drove after drug use (used by $70 \%$ of those who drove after drug use).

- Among those who reported driving after using marijuana:

- The majority reported heavy or weekly use in the past year (60\%).

- Drivers age 21 and older were more likely than drivers age 16-20 to report driving after using marijuana in combination with alcohol ( $37 \%$ and $24 \%$, respectively).

- More than half claimed that the marijuana use did not at all affect their ability to drive safely $(56 \%)$

- More than half perceived that they were no more likely to be stopped by police when driving after marijuana use than on other occasions $(69 \%$ of those age 21 and older and $54 \%$ of those age 16-20).

- A large majority of those who drove after the use of tranquilizers and sedatives ( $84 \%$ and $71 \%$, respectively) drove following the medical use of these drugs. In contrast, only 43 percent of those who drove after the use of stimulants used these drugs for medical purposes.

- Driving after drug use most commonly occurred on smaller roads (55\%), in urban areas (56\%), on the weekend (67\%), and usually began between 6:00 p.m. and 11:59 p.m. (49\%).

- The most commonly reported reasons for driving on these occasions were that drivers felt there was "no other way to get there" (69\% of those age 16-20 and 59\% of those age 21 and older) and that they were "not high enough to cause a crash" (57\% of those age $16-20$ and $60 \%$ of those age 21 and older). 


\section{Characteristics of Drivers Who Drove After Alcohol Use}

- Driving after alcohol use was more common among:

- Those age 21 and older ( $9 \%$ of those age $16-18$ and $15 \%$ of those age $19-20$ vs. $29 \%$ of those age $21-34$ and $17 \%$ of those age 50 and older).

- Males rather than females ( $31 \%$ and $14 \%$, respectively).

- Among those who reported driving after alcohol use:

- A large majority (86\%), reported low or medium past month alcohol use.

- Drivers age 16-20 were more likely than drivers age 21 and older to report heavy alcohol use ( 5 or more drinks on 5 or more occasions in the past month) ( $32 \%$ vs. $14 \%)$.

- On the most recent occasion of driving after alcohol use (with or without drugs):

- Those age 16-20 were more likely than drivers age 21 and older to report binge drinking (consuming 5 or more drinks on one occasion) ( $39 \%$ vs. $13 \%$ ).

- Drivers age 16-20 were more likely than drivers age 21 and older to report that they drank their first and last drink in less than one hour ( $30 \%$ vs. $15 \%)$.

- More than one-third of drivers age 16-20 had an average estimated blood alcohol concentration $(\mathrm{BAC})$ level greater than $.08 \mathrm{~g} / \mathrm{dl}$ (the legal limit for drivers age 21 and older in some states).

- Female drivers age 21 and older generally had higher average BAC levels than males of the same age ( $48 \%$ of females had a BAC level equal to or greater than $0.2 \mathrm{~g} / \mathrm{dl} \mathrm{vs.} 32 \%$ of males). 


\section{CHAPTER 1: INTRODUCTION}

Drug-impaired driving has been identified as a major threat to public health, but there are limited data on the prevalence and nature of drug use and driving. In an effort to address the lack of available data, the Substance Abuse and Mental Health Services Administration (SAMHSA), in conjunction with the National Highway Traffic Safety Administration (NHTSA), developed and implemented a special module of questions in the 1996 National Household Survey on Drug Abuse (NHSDA). The Driving Behaviors Module was designed to gather information about the prevalence and patterns of substance use among U.S. drivers.

An earlier study conducted by the NHTSA (1992b) examined the incidence and role of drug use and driving in fatal traffic crashes. Using blood specimens, police reports, coroner/medical examiner reports, and reports from the Fatality Analysis Reporting System ${ }^{1}$ (FARS), the study examined the role of alcohol and 43 other drugs in the deaths of 1,882 drivers of cars, trucks, and motorcycles in seven states from 1990 to 1991 . Nearly 60 percent of the blood specimens examined tested positive for at least one substance. Among drivers who tested positive for only one substance, alcohol was the most common substance. The majority of drivers were legally intoxicated with blood alcohol concentration (BAC) levels greater than 10 $\mathrm{g} / \mathrm{dl}$. Even though alcohol was by far the most prevalent substance found, cannabis and cocaine were detected in about six percent of the sample. Additionally, among drivers who tested positive for multiple substances, multiple drug use without alcohol use was extremely rare.

The 1992 NHTSA study also examined the demographic characteristics of drivers who tested positive for drug use. Drivers age 15-24 were more likely to test positive for cannabis and cocaine, with or without alcohol, than drivers age 25 and older. Additionally, male drivers were over-represented among those who tested positive for alcohol and every drug group except the benzodiazepines-only group (i.e., minor tranquilizers), where females predominated.

Studies on driving following drug use are limited; therefore, this report makes a significant contribution to our knowledge of the prevalence and patterns of drug use and driving. The primary focus of this report is driving following drug use, however, data on drinking and driving are also presented for comparison purposes. The data presented in this report were obtained in face-to-face interviews with 11,847 NHSDA respondents age 16 and older, representing over 166 million U.S. drivers, who reported that they had driven a car or other motor vehicle in the 12 months prior to the interview, as well as whether or not they had driven within two hours of drug and/or alcohol use.

\footnotetext{
${ }^{1}$ Previously called the Fatal Accident Reporting System.
} 


\section{Summary of NHSDA Methodology}

The NHSDA is the primary source of statistical information on the use of tobacco, alcohol, and illicit drugs in the United States. Conducted by the Federal Government since 1971, the NHSDA is administered to a representative sample of the U.S. population age 12 and older at their place of residence. The NHSDA has been directed by the Substance Abuse and Mental Health Services Administration (SAMHSA) of the U.S. Department of Health and Human Services since October 1992. The main goal of the survey is to estimate and monitor trends in the prevalence of substance use in the United States.

The NHSDA sample consists of residents of households, persons living in noninstitutional group quarters (e.g., shelters, dormitories, rooming houses), and civilians living on military bases. The sample excludes active military personnel, U.S. citizens living abroad, residents of institutional settings (e.g., prisons and hospitals), and homeless persons not living in a shelter at the time of the survey.

The household interview takes approximately one hour to complete and incorporates procedures designed to maximize truthful responses to potentially sensitive questions about illicit drug use (e.g., the use of self-administered answer sheets). Data are collected on the recency and frequency of use of various licit and illicit drugs, opinions about drugs, problems associated with drug use, and drug treatment experiences. In addition to detailed information about substance use, the NHSDA also collects basic demographic information on employment, race/ethnicity, age, education, income, marital status, health status, mental problems, health insurance, utilization of health services, and access to health care. A more detailed description of the NHSDA methodology is included in Appendix C.

In some years, agencies have co-sponsored the NHSDA to support the collection of data on special topics. The 1996 NHSDA included a special module of supplemental questions on driving behaviors in conjunction with substance use. The Driving Behaviors Module, funded by the National Highway Traffic Safety Administration, collected detailed information on the occurrence of driving within two hours of drug and/or alcohol use. The data collected in the module include: substance use and driving patterns, perceived ability to drive safely and likelihood of being stopped by the police when driving following substance use, as well as reasons for driving within two hours of substance use. A copy of the module is included in Appendix E.

\section{Limitations of the Data}

The data presented in this report have several important limitations. First, the data are entirely self-reported, including the main analysis variable (i.e., whether or not the respondent drove after drug and/or alcohol use). Therefore, behavioral estimations may be inaccurate or biased, particularly for substance use behaviors. A second limitation of the data is that the Driving Behaviors Module addresses the use of only the following drugs: marijuana/ hashish, 
cocaine, tranquilizers, sedatives, and stimulants. For tranquilizers, sedatives, and stimulants, over-the-counter use for medical reasons and use "for the experience or feeling caused" are included; however, driving following either type of use would constitute drug-impaired driving. In addition, some of the more detailed data are available only for driving after marijuana/hashish or cocaine use; however, use of these drugs is generally more common. Third, there are no data on the quantity of each drug used before driving; however, level of impairment following alcohol use is inferred from blood alcohol concentration (BAC) level estimates. A final limitation of the data is the relatively rare occurrence of driving after drug use. In some cases, due to small sample sizes, statistical precision for the behavioral estimates was inadequate ${ }^{2}$ or statistical significance at the .05 level was not achieved. Only the statistically significant findings are discussed in the text. These, as well as other limitations of the data, are discussed in further detail in Appendix C.

\section{Overview of the Report}

The format of this report is primarily graphical, with text presented to highlight statistically significant findings. However, when two estimates are found to be significantly different it does not necessarily imply that the difference is large or meaningful. Rather, statistical significance means that one can conclude, with a small risk of error, that the two estimates would be found to be different if the survey were replicated with different samples drawn from the same population, using the same sampling procedures. That is, the differences cannot be attributed solely to sampling error.

All of the data in this report reflect behaviors that occurred during the 12 month period immediately preceding the NHSDA interviews. Chapter 2 begins by examining the prevalence of driving after substance use in various demographic groups. Chapter 2 also contains the following sections:

- Section A- Comparison of the demographic characteristics of respondents who drove within two hours of drug use, with or without alcohol, to those of respondents who drove following alcohol use only.

- Section B - Description of the driving patterns of respondents who drove within two hours of marijuana use.

- Section C - Description of the perceptions of respondents who drove within two hours of marijuana use.

\footnotetext{
2 These estimates are indicated with an asterisk in the tables.
} 
- Section D-Description of the substance use patterns of respondents who drove within two hours of marijuana use.

- Section E- Examination of the drinking patterns and blood alcohol concentration (BAC) level estimates of respondents who drove within two hours of alcohol use.

Chapter 3 summarizes the findings of this report, providing a demographic profile of NHSDA respondents who reported driving following drug use. Chapter 3 also provides implications for policy and suggestions for future research. The appendices contain detailed data tables, tables of the standard errors for the estimates, a detailed description of the NHSDA methodology, the procedure used for calculating the BAC level estimates, and the Driving Behaviors Module. 


\section{CHAPTER 2: FINDINGS ON DRUG USE AND DRIVING BEHAVIORS FROM THE 1996 NHSDA}

In the 1996 NHSDA, more than one-quarter (28\%) of the 166 million drivers age 16 and older reported that they had driven within two hours of drug and/or alcohol use in the past year. ${ }^{1}$ This included 23 percent, approximately 38 million drivers, who drove after using alcohol but not drugs; one percent, approximately 1.8 million drivers, who drove after using drugs but not alcohol; and four percent, approximately 7 million drivers, who drove following drug use and following alcohol use.

\section{Figure 2.1 Percentage and Number (in thousands) of Drivers Age 16+ who Reported Whether or Not They Drove within Two Hours of Substance Use in the Past Year $^{2}$}

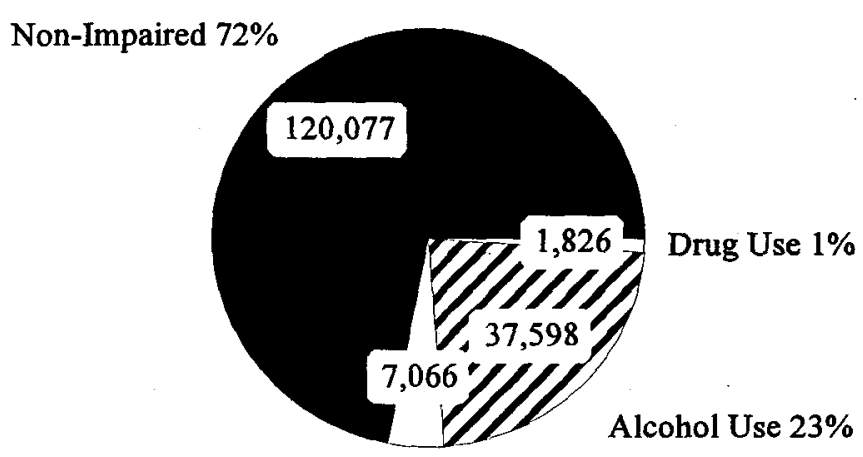

Alcohol and Drug Use 4\%

Source: OAS, SAMHSA, NHSDA, 1996.

More than one-quarter (27\%) of all drivers, or approximately 45 million people, drove after alcohol use, with or without drug use. As indicated in Table 2, about one-third of drivers age 21-34, male drivers, and residents of the North Central region of the country reported driving after alcohol use. Six percent of all drivers, or approximately 12 million people, drove after drug

1 As stated earlier, all of the behaviors described in this report occurred in the 12 months prior to the NHSDA interview, unless otherwise noted. The 166 million drivers are those age $16+$ who reported driving in the past year and answered the question on whether or not they drove within two hours after substance use.

2 "Non-impaired" drivers are those respondents age 16 and older who drove a motor vehicle in the 12 months prior to the NHSDA interview, but reported that they did not drive within two hours after using drugs and/or alcohol during that same period. 
use, with or without alcohol. As shown in Figure 2.1a, four percent of drivers, about 6.3 million people, reported driving after marijuana use. Driving after marijuana use was more common among drivers age 16-20 and male drivers than among older and female drivers (see Table 2). Driving after the use of other drugs (i.e., cocaine, and medical and non-medical use of tranquilizers, sedatives, and stimulants) was much less common. Approximately 1.8 million drivers (about $1 \%$ of all drivers) reported driving after cocaine use. Another 1.7 million drivers drove after the medical and non-medical use of tranquilizers, while 1.4 million and 0.7 million drivers reported driving after the medical and non-medical use of stimulants and sedatives respectively. ${ }^{3}$

\section{Figure 2.1a Percentage of Drivers Age 16+ who Drove within Two Hours of Drug Use in the Past Year by Drug Used}

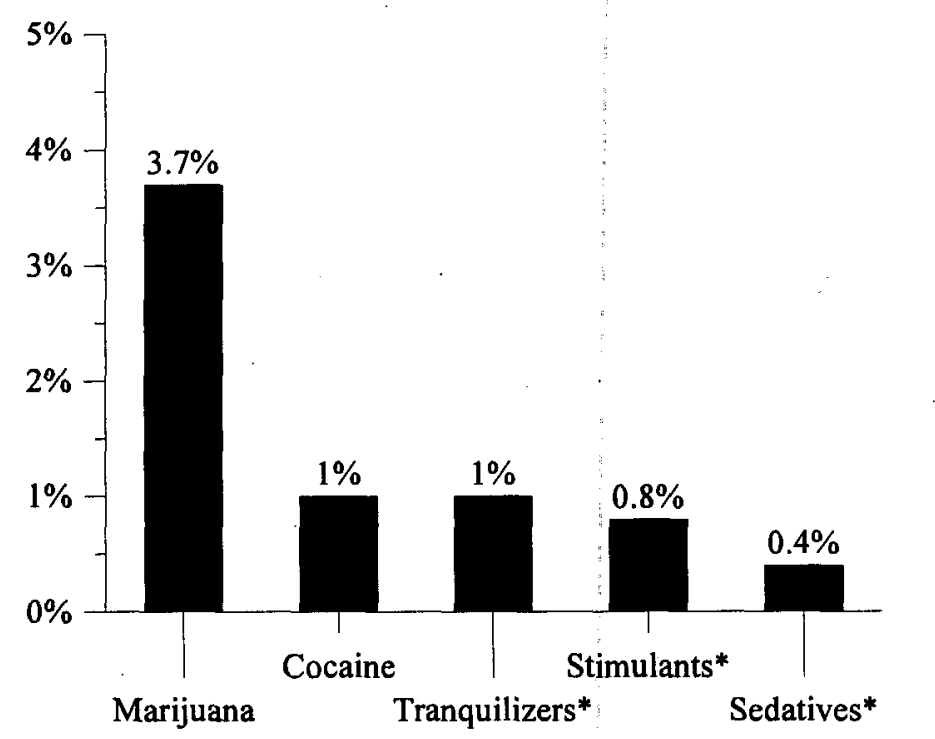

Note: A respondent may have used more than one drug.

* Includes both medical and non-medical use. Source: OAS, SAMHSA, NHSDA, 1996.

Figures 2.2 - 2.14 on the following pages provide estimates of the prevalence of driving within two hours of drug use, with or without alcohol, and driving after alcohol use only for various demographic groups. These estimates represent the likelihood that members of a certain demographic group would engage in these behaviors. The data are taken from Tables $3 a-5$.

${ }^{3}$ On the most recent occasion of driving following tranquilizer use, the vast majority of respondents $(84 \%)$ reported driving following medical use of the drug. Similarly, nearly three-quarters (71\%) of those who drove after sedative use reported that on the most recent occasion it was following medical use of the drug. By contrast, less than half (43\%) of those who drove after stimulant use reported that on the most recent occasion it was following medical use of the drug. 
Figure 2.2 Percentage of Drivers Age 16+ within Age Groups who Drove within Two Hours of Substance Use in the Past Year by Substance Used

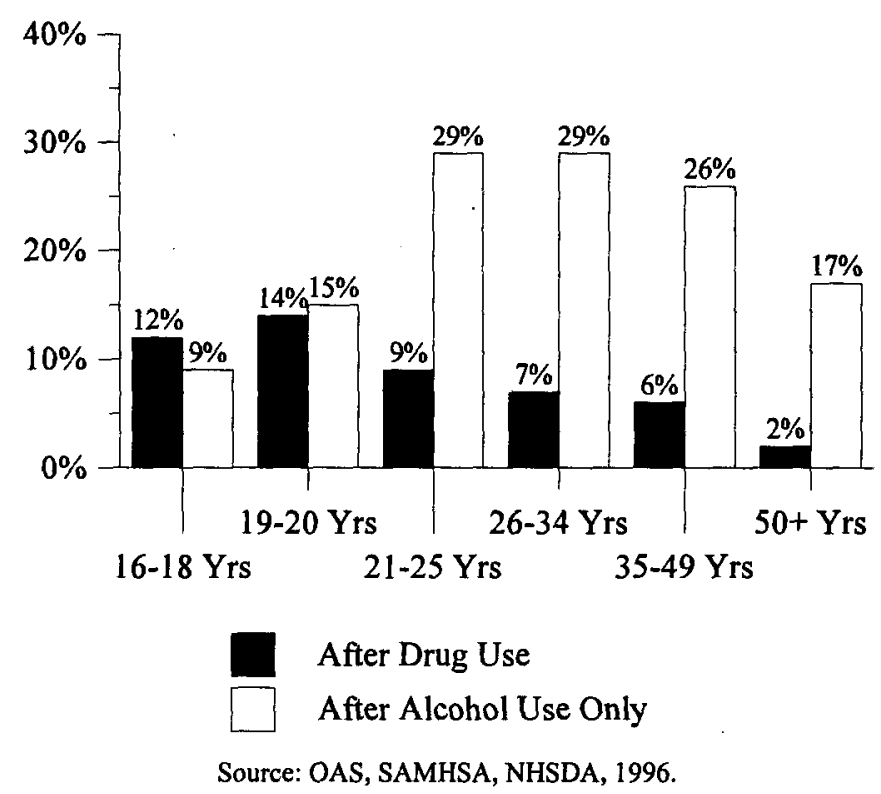

- Drivers age 16-20 were more likely than drivers age 21 and older to report driving within two hours of drug use, with or without alcohol, while drivers age 21 and older were generally more likely than drivers age 16-20 to report driving after alcohol use only. (See Table 3a)

Figure 2.3 Percentage of Male and Female Drivers Age 16+ who Drove within Two Hours of Substance Use in the Past Year by Substance Used

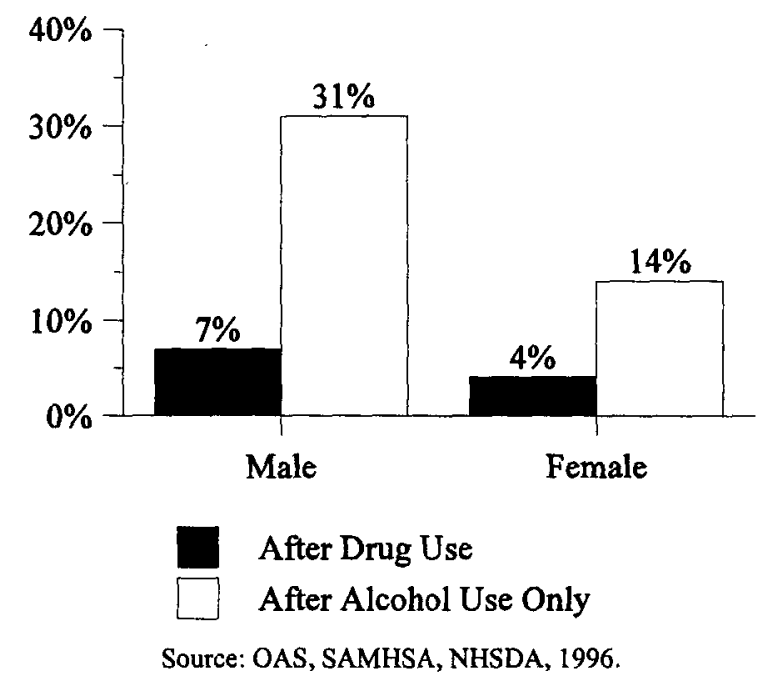

- Males were about twice as likely as females to report driving within two hours of drug use, with or without alcohol, and to report driving after alcohol use only. (See Table 3a) 
Figure 2.4 Percentage of Drivers Age 16+ within Racial/Ethnic Groups who Drove within Two Hours of Substance Use in the Past Year by Substance Used

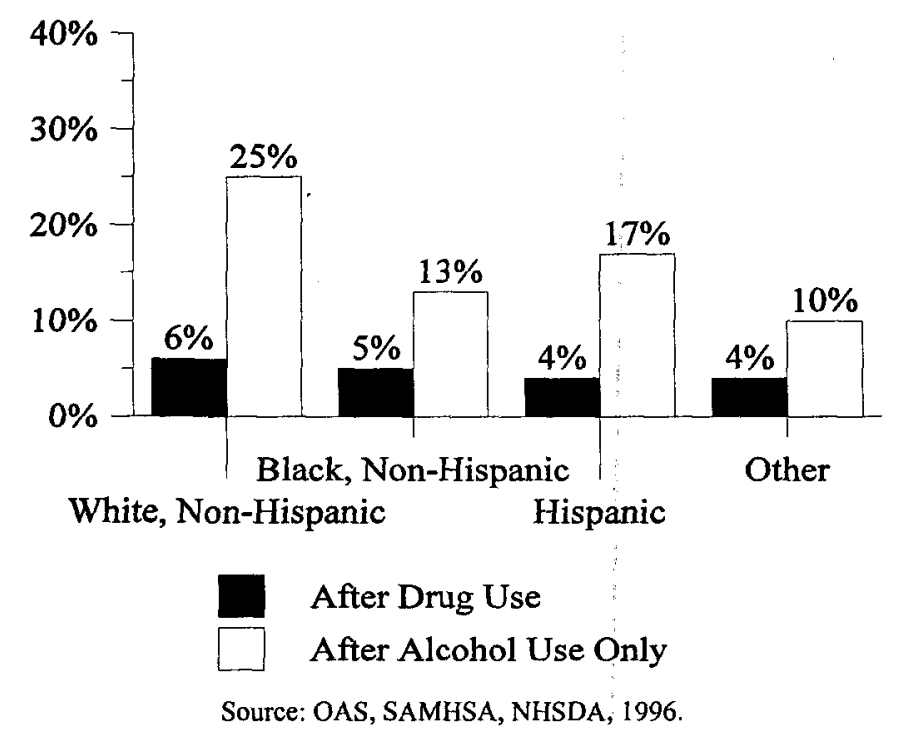

- Non-Hispanic whites were more likely than Hispanics to report driving within two hours of drug use, with or without alcohol. Non-Hispanic whites were also more likely than Hispanics, who both were more likely than non-Hispanic blacks, to report driving after alcohol use only. (See Table 3a)

Figure 2.5 Percentage of Drivers Age 16+ within each Region who Drove within Two Hours of Substance Use in the Past Year by Substance Used
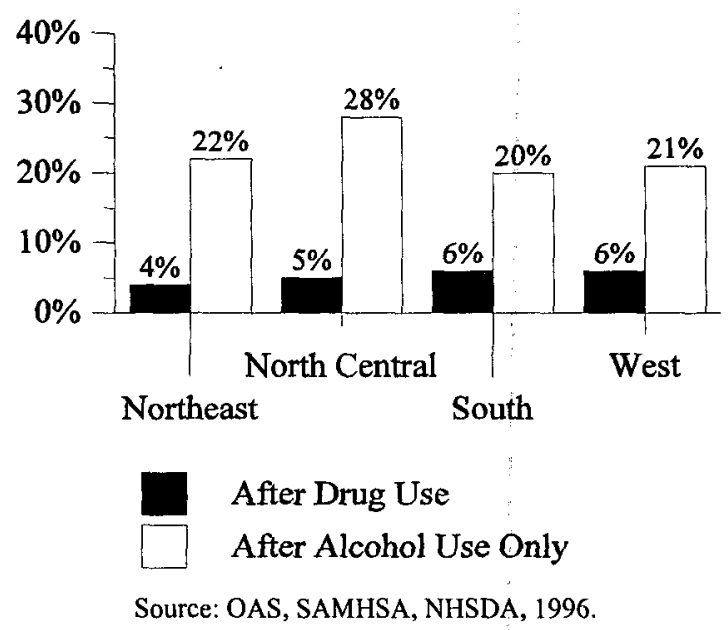

- Drivers in the West, but not the South were slightly more likely than those in the Northeast to report driving within two hours of drug use, with or without alcohol. Residents of the North Central region were the most likely to report driving after alcohol use only. (See Table 3a) 
Figure 2.6 Percentage of Drivers Age 16+ within Marital Categories who Drove within Two Hours of Substance Use in the Past Year by Substance Used
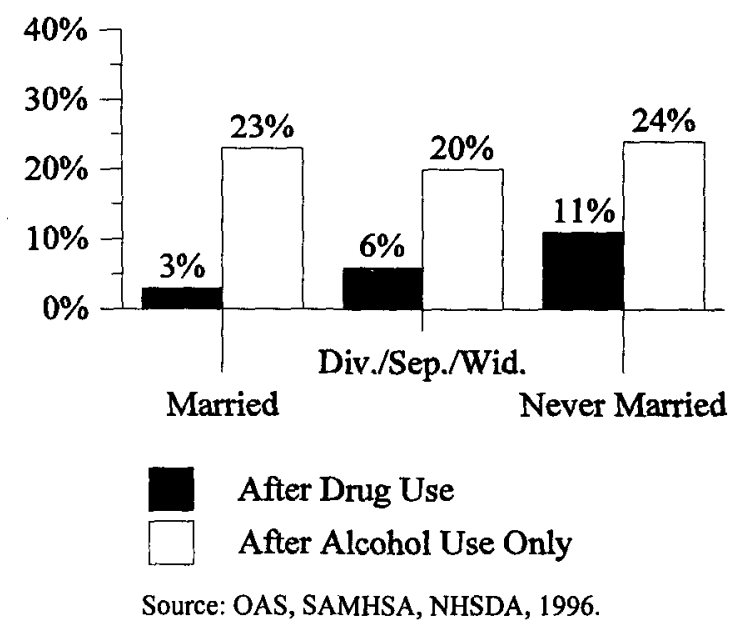

- Never married drivers were more than three times as likely as married drivers, and twice as likely as divorced, separated, or widowed drivers, to report driving within two hours of drug use, with or without alcohol. Driving after alcohol use only was equally common among married, divorced, separated or widowed and never married drivers. (See Table 3b)

Figure 2.7 Percentage of Drivers Age 16+ within Educational Levels who Drove within Two Hours of Substance Use in the Past Year by Substance Used

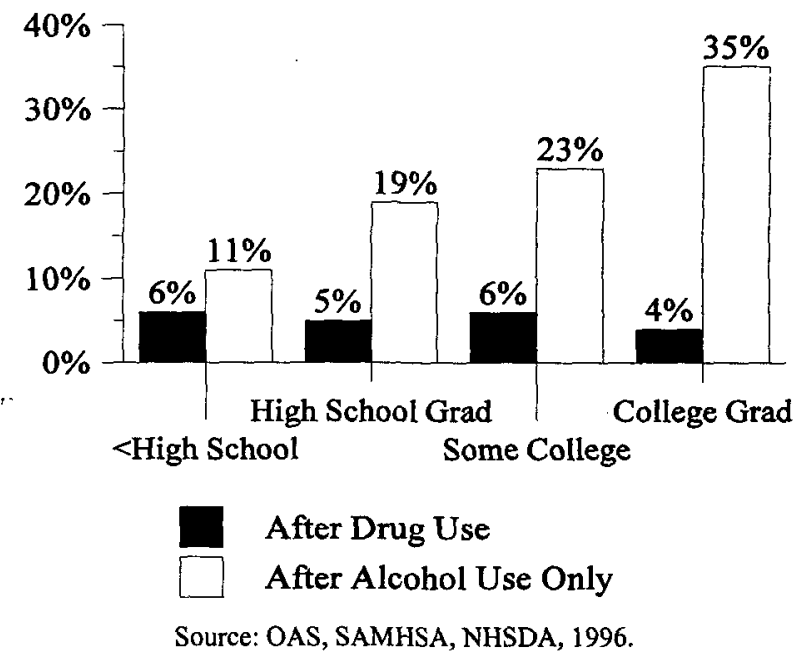

- Drivers with only some college education were significantly more likely than college graduates to report driving within two hours of drug use, with or without alcohol. With each increase in educational level, drivers were significantly more likely to report driving after alcohol use only. College graduates were three times as likely as those with less than a high school education to report driving after alcohol use. (See Table 3b) 
Figure 2.8 Percentage of Drivers Age 16+ within Employment Categories who Drove within Two Hours of Substance Use in the Past Year by Substance Used

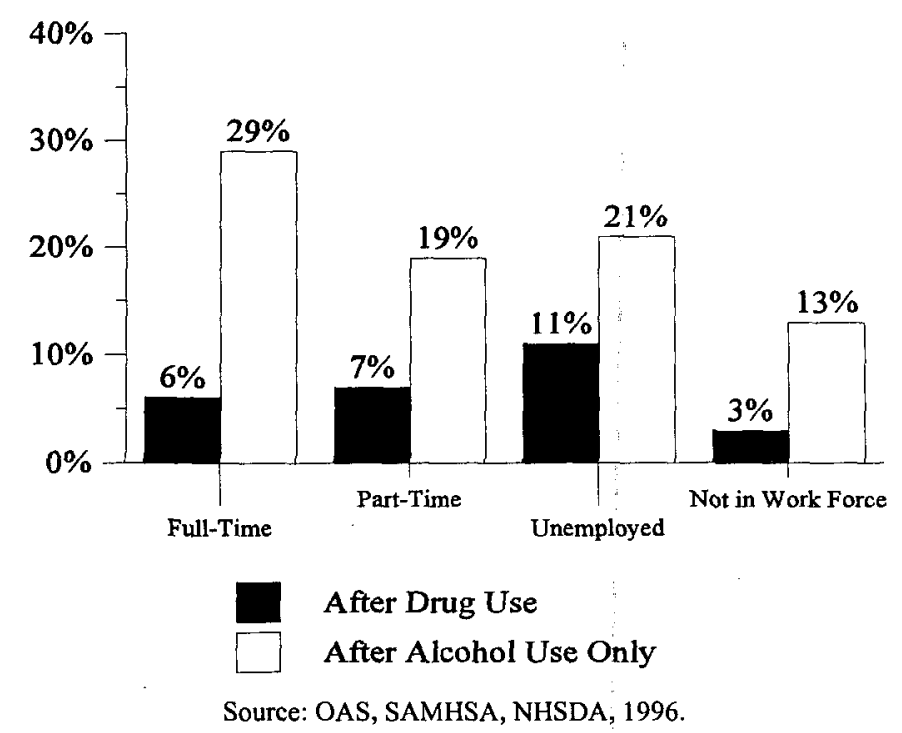

- The unemployed were the most likely to report driving within two hours of drug use, with or without alcohol, and full-time workers were the most likely to report driving after alcohol use only. Those not in the work force were least likely to report either behavior. (See Table 3b)

Figure 2.9 Percentage of Drivers Age 16+ within Personal Income Levels who Drove within Two Hours of Substance Use in the Past Year by Substance Used

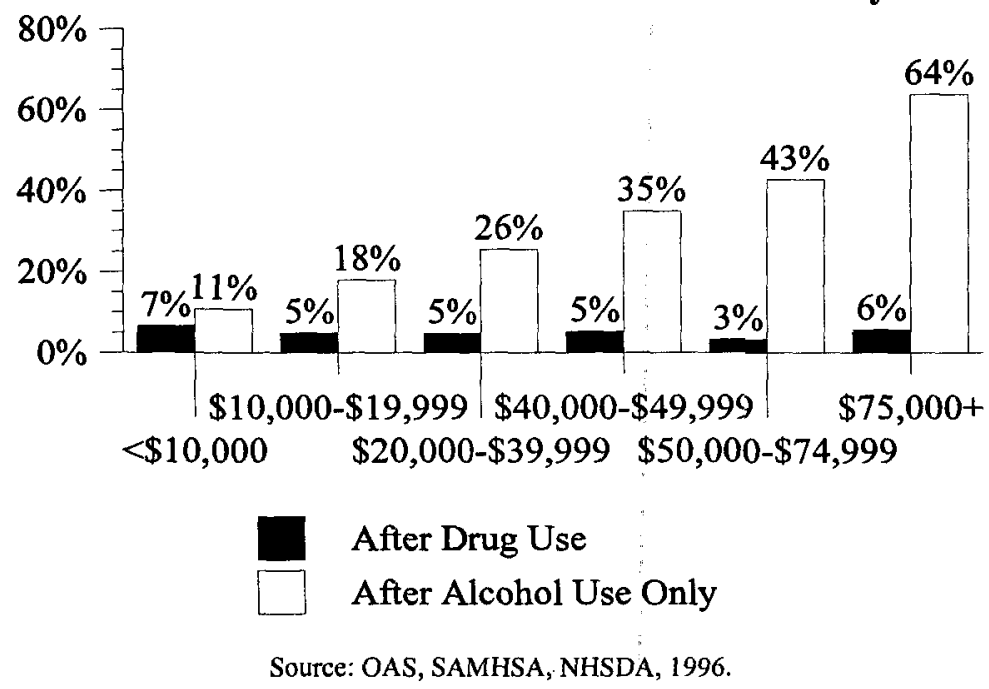

- Those with annual personal incomes less than $\$ 10,000$ were generally more likely than those with higher incomes to report driving within two hours of drug use, with or without alcohol. By contrast, those with higher incomes were more likely than those with lower incomes to report driving after alcohol use only. (See Table $3 b$ ) 
Figure 2.10 Percentage of Drivers Age 16+ within Gender by Age Groups who Drove within Two Hours of Substance Use in the Past Year by Substance Used
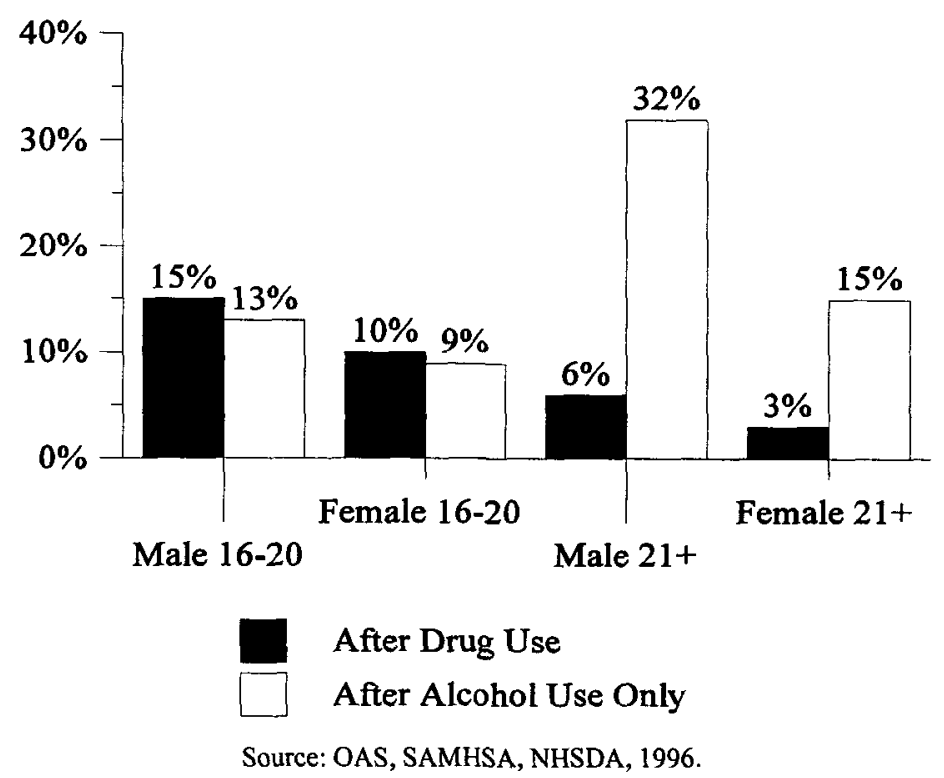

- Regardless of age, males were more likely than females to report driving within two hours of drug use, with or without alcohol, and after alcohol use only. This difference was especially marked for drivers age 21 and older. For drivers age 21 and older, males were twice as likely as females to drive after alcohol use. (See Table 4) 
Figure 2.11 Percentage of Drivers Age 16+ within Racial/Ethnic by Age Groups who Drove within Two Hours of Substance Use in the Past Year by Substance Used

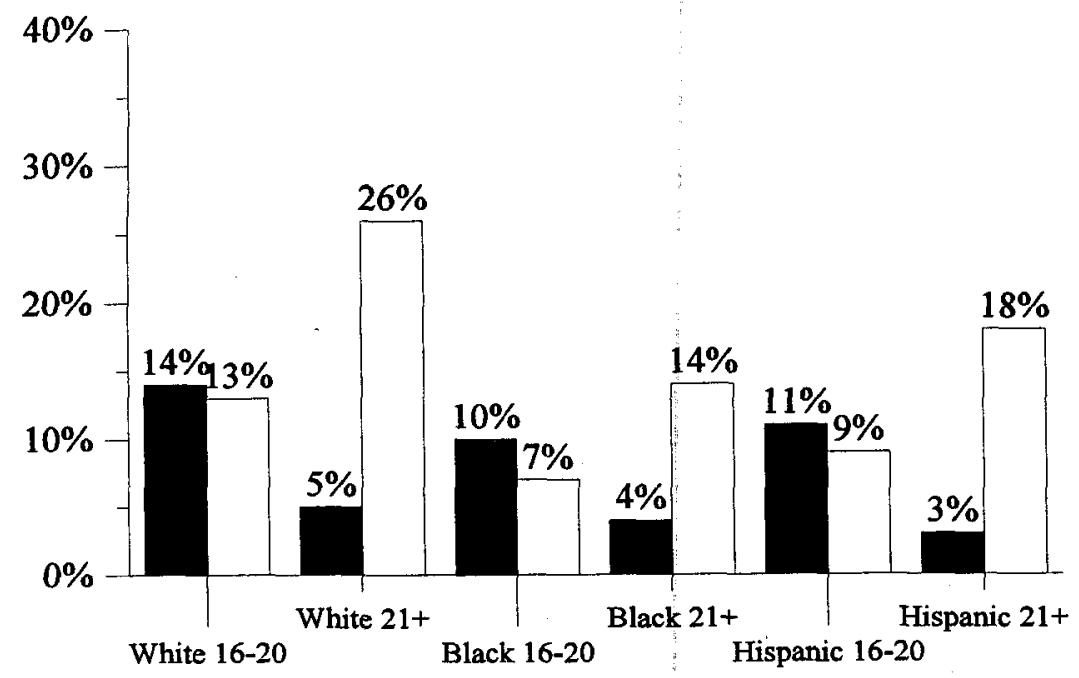

After Drug Use

After Alcohol Use Only

Source: OAS, SAMHSA, NHSDA, 1996.

- For non-Hispanic whites, driving within two hours of drug use, with or without alcohol, was more common among those age 16-20 than among drivers age 21 and older; whereas, the reverse was true for driving after alcohol use only. The same pattern was found for nonHispanic black and Hispanic drivers; however, almost all of the estimates for these groups lacked statistical precision. (See Table 4) 
Figure 2.12 Percentage of Drivers Age 16+ within Racial/Ethnic by Gender Groups who Drove within Two Hours of Substance Use in the Past Year by Substance Used

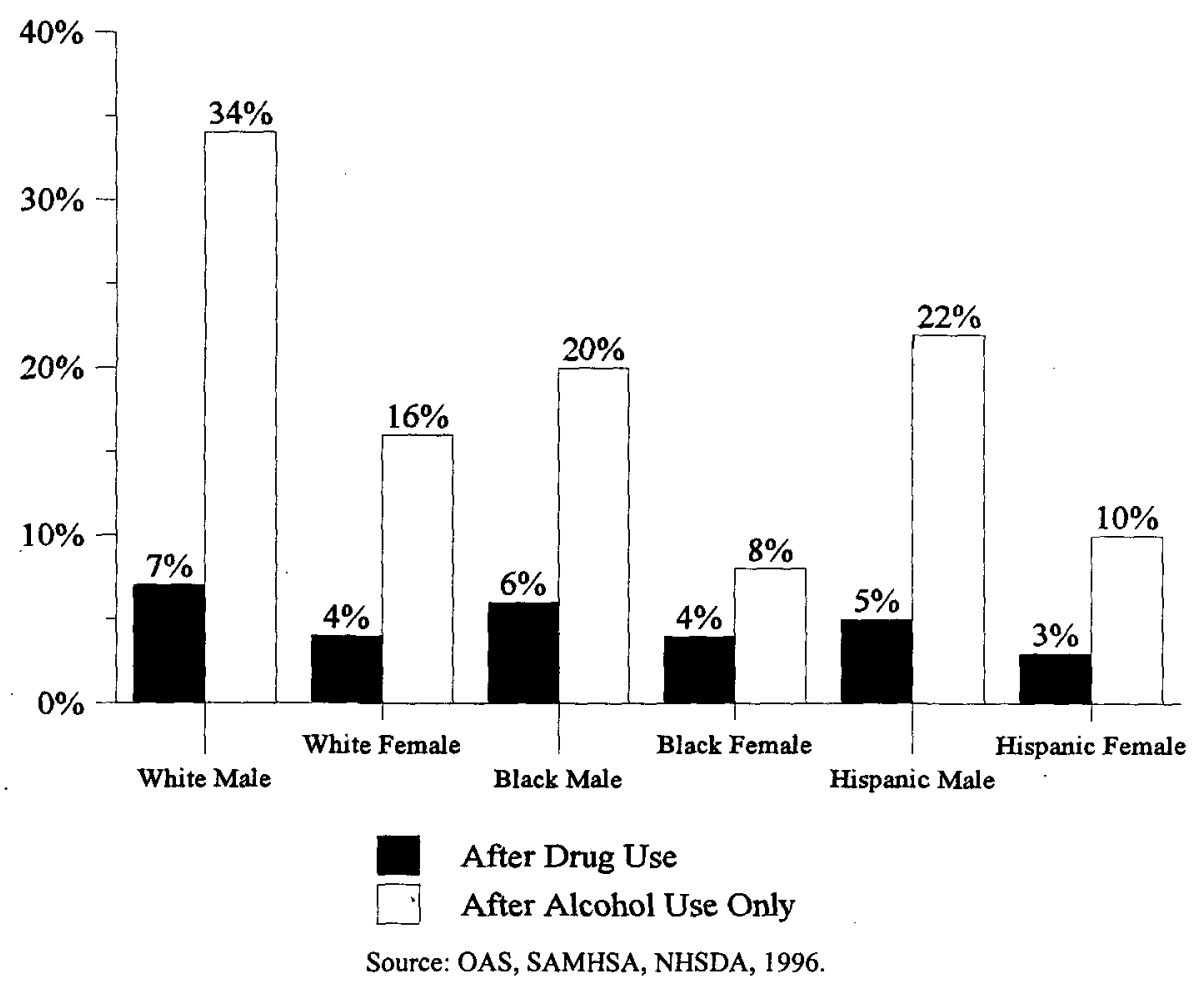

- For non-Hispanic whites, males were more likely than females to report driving within two hours of drug use, with or without alcohol, and to report driving after alcohol use only. In fact, this gender difference was found among all racial/ethnic groups for those who reported driving after alcohol use. Regardless of race, males were about twice as likely as females to report driving after alcohol use. (See Table 4) 
Figure 2.13 Percentage of Drivers Age 16+ with and without Past-Year Arrests who Drove within Two Hours of Substance Use in the Past Year by Substance Used

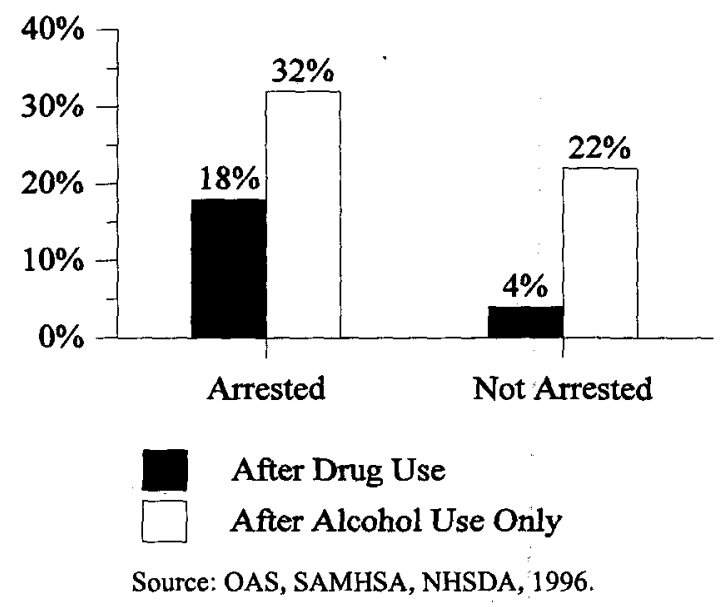

- Those who had been arrested in the past year were more likely than those who had not been arrested to report driving within two hours of drug use, with or without alcohol. In fact, those who had been arrested were four times as likely as those who had not been arrested to report driving after drug use. Those who had been arrested were also more likely than those who had not been arrested to report driving after alcohol use only. (See Table 5)

Figure 2.14 Percentage of Drivers Age 16+ on Probation and Not on Probation in the Past Year who Drove within Two Hours of Substance Use in the Past Year by Substance Used

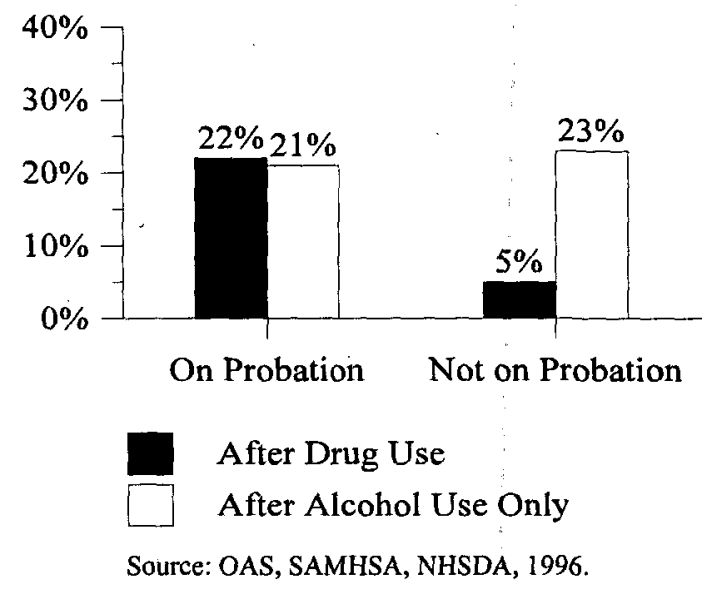

- Those who were on probation in the past year were more likely than those who were not on probation to report driving within two hours of drug use, with or without alcohol. In fact, those who were on probation were four times as likely as those who had not been on probation to report driving after drug use. (See Table 5) 


\section{A. Demographic Characteristics}

The previous figures provided prevalence estimates for driving within two hours of drug use, with or without alcohol, and driving after alcohol use only. The figures in this section provide demographic profiles of each of these groups of drivers. When appropriate, demographic comparisons between those who drove after drug use and those who drove after alcohol use are made. The data presented in this section are taken from Tables 6-7.

\section{Figure 2.15 Age Distribution of Drivers Age 16+ who Drove within Two Hours of Substance Use in the Past Year by Substance Used}

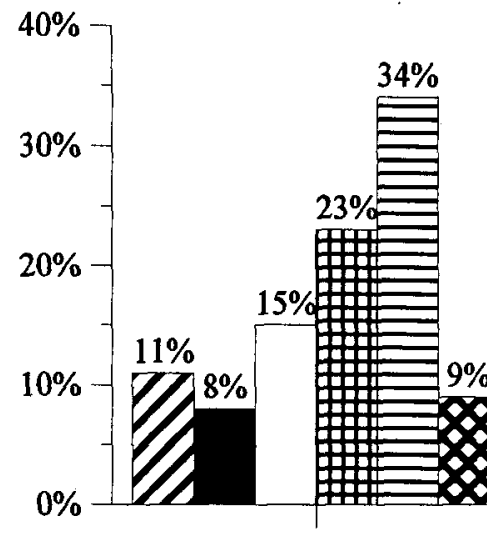

After Drug Use

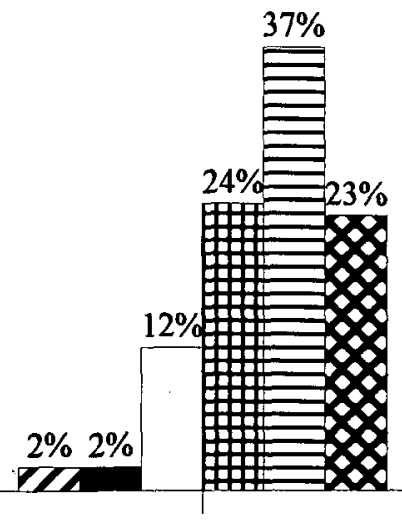

After Alcohol Use Only

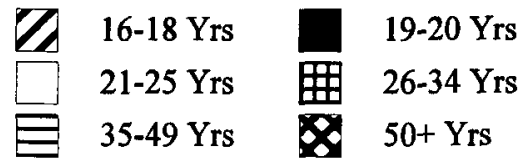

Source: OAS, SAMHSA, NHSDA, 1996.

- The majority of those who drove within two hours of drug use, with or without alcohol, and of those who drove after alcohol use only were age $26-49(57 \%$ and $61 \%$, respectively). However, a higher percentage of those who drove after drug use than of those who drove after alcohol use were age 16-20. (See Table 6a) 
Figure 2.16 Gender Distribution of Drivers Age 16+ who Drove within Two Hours of Substance Use in the Past Year by Substance Used

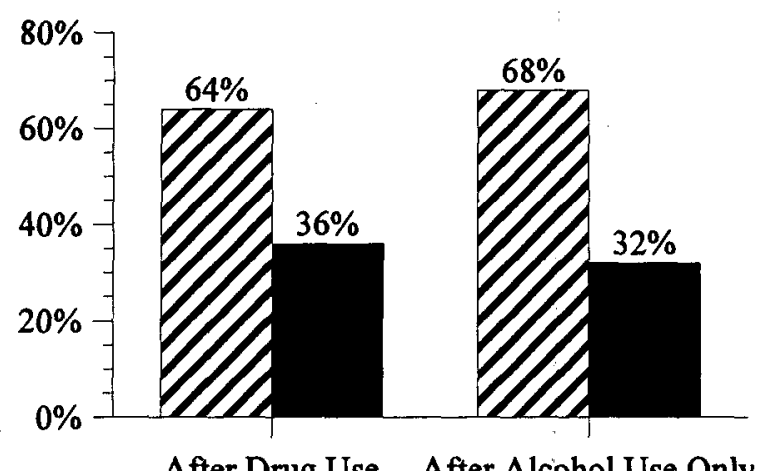

After Drug Use After Alcohol Use Only

$$
1 \begin{aligned}
& \text { Male } \\
& \text { Female }
\end{aligned}
$$

Source: OAS, SAMHSA, NHSDA, 1996.

- About two-thirds of those who drove within two hours of drug use, with or without alcohol, as well as of those who drove after alcohol use only, were male. (See Table 6a)

Figure 2.17 Racial/Ethnic Distribution of Drivers Age 16+ who Drove within Two Hours of Substance Use in the Past Year by Substance Used

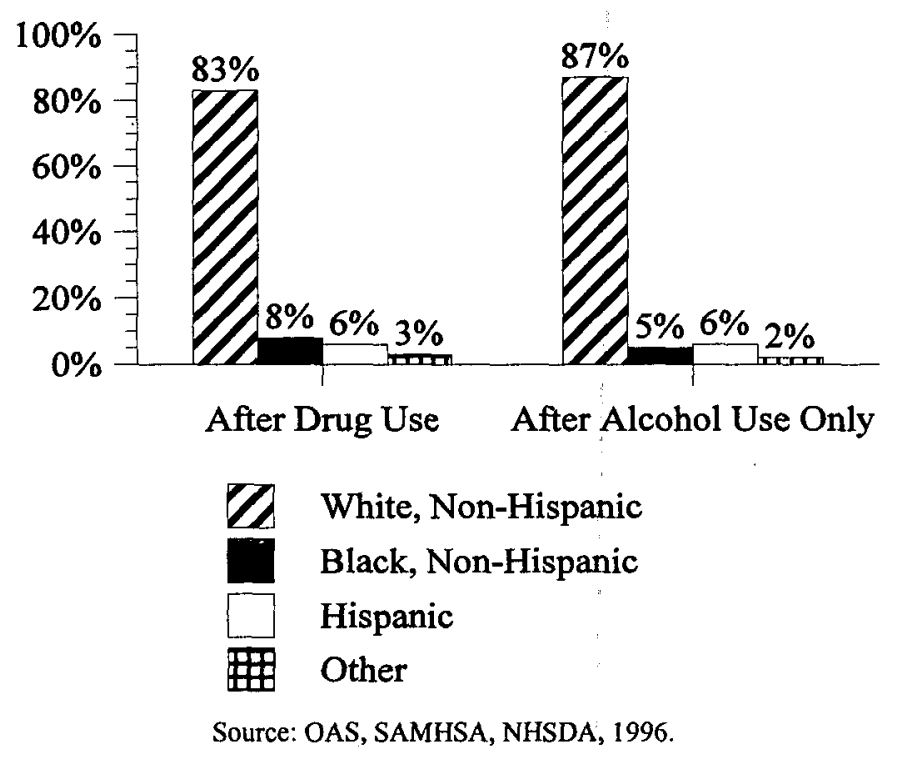

- The vast majority of those who reported driving within two hours of drug use, with or without alcohol, and of those who drove after alcohol use only were non-Hispanic white. However, non-Hispanic blacks were slightly more likely to have driven after drug use than after alcohol use. (See Table 6a) 
Figure 2.18 Marital Distribution of Drivers Age 16+ who Drove within Two Hours of Substance Use in the Past Year by Substance Used

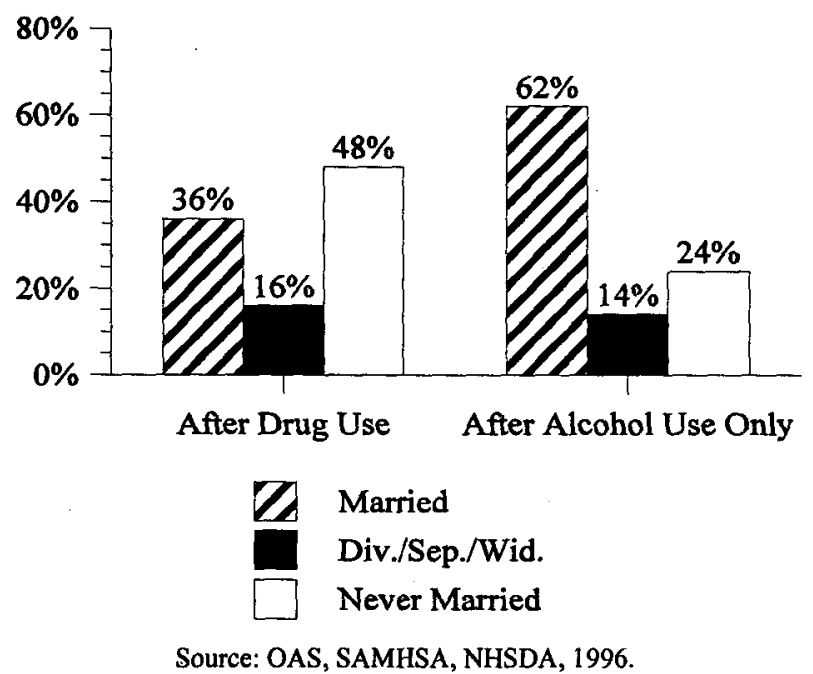

- Nearly half of those who drove within two hours of drug use, with or without alcohol, had never been married; whereas, only one-quarter of those who drove after alcohol use only had never been married. By contrast, more than 60 percent of those who drove after alcohol use were married, while slightly more than one-third of those who drove after drug use were married. (See Table 6b)

Figure 2.19 Educational Distribution of Drivers Age 16+ who Drove within Two Hours of Substance Use in the Past Year by Substance Used

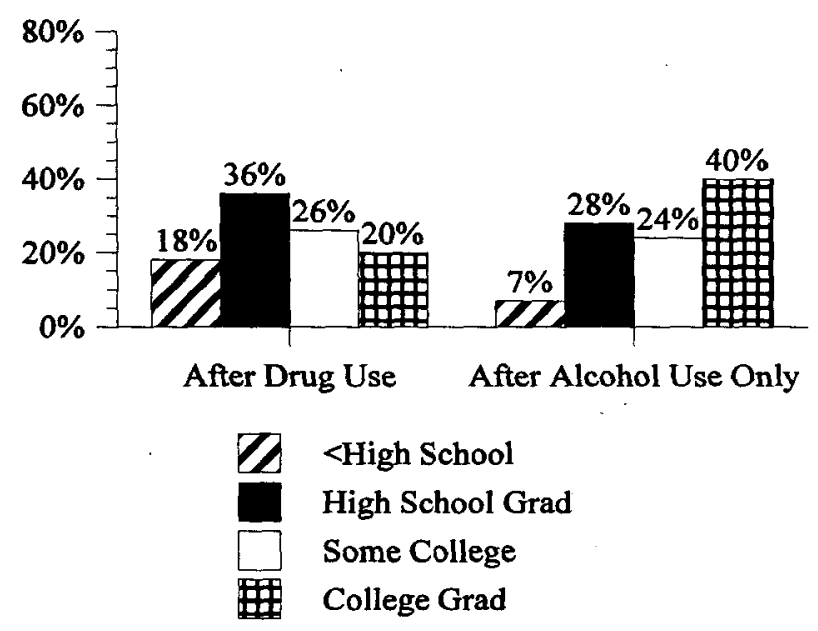

Source: OAS, SAMHSA, NHSDA, 1996.

- More than half (54\%) of those who drove within two hours of drug use, with or without alcohol, had a high school education or less. By contrast, almost two-thirds (64\%) of those who drove after alcohol use only had at least some college education. (See Table 6b) 
Figure 2.20 Employment Distribution of Drivers Age 16+ who Drove within Two Hours of Substance Use in the Past Year by Substance Used

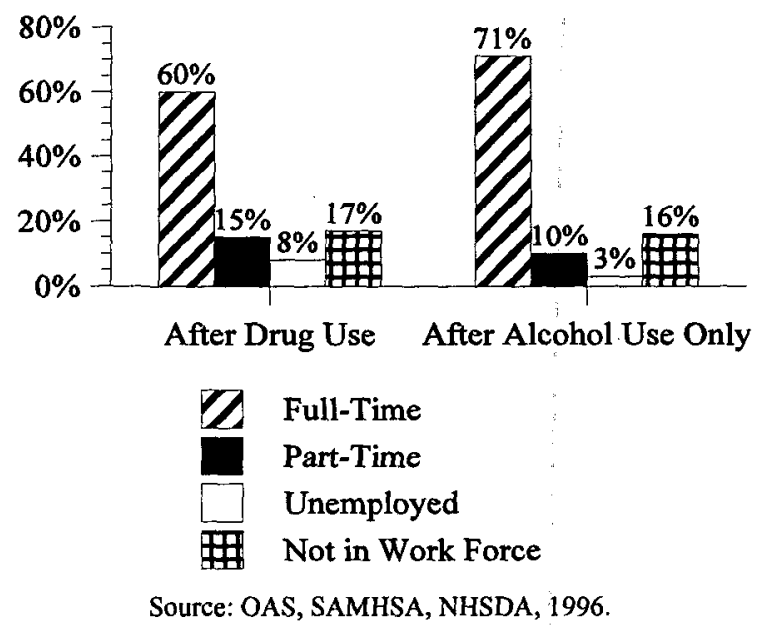

- The majority of those who drove within two hours of drug use, with or without alcohol, and of those who drove after alcohol use only were employed full-time. However, a higher percentage of those who drove after drug use than of those who drove after alcohol use were unemployed. (See Table 6b)

Figure 2.21 Personal Income Distribution of Drivers Age 16+ who Drove within Two Hours of Substance Use in the Past Year by Substance Used

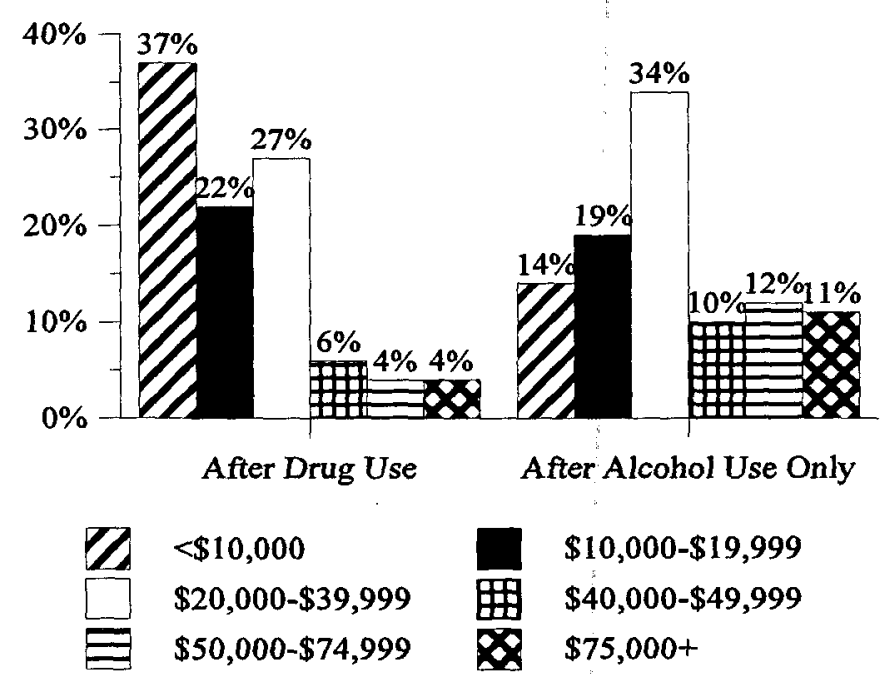

Source: OAS, SAMHSA, NHSDA, 1996.

- More than half of those who drove within two hours of drug use, with or without alcohol, had an annual personal income less than $\$ 20,000$. In fact, those who drove after drug use were more than twice as likely as those who drove after alcohol use only to have an income of less than $\$ 10,000$. (See Table 6b) 
Figure 2.22 Racial/Ethnic by Gender Distribution of Drivers Age 16+ who Drove within Two Hours of Substance Use in the Past Year by Substance Used

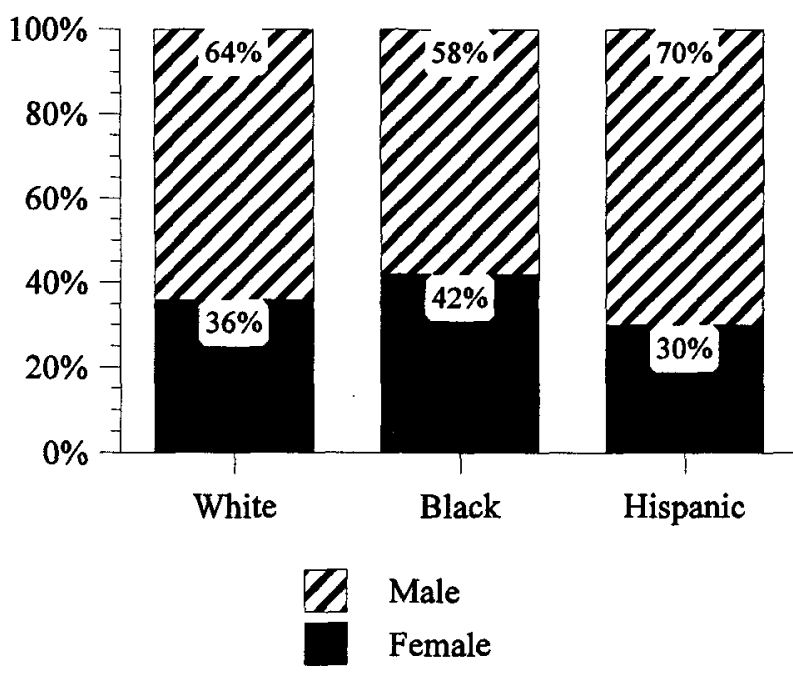

After Drug Use

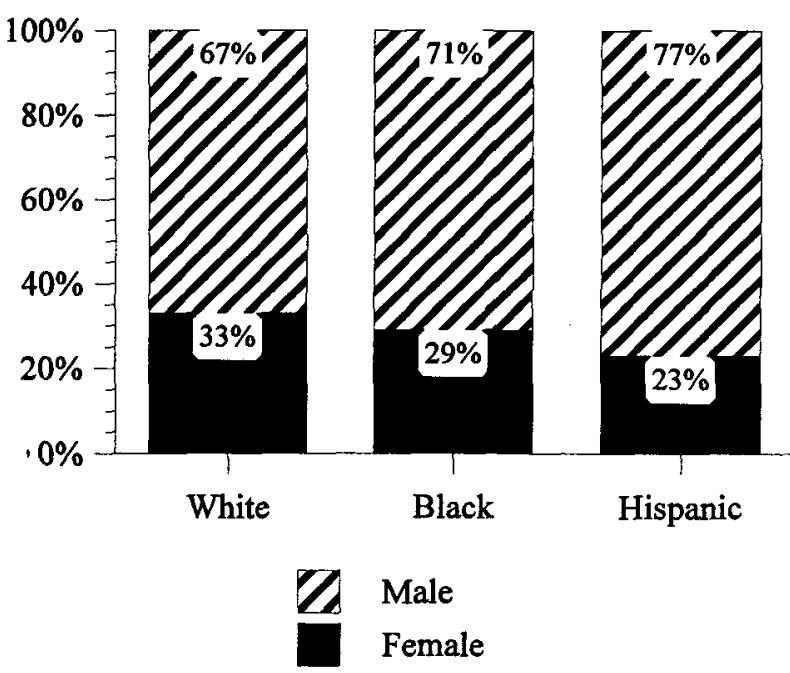

After Alcohol Use Only

Source: OAS, SAMHSA, NHSDA, 1996.

- Regardless of race, the majority of those who drove within two hours of drug use, with or without alcohol, and of those who drove after alcohol use only were male. However, for non-Hispanic blacks, a significantly higher percentage of those who drove after alcohol use than of those who drove after drug use were male. The same was true for Hispanics, but the estimate for driving after drug use lacked statistical precision. (See Table 7) 
Figure 2.23 Past-Year Arrest Distribution of Drivers Age 16+ who Drove within Two Hours of Substance Use in the Past Year by Substance Used

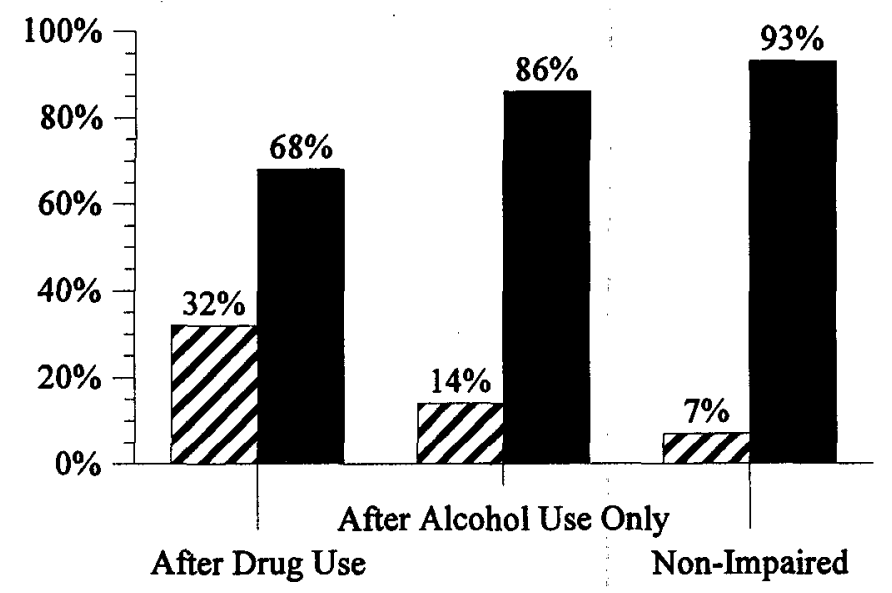

- The majority of both those who drove within two hours of drug use, with or without alcohol, and of those who drove after alcohol use only had not been arrested in the past year for any reason. However, those who drove after drug use were more than twice as likely as those who drove after alcohol use, and more than four times as likely as non-impaired drivers ${ }^{4}$, to report that they had been arrested during the past year. (See Table 8)

${ }^{4}$ As stated earlier, "non-impaired" drivers are those respondents age 16 and older who drove a motor vehicle in the 12 months prior to the NHSDA interview, but reported that they did not drive within two hours after using drugs and/or alcohol during that same period. 
Figure 2.24 Past-Year Probation Status Distribution of Drivers Age 16+ who Drove within Two Hours of Substance Use in the Past Year by Substance Used

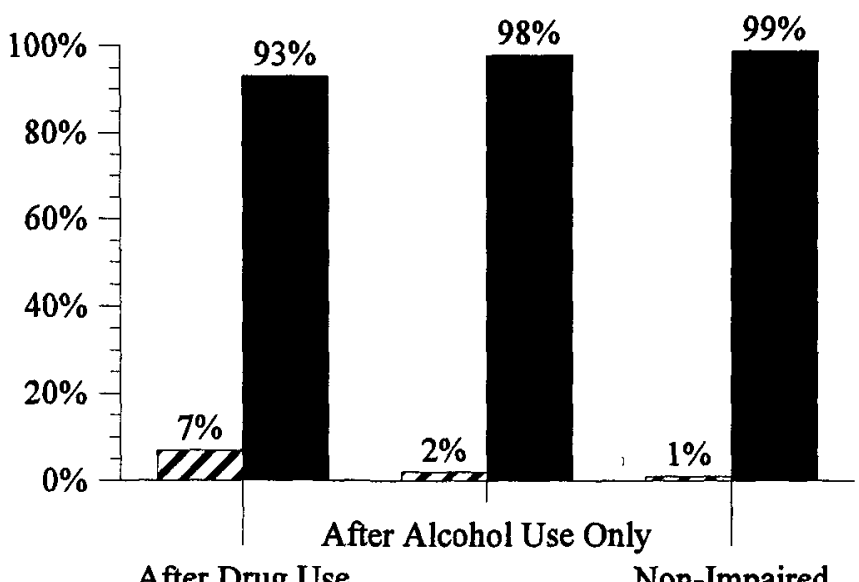

After Drug Use Non-Impaired

2 On Probation in Past Year
Not on Probation in Past Year

Source: OAS, SAMHSA, NHSDA, 1996.

- The vast majority of both those who drove within two hours of drug use, with or without alcohol, and those who drove after alcohol use only were not on probation during the past year for any reason. However, both those who drove after alcohol and non-impaired ${ }^{5}$ drivers were more likely than those who drove after drug use to have not been on probation. (See Table 8)

${ }^{5}$ As stated earlier, "non-impaired" drivers are those respondents age 16 and older who drove a motor vehicle in the 12 months prior to the NHSDA interview, but reported that they did not drive within two hours after using drugs and/or alcohol during that same period. 


\section{B. Driving Patterns}

This section describes the driving patterns of drivers age 16 and older who reported driving within two hours of marijuana use, with or without alcohol, in the past year. The goal of this section is to summarize the circumstances of the most recent reported occasions of driving following marijuana use. The data presented in this section are taken from Tables 9-11.

Figure 2.25 Distribution of Size of Road Driven on Most Recent Occasion of Driving within Two Hours of Marijuana Use for Drivers Age 16+ who Drove Following Marijuana Use in the Past. Year by Age Group

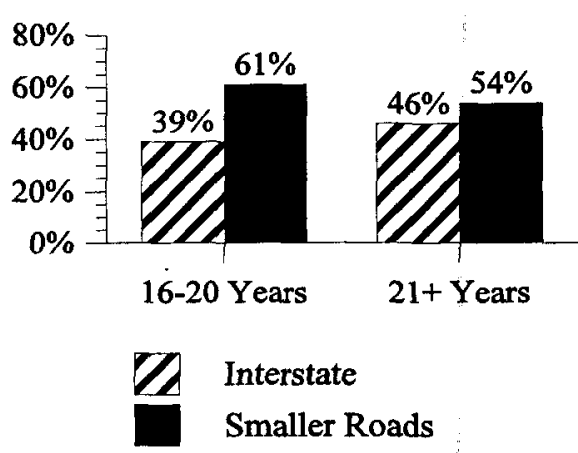

Source: OAS, SAMHSA, NHSDA, 1996.

- On the most recent reported occasion of driving within two hours of marijuana use, with or without alcohol, the majority of all driving occurred on smaller roads, for both those age 1620 and those age 21 and older. (See Table 9)

Figure 2.26 Distribution of Area Driven on Most Recent Occasion of Driving within Two Hours of Marijuana Use for Drivers Age 16+ who Drove Following Marijuana Use in the Past Year by Age Group

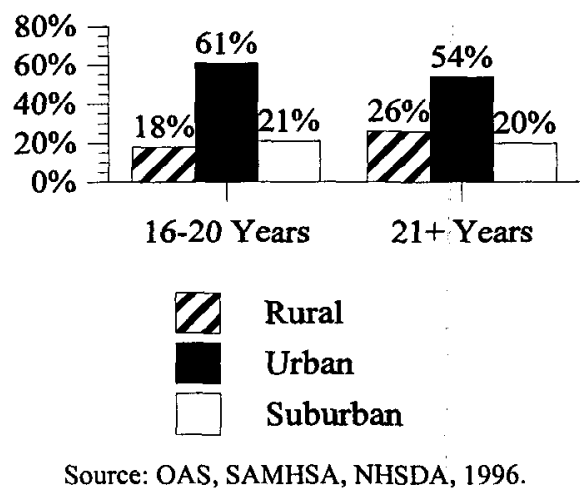

- On the most recent reported occasion of driving within two hours of marijuana use, with or without alcohol, the majority of all driving was in urban areas, rather than rural or suburban areas, regardless of the driver's age. (See Table 9) 
Figure 2.27 Distribution of Day of Week Driven on Most Recent Occasion of Driving within Two Hours of Marijuana Use for Drivers Age 16+ who Drove Following Marijuana Use in the Past Year by Age Group

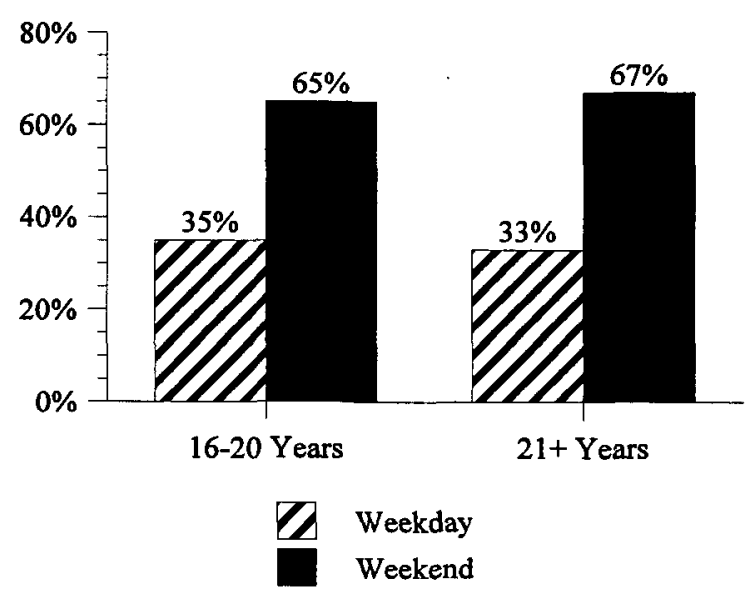

Source: OAS, SAMHSA, NHSDA, 1996.

- On the most recent reported occasion of driving within two hours of marijuana use, with or without alcohol, the majority of all driving took place on the weekend, rather than on a weekday, regardless of the driver's age. (See Table 9)

Figure 2.28 Distribution of Time of Day Driving Began on Most Recent Occasion of Driving within Two Hours of Marijuana Use for Drivers Age 16+ who Drove Following Marijuana Use in the Past Year by Age Group

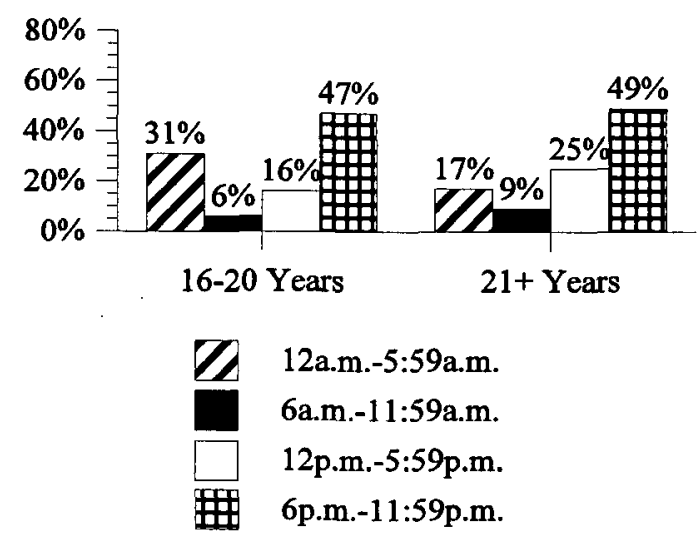

Source: OAS, SAMHSA, NHSDA, 1996.

- On the most recent reported occasion of driving within two hours of marijuana use, with or without alcohol, about half of all driving began between 6:00 p.m. and 11:59 p.m, regardless of the driver's age. However, a higher percentage of drivers age 16-20 than of drivers age 21 and older began driving between 12:00 a.m. and 5:59 a.m. (See Table 9) 
Figure 2.29 Distribution of Starting Point on Most Recent Occasion of Driving within Two Hours of Marijuana Use for Drivers Age 16+ who Drove Following Marijuana Use in the Past Year by Age Group

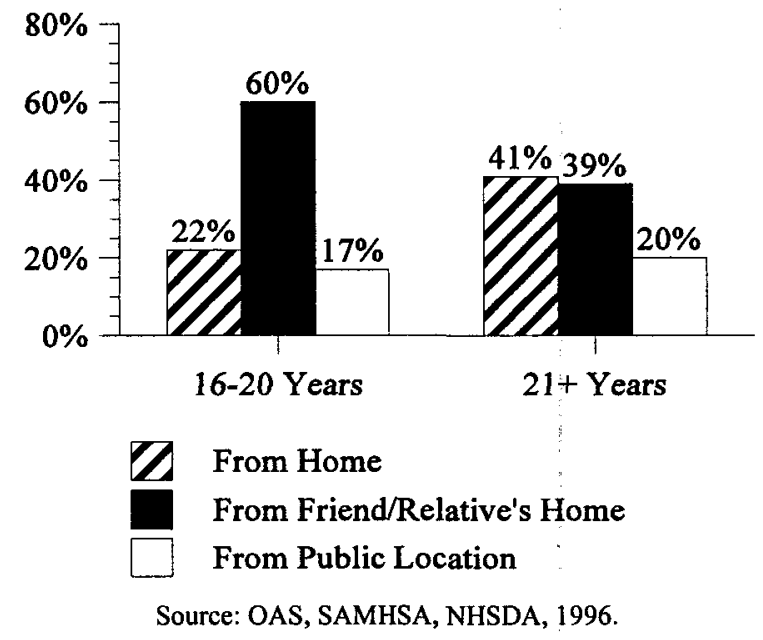

- On the most recent occasion of driving within two hours of marijuana use, with or without alcohol, the majority of drivers age 16-20 drove from a friend or relative's home. By contrast, drivers age 21 and older were just as likely to have driven from their own home as from a friend or relative's home. (See Table 10)

Figure 2.30 Distribution of Destination on Most Recent Occasion Drove within Two Hours of Marijuana Use for Drivers Age 16+ who Drove Following Marijuana Use in the Past Year by Age Group

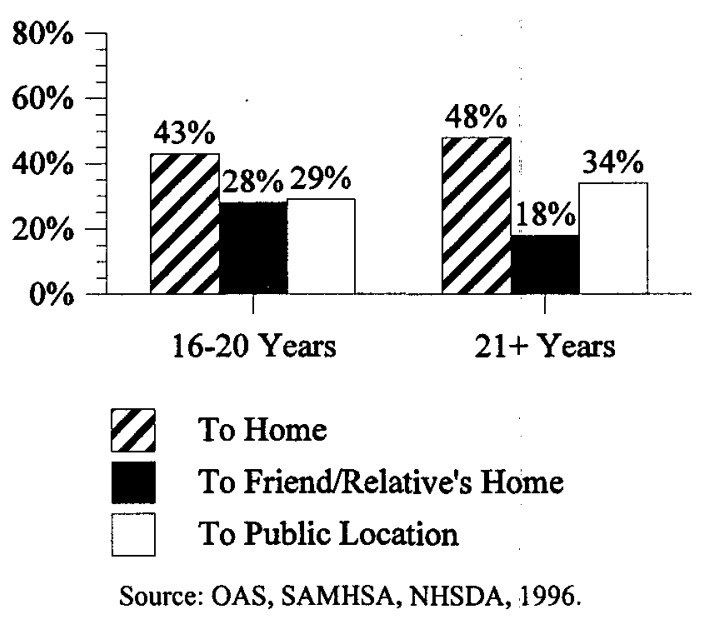

- On the most recent occasion of driving within two hours of marijuana use, with or without alcohol, about half of all drivers were driving home. However, drivers age 16-20 were more likely than drivers age 21 and older to drive to a friend or relative's home. (See Table 10) 
Figure 2.31 Percentage of Drivers Age 16+ who Drove within Two Hours of Marijuana Use in the Past Year Reporting Reasons for Driving on Most Recent Occasion of Driving Following Marijuana Use by Age Group

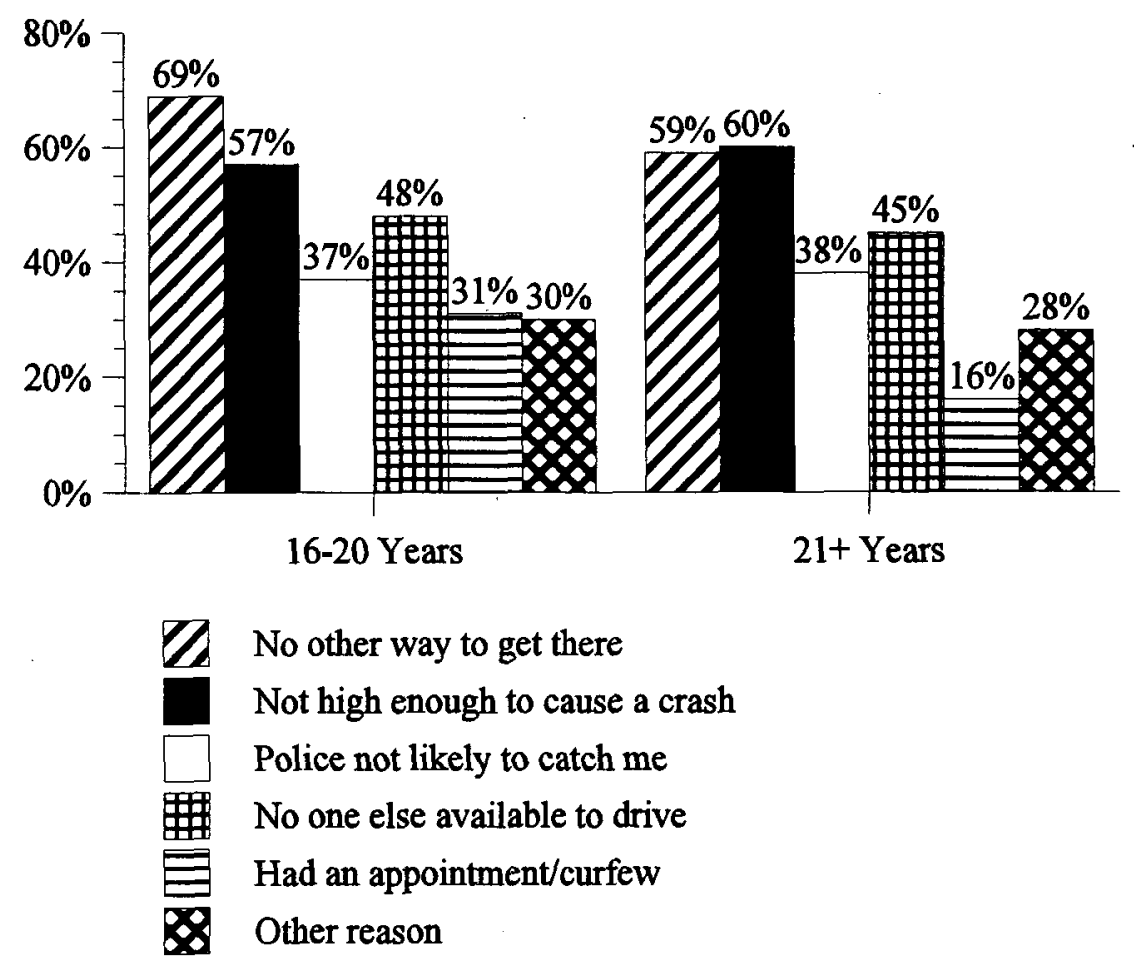

Note: Respondents could report more than one reason.

Source: OAS, SAMHSA, NHSDA, 1996.

- For the most recent occasion of driving within two hours of marijuana use, with or without alcohol, the most common reasons for driving reported by drivers of all ages were "no other way to get there" and "not high enough to cause a crash." (See Table 11) 


\section{Perceptions of Drivers}

This section describes the perceptions of drivers who reported driving within two hours of marijuana use, with or without alcohol, in the past year. The purpose of this section is to document these drivers' perceptions of their ability to drive safely and their likelihood of being stopped by the police when driving following marijuana use. The data presented in this section are taken from Tables 12 and 13.

Figure 2.32 Distribution of Perceived Extent to which Marijuana Affected Ability to Drive Safely on Most Recent Occasion of Driving within Two Hours of Marijuana Use for Drivers Age 16+ who Drove Following Marijuana Use in the Past Year by Age Group

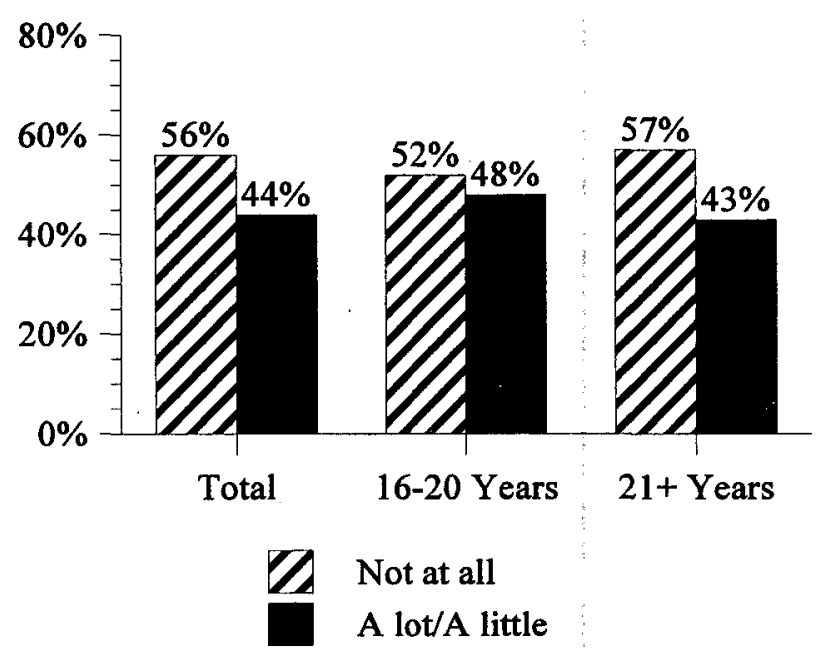

Source: OAS, SAMHSA, NHSDA, 1996.

- Regardless of age, those who reported driving within two hours of using marijuana, with or without alcohol, were about equally likely to feel that on the most recent occasion that they drove after marijuana use, their ability to drive safely was affected "a little" or "a lot" or not at all. (See Table 12) 
Figure 2.33 Distribution of Perceived Likelihood of Being Stopped by the Police when Driving Following Marijuana Use Compared to when Driving on Other Occasions for Drivers Age 16+ who Drove within Two Hours of Marijuana Use in the Past Year by Age Group

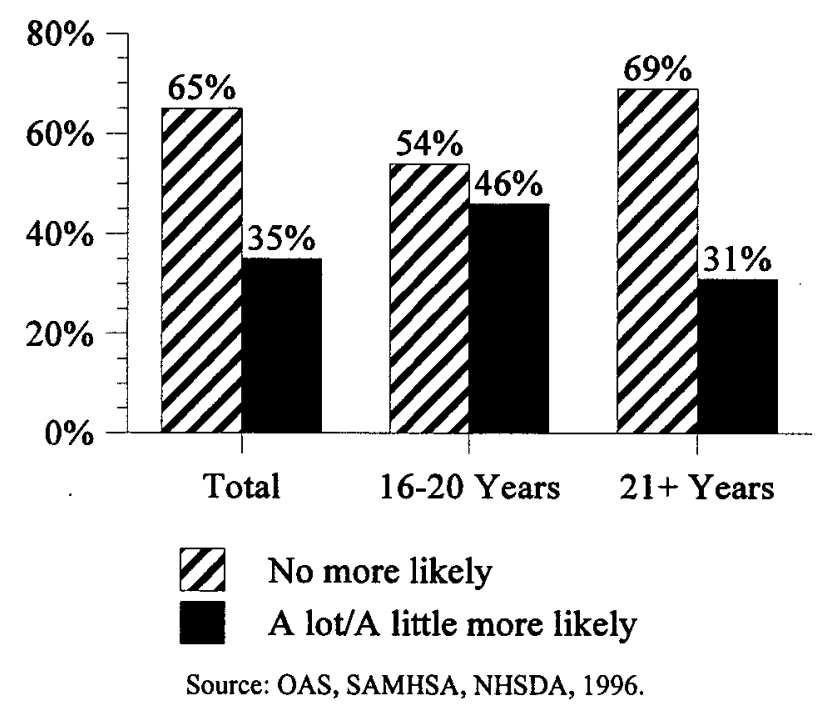

- The majority of drivers age 16 and older who reported driving within two hours of marijuana use, with or without alcohol, felt that they were "no more likely" to be stopped by the police if driving after using marijuana than when driving on other occasions. However, drivers age 21 and older were more likely than drivers age 16-20 to hold this belief. (See Table 13) 


\section{Substance Use Patterns}

This section primarily describes the substance use patterns of drivers age 16 and older who reported driving within two hours of marijuana use, with or without alcohol. Where possible, comparisons are made to the substance use patterns of those who reported driving after alcohol use only. The goal of this section is to estimate the frequency of substance use and the multi-drug use patterns of drivers who reported driving following drug use. The data presented in this section are taken from Tables 14-17.

Figure 2.34 Distribution of Number of Days in Past Month Drove within Two Hours of Marijuana or Alcohol Use for Drivers Age 16+ who Drove Following Marijuana Use or Alcohol Use in the Past Year by Age Group

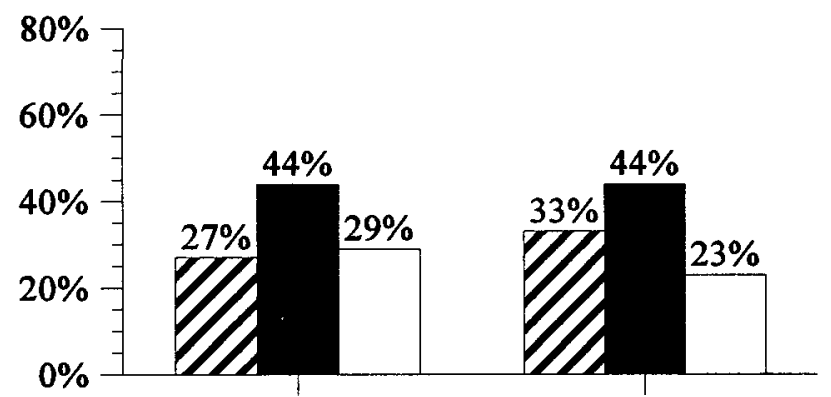

16-20 Years

$$
21+\text { Years }
$$

$$
\begin{aligned}
& \text { No Days in Past Month } \\
& \text { 1-5 Days in Past Month } \\
& \text { 6+ Days in Past Month }
\end{aligned}
$$

Drove Following Marijuana Use
$80 \%$
$60 \%$
$40 \%$
$20 \%$
$0 \%$

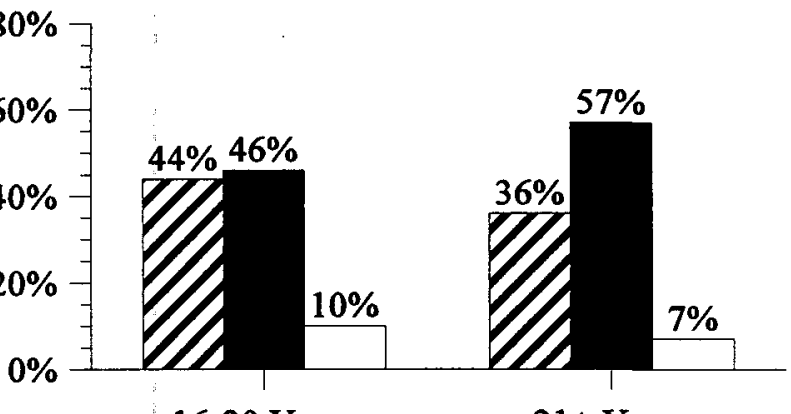

16-20 Years

$$
21+\text { Years }
$$

Source: OAS, SAMHSA, NHSDA, 1996.

- Regardless of age, about 7 out of 10 drivers who reported driving within two hours of marijuana use, with or without alcohol, reported driving following marijuana use on one or more days in the past month. Regardless of age, about 6 out of 10 drivers who reported driving after alcohol use only did so on one or more days in the past month. However, drivers age 21 and older were more likely than drivers age 16-20 to report driving after alcohol use between one and five days in the past month. (See Table 14) 
Figure 2.35 Distribution of Level of Past-Year Marijuana Use ${ }^{6}$ and Past-Month Alcohol Use $^{7}$ for Drivers Age 16+ who Drove within Two Hours of Marijuana Use or Alcohol Use Only in the Past Year by Age Group

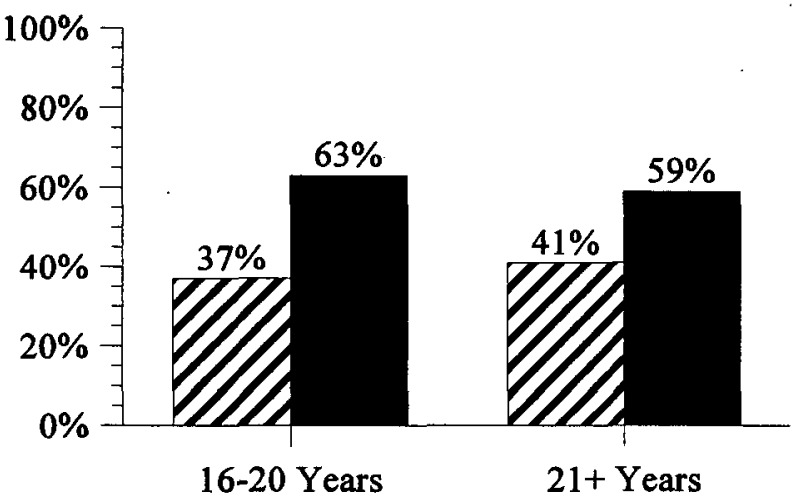

Low/Medium Marijuana Use

Heavy Marijuana Use

Past-Year Marijuana Use

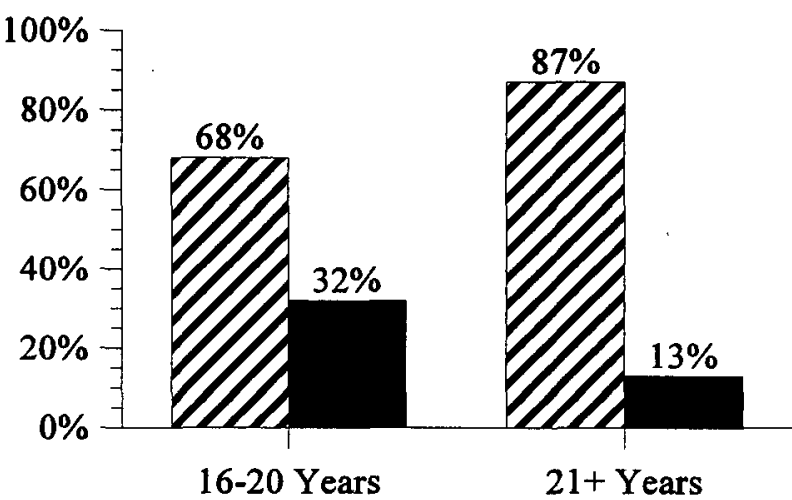

Low/Medium Alcohol Use Heavy Alcohol Use

Past-Month Alcohol Use

- Regardless of age, about 60 percent of drivers who reported driving within two hours of marijuana use, with or without alcohol, reported heavy/weekly past-year marijuana use. By contrast, the majority of those who reported driving after alcohol use only, reported low or medium alcohol use; however, drivers age 16-20 were twice as likely as drivers age 21 and older to report heavy alcohol use. (See Table 15)

${ }^{6}$ Low marijuana use is defined as past-year use, but not weekly or monthly use. Medium marijuana use is defined as monthly, but not weekly use. Heavy marijuana use is defined as weekly marijuana use.

${ }^{7}$ Low alcohol use is defined as having at least one drink, but never more than four on any single occasion in the past 30 days. Medium alcohol use is defined as having at least five drinks on at least one, but fewer than five, occasions in the past 30 days (i.e., binge drinking). Heavy alcohol use is defined as having at least five drinks on at least five occasions in the past 30 days. 
Figure 2.36 Distribution of Whether or Not Other Substances Were Also Used on Most Recent Occasion of Driving within Two Hours of Marijuana Use for Drivers Age 16+ who Drove Following Marijuana Use in the Past Year by Age Group

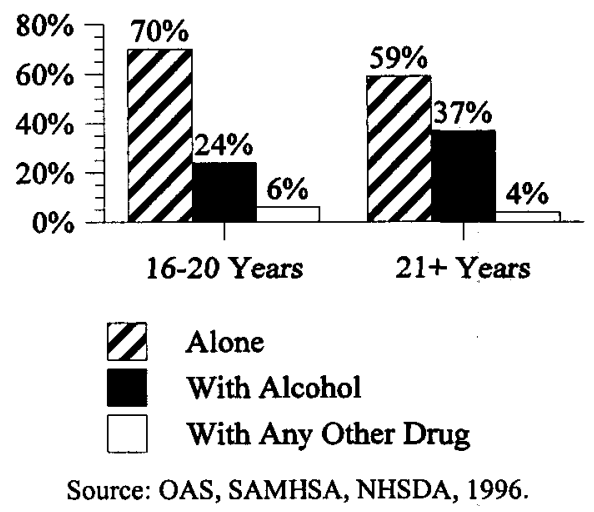

- Regardless of age, the majority of those who drove within two hours of marijuana use, with or without alcohol, in the past year used only marijuana on the most recent occasion of driving after marijuana use. However, drivers age 16-20 were more likely than drivers age 21 and older to report driving after using only marijuana, while drivers age 21 and older were more likely than drivers age 16-20 to report driving after using marijuana in combination with alcohol. (See Table 16)

Figure 2.37 Percentage of Drivers Age 16+ who Drove within Two Hours of Marijuana Use in the Past Year Reporting Use of Other Substances when Driving Following Marijuana Use by Age Group

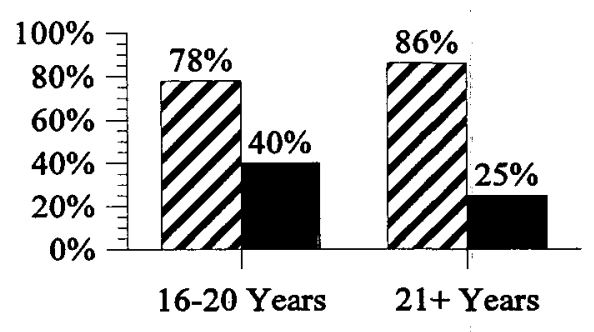

$$
\begin{aligned}
& \text { With Alcohol } \\
& \text { With Any Other Drug }
\end{aligned}
$$

Note: Respondents can be in more than one category.

Source: OAS, SAMHSA, NHSDA, 1996.

- For those who reported driving within two hours of marijuana use, with or without alcohol, drivers age 16-20 were almost twice as likely as drivers age 21 and older to report driving after using marijuana in combination with other drugs such as cocaine, heroin, tranquilizers, analgesics, stimulants, sedatives, and inhalants. (See Table 17) 


\section{E. Blood Alcohol Concentration}

In previous sections of this chapter, those who drove after drug and/or alcohol use have been characterized without any indication of the level of their impairment while driving. Blood alcohol concentration (BAC) levels are the primary indices of the level of driver impairment following alcohol use; however, there is no comparable measure for impairment following drug use.

In order to address level of impairment, this section uses the amount and timing of alcohol consumption prior to driving, along with the physical characteristics of the driver, to estimate the driver's BAC level. (The method by which the estimated BAC levels were calculated is described in greater detail in Appendix D.) The goal of this section is to provide estimates of the BAC levels of drivers within age and gender categories. The data presented in this section are taken from Tables 18-20.

\section{Figure 2.38 Distribution of Number of Drinks Consumed on Most Recent Occasion of Driving within Two Hours of Alcohol Use for Drivers Age 16+ who Drove Following Alcohol Use in the Past Year by Age Group}

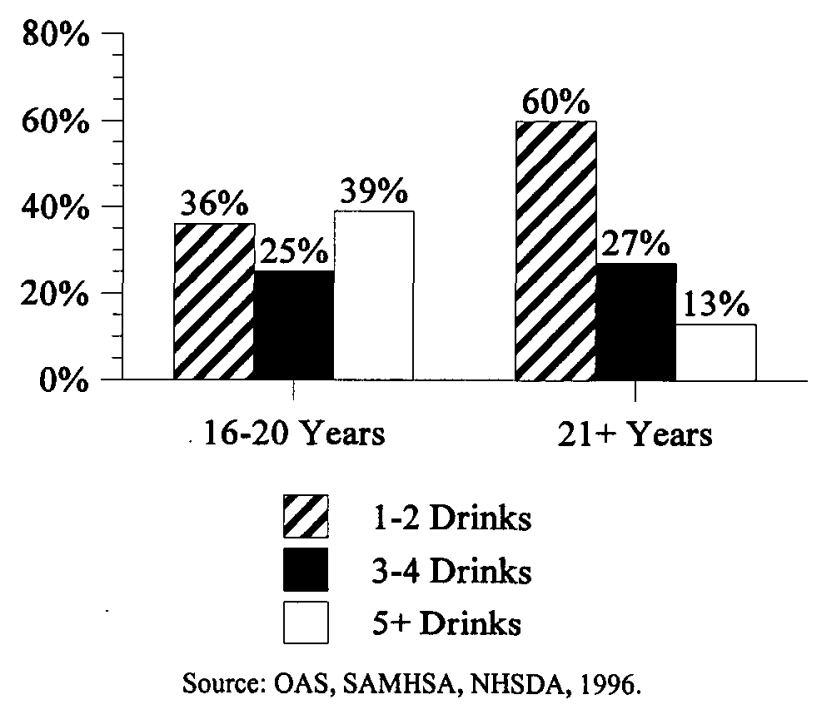

- For those who reported driving within two hours of alcohol use, with or without drugs, those age 16-20 were about three times as likely as drivers age 21 and older to have consumed at least five drinks on the most recent occasion of driving after alcohol use. By contrast, the majority of drivers age 21 and older consumed one or two drinks on the most recent occasion of driving following alcohol use. (See Table 18) 
Figure 2.39 Distribution of Number of Hours between First and Last Drink on Most Recent Occasion of Driving within Two Hours of Alcohol Use for Drivers Age 16+ who Drove Following Alcohol Use in the Past Year by Age Group

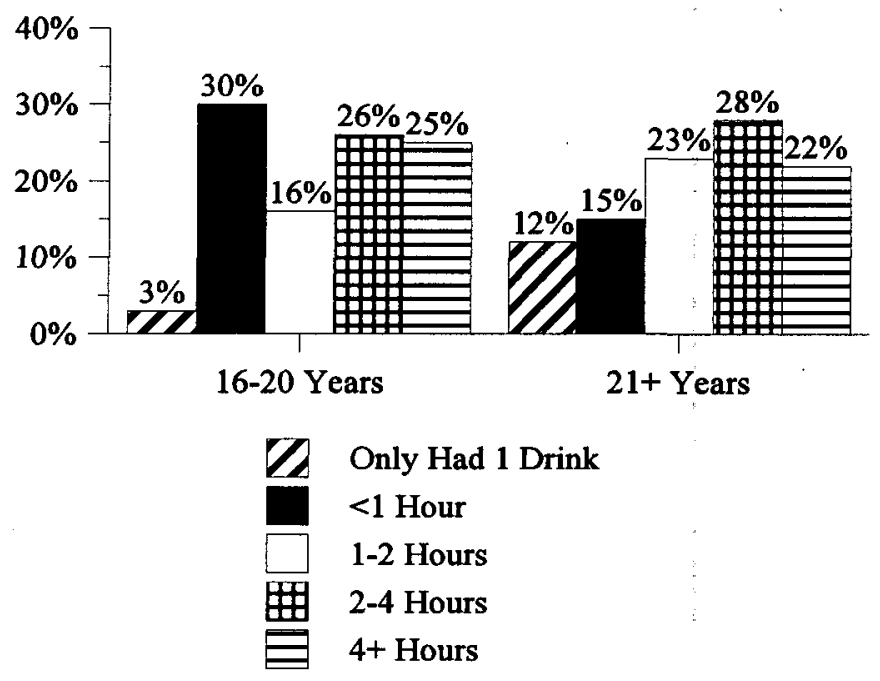

Source: OAS, SAMHSA, NHSDA, 1996.

- Among those who reported driving within two hours of alcohol use, with or without drugs, nearly twice as many drivers age 16-20 as drivers age 21 and older consumed their first and last drink within an hour on the most recent occasion of driving after alcohol use. (See Table 17.)

Figure 2.40 Distribution of Time between Last Drink and when Driving Began on Most Recent Occasion of Driving within Two Hours of Alcohol Use for Drivers Age 16+ who Drove Following Alcohol Use in the Past Year by Age Group

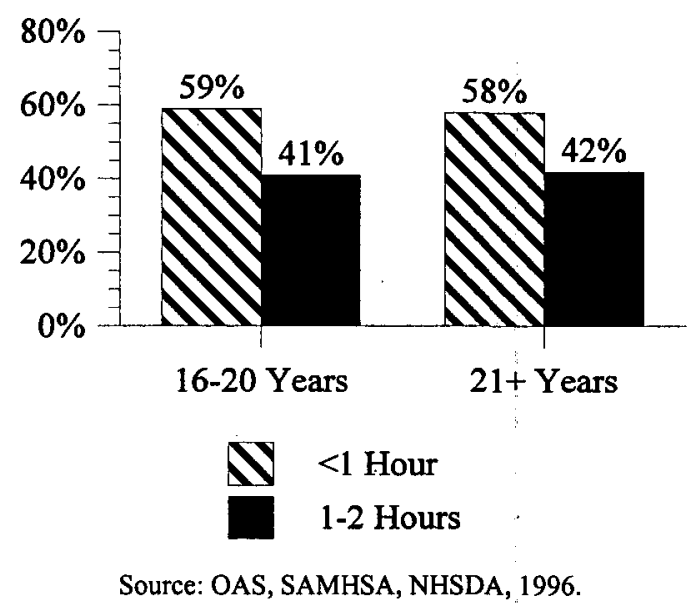

- Regardless of age, about 60 percent of those who drove within two hours of alcohol use in the past year drove within one hour after they consumed their last drink. 
Figure 2.41 Distribution of Estimated Blood Alcohol Concentration Levels on Most Recent Occasion of Driving within Two Hours of Alcohol Use for Drivers Age 16+ who Drove Following Alcohol Use in the Past Year by Gender

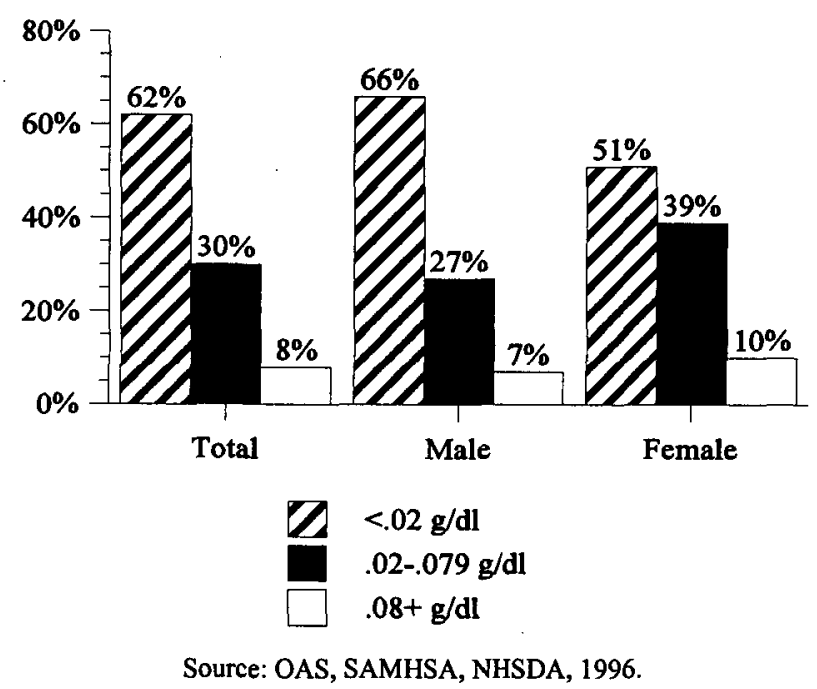

- The vast majority of drivers who reported driving within two hours of alcohol use, with or without drugs, had estimated BAC levels less than $.08 \mathrm{~g} / \mathrm{dl}$ on the most recent occasion of driving following alcohol use; however, a greater percentage of females than males had an estimated BAC level of $.08 \mathrm{~g} / \mathrm{dl}$ or higher. (See Table 19)

Figure 2.42 Average Estimated Blood Alcohol Concentration Level on Most Recent Occasion of Driving within Two Hours of Alcohol Use for Male and Female Drivers Age 16+ who Drove Following Alcohol Use in the Past Year by Age

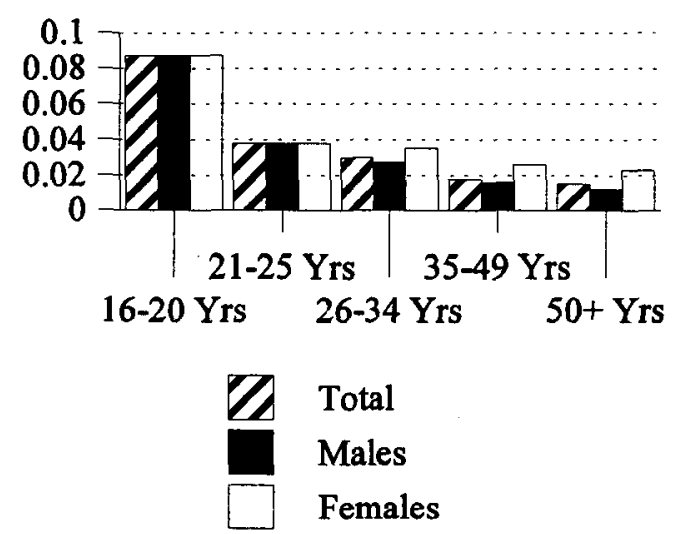

Source: OAS, SAMHSA, NHSDA, 1996.

- For the most recent occasion of driving after alcohol use, with or without drugs, drivers age 16-20 had the highest average estimated BAC level (.087 g/dl). Additionally, females age 26 and older generally had slightly higher estimated BAC levels than males of the same age. (See Table 20) 


\section{CHAPTER 3: CONCLUSIONS}

In an effort to address the lack of available data on drug use and driving, this report contains findings from questions included in the 1996 National Household Survey on Drug Abuse (NHSDA). The data presented describe the prevalence and patterns of driving following drug and/or alcohol use by 11,847 NHSDA respondents, representing over 166 million persons age 16 and older who drove in the past year and also answered the question on driving after substance use. The data provide a demographic and behavioral profile of individuals who reported driving after drug use that may be used to guide the development of appropriate prevention and intervention measures. This chapter summarizes the major findings and briefly notes some policy implications.

\section{Major Findings}

In the year prior to their interviews, approximately 9 million people, or 5 percent of drivers, reported driving within two hours after drug use. About 45 million people, or 27 percent of drivers, drove within two hours after alcohol use. About 7 million people, or four percent of drivers drove after both alcohol and drug use (not necessarily concurrently). Marijuana was by far the most commonly used drug by those who drove after drug use. About four percent of drivers reported driving after marijuana use; one percent or less of drivers reported driving following each of the other drugs examined (i.e., cocaine, tranquilizers, stimulants, and sedatives).

Although the majority of both those who drove after drug use and those who drove after alcohol use were age 21-49, the prevalence of driving after drug use was highest among drivers age 16-20. By contrast, driving after alcohol use was more common among drivers age 21-49, particularly for non-Hispanic whites. Both behaviors were much less common among drivers age 50 and older.

Even though driving after drug use was more common among drivers age 16-20 than among drivers age 21 and older, the driving patterns of those who drove after marijuana use were similar for both age groups. The majority of those who drove after marijuana use were heavy marijuana users, having driven after marijuana use on at least one occasion in the past month. Regardless of the driver's age, the majority of driving following marijuana use occurred in urban areas, on smaller roads, on weekends, and between the hours of 6:00 p.m. and 6:00 a.m. In addition, drivers most commonly reported that they had "no other way to get there" or were "not high enough to cause a crash" on their most recent occasion of driving after marijuana use. Drivers generally felt that marijuana did not affect their ability to drive and that they were no more likely to be stopped by the police when driving after marijuana use than when driving on 
other occasions. Drivers age 16-20 were most likely driving from a friend or relative's home to their own home on their most recent occasion of driving after marijuana use. Drivers age 16-20 were also more likely to use marijuana alone or in combination with other drugs, while drivers age 21 and older were more likely to use marijuana in combination with alcohol.

Driving after alcohol use was more common among drivers age 21 and older and these drivers also reported driving after alcohol use on more occasions in the past month than drivers age 16-20. However, the younger drivers were more likely to report heavy alcohol use. In addition, drivers age 16-20 were more likely to report having consumed larger amounts of alcohol in a shorter period of time on their most recent occasion of driving following alcohol use. As a result of heavier alcohol use, drivers age 16-20 also had substantially higher average estimated blood alcohol concentration (BAC) levels than drivers age 21 and older, indicating a higher level of impairment.

Consistent with the finding that driving after drug use was more common among drivers age 16-20, these drivers were also more likely to have been never married and to have annual personal incomes less than $\$ 10,000$. In contrast, driving after alcohol use was more common among those who were married and had an annual personal income of $\$ 50,000$ or more. The latter finding may also be related to the fact that driving after drug use was more common among unemployed drivers, while driving after alcohol use was more common among those who were working full-time.

Males were substantially more likely than females, regardless of race/ethnicity, to drive after drug and/or alcohol use. This gender difference was especially large for Hispanics. For those who drove after alcohol use, the gender difference was greater among drivers age 21 and older than among drivers age 16-20. However, there was a tendency for female drivers age 25 and older to have higher average estimated BAC levels than males of the same age.

Drivers who had been arrested or who were on probation in the past year were more likely to report driving after drug and/or alcohol use. Driving after alcohol use was equally common among those with and without this criminal justice involvement.

\section{Policy Implications}

Many of these findings have practical and policy implications. For example, those who reported driving after marijuana use generally did not feel that this use impaired their driving ability. This finding suggests the need to develop targeted drug awareness education programs that highlight the physiological effects of marijuana use. 
The section of this report on estimated BAC levels also contains important policyrelevant findings. For example, despite the presence of zero tolerance laws for drivers under age 21, when drivers age 16-20 drive after alcohol use they are likely to have estimated BAC levels higher than $.08 \mathrm{~g} / \mathrm{dl}$ (the legal limit for drivers age 21 and older in some states). Given this finding, and also given the fact that drug use and driving is more common among drivers age 1620 , age-appropriate prevention and intervention measures should be developed to specifically target this age group, particularly the heavy drug and alcohol users.

Females over age 25 had higher estimated BAC levels than males of the same age. This finding may indicate lack of knowledge among females about the differential physiological effects of alcohol on women. Therefore, even though driving after substance use is substantially more common among males, prevention and intervention measures should address gender differences in the physiological response to alcohol.

As noted in Chapter 1, there are some limitations to these data that should be considered in interpreting the results. First, the data are entirely self-reported and may be under or overreported. Second, the reported occurrence of driving following drug use was relatively uncommon relative to driving following alcohol use; therefore, the analysis of this behavior is based on a substantially smaller sample size than that for driving following alcohol use. Results should be interpreted with this in mind. Third, even though BAC levels were calculated to serve as a proxy for level of alcohol impairment, there is no true indicator for the level of driver impairment, particularly following drug use. Furthermore, even though the legal BAC limit is currently $.08 \mathrm{~g} / \mathrm{dl}$ in 16 states, research suggests that there can be significant impairment in driving-related skills at BAC levels as low as .02 g/dl (IIHS, 1995; NHTSA, 1988; NHTSA, 1992a). Therefore, comparisons of estimated BAC levels to legal BAC levels serves primarily as an indication of the prevalence of illegal behavior. Finally, this report is an analysis of every reported instance of driving following drug and/or alcohol use, regardless of the amount of the substance consumed. A more detailed examination of the average quantity of these substances consumed prior to driving would aid the development effective policies and prevention and intervention programs. 


\section{REFERENCES}

Insurance Institute for Highway Safety. (1995). Facts, 1995 Edition. Arlington, VA.

NHTSA. (1988). Effects of Low Doses of Alcohol on Driving-related Skills: A Review of the Evidence. U.S. Department of Transportation, Washington, D.C.

NHTSA. (1992a). Driving Under the Influence: A Report to Congress on Alcohol Limits. U.S. Department of Transportation, Washington, D.C.

NHTSA. (1992b). The Incidence and Role of Drugs in Fatally Injured Drivers. U.S. Department of Transportation, Washington, D.C.

Office of Applied Studies, SAMHSA. (1997). National Household Survey on Drug Abuse: Main Findings, 1996. U.S. Department of Health and Human Services, Rockville, MD. 
APPENDIX A: DETAILED DATA TABLES 
TABLE 1a. Age, Gender, Racial/Ethnic, and Regional Distribution of Total Driving Population Age 16+ who Reported Driving in the Past Year, 1996

\begin{tabular}{|c|c|c|}
\hline \multirow[b]{2}{*}{$\begin{array}{l}\text { Demographic } \\
\text { Characteristic }\end{array}$} & \multicolumn{2}{|c|}{ Drivers Age 16+ } \\
\hline & $\begin{array}{l}\text { Unweighted } \\
\text { Total }\end{array}$ & $\begin{array}{l}\text { Weighted } \\
\text { Percent }\end{array}$ \\
\hline TOTAL & 12,252 & $100.0 \%$ \\
\hline AGE & & $100.0 \%$ \\
\hline 16-18 Yrs & 1,401 & 4.9 \\
\hline 19-20 Yrs & 803 & 3.2 \\
\hline 21-25 Yrs & 2,215 & 8.8 \\
\hline 26-34 Yrs & 4,511 & 18.6 \\
\hline 35-49 Yrs & 2,441 & 32.4 \\
\hline $50+$ Yrs & 881 & 32.2 \\
\hline GENDER & & $100.0 \%$ \\
\hline Male & 5,344 & 50.1 \\
\hline Female & 6,908 & 49.9 \\
\hline RACE/ETHNICITY & & $100.0 \%$ \\
\hline White (Non-Hispanic) & 6,504 & 79.2 \\
\hline Black (Non-Hispanic) & 2,605 & 9.2 \\
\hline Hispanic & 2,747 & 7.8 \\
\hline Other & 396 & 3.9 \\
\hline REGION & & $100.0 \%$ \\
\hline Northeast & 1,793 & 18.4 \\
\hline North Central & 2,537 & 25.3 \\
\hline South & 4,960 & 34.8 \\
\hline West & 2,962 & 21.5 \\
\hline
\end{tabular}


TABLE 1b. Marital, Educational, Employment, and Personal Income Distribution of Total Driving Population Age 16+ who Reported Driving in the Past Year, 1996

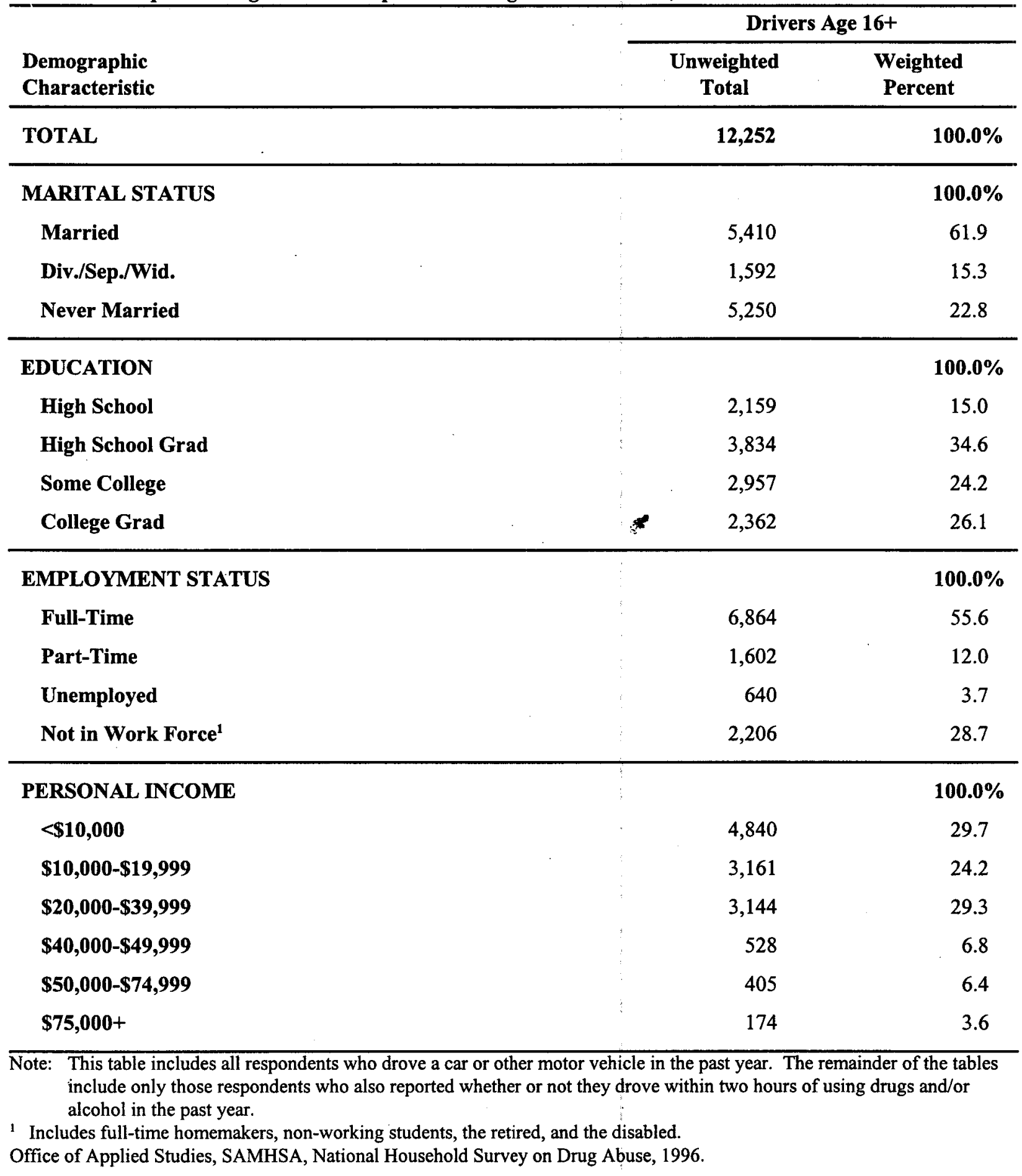


TABLE 2. Percentage of Drivers Age 16+ in Age, Gender, and Regional Groups who Drove Within Two Hours of Substance Use by Substance Used, 1996

\begin{tabular}{|c|c|c|c|c|c|c|}
\hline \multirow[b]{3}{*}{$\begin{array}{l}\text { Demographic } \\
\text { Characteristic }\end{array}$} & \multicolumn{6}{|c|}{ Drove within Two Hours of Substance Use } \\
\hline & \multicolumn{2}{|c|}{ After Alcohol Use } & \multicolumn{2}{|c|}{ After Marijuana Use } & \multicolumn{2}{|c|}{$\begin{array}{c}\text { After Other } \\
\text { Drug Use }^{1}\end{array}$} \\
\hline & $\begin{array}{l}\text { Weighted } \\
\text { Total } \\
\text { (in 1000's) }\end{array}$ & $\begin{array}{c}\text { Weighted } \\
\text { Percent }\end{array}$ & $\begin{array}{l}\text { Weighted } \\
\text { Total } \\
\text { (in 1000's) }\end{array}$ & $\begin{array}{l}\text { Weighted } \\
\text { Percent }\end{array}$ & $\begin{array}{l}\text { Weighted } \\
\text { Total } \\
\text { (in 1000's) }\end{array}$ & $\begin{array}{c}\text { Weighted } \\
\text { Percent }\end{array}$ \\
\hline TOTAL & 45,317 & $26.6 \%$ & 6,327 & $3.7 \%$ & 4,239 & $2.5 \%$ \\
\hline \multicolumn{7}{|l|}{$\overline{\mathbf{A G E}}$} \\
\hline 16-20 Yrs & 2,913 & 21.2 & 1,571 & 11.4 & 509 & $3.8^{*}$ \\
\hline 21-34 Yrs & 16,423 & 35.0 & 2,659 & 5.6 & 1,568 & 3.4 \\
\hline $35+$ Yrs & 25,980 & 23.7 & 2,097 & $1.9^{*}$ & 2,161 & $2.0^{*}$ \\
\hline \multicolumn{7}{|l|}{ GENDER } \\
\hline Male & 30,976 & 36.4 & 4,604 & 5.4 & 2,233 & 2.7 \\
\hline Female & 14,341 & 16.9 & 1,723 & 2.0 & 2,006 & 2.4 \\
\hline \multicolumn{7}{|l|}{ REGION } \\
\hline Northeast & 7,974 & 25.4 & 866 & $2.7^{*}$ & 655 & $2.1^{*}$ \\
\hline North Central & 13,948 & 32.4 & 1,740 & 4.0 & 907 & $2.1^{*}$ \\
\hline South & 14,267 & 24.1 & 2,328 & 3.9 & 1,579 & 2.7 \\
\hline West & 9,127 & 25.1 & 1,393 & 3.8 & 1,098 & $3.1^{*}$ \\
\hline
\end{tabular}

Note: This table is restricted to people who drove a car or other motor vehicle in the past year.

1 Includes cocaine, and the medical and non-medical use of tranquilizers, stimulants, and sedatives.

* Denotes low precision.

Office of Applied Studies, SAMHSA, National Household Survey on Drug Abuse, 1996. 
TABLE 3a. Percentage of Drivers 16+ within Age, Gender, Racial/Ethnic, and Regional Groups Age who Drove within Two Hours of Substance Use in the Past Year by Substance Used, 1996

\begin{tabular}{|c|c|c|c|c|c|c|c|}
\hline \multirow[b]{3}{*}{$\begin{array}{l}\text { Demographic } \\
\text { Characteristic } \\
\end{array}$} & \multirow{3}{*}{$\begin{array}{c}\text { TOTAL } \\
\begin{array}{c}\text { Weighted } \\
\text { Percent }\end{array} \\
\end{array}$} & & & \multicolumn{4}{|c|}{ Drove within Two Hours of Substance Use } \\
\hline & & \multicolumn{2}{|c|}{$\underset{\text { Driver }^{1}}{\text { Non-Impaired }}$} & \multicolumn{2}{|c|}{$\underset{\text { After Alcohol Use Only }}{\text { (No Drugs) }}$} & \multicolumn{2}{|c|}{$\begin{array}{c}\text { After Drug Use } e^{2} \\
\text { (With or Withoüt Alcohol) }\end{array}$} \\
\hline & & $\begin{array}{c}\text { Unweighted } \\
\text { Total }\end{array}$ & $\begin{array}{c}\text { Weighted } \\
\text { Percent }\end{array}$ & $\begin{array}{c}\text { Unweighted } \\
\text { Total }\end{array}$ & $\begin{array}{l}\text { Weighted } \\
\text { Percent }\end{array}$ & $\begin{array}{c}\text { Unweighted } \\
\text { Total }\end{array}$ & $\begin{array}{c}\text { Weighted } \\
\text { Percent }\end{array}$ \\
\hline TOTAL & $100.0 \%$ & 8,610 & $72.1 \%$ & 2,460 & $22.6 \%$ & 777 & $5.3 \%$ \\
\hline \multicolumn{8}{|l|}{ AGE } \\
\hline 16-18 Yrs & $100.0 \%$ & 1,115 & 79.5 & 103 & 8.7 & 144 & 11.7 \\
\hline 19-20 Yrs & $100.0 \%$ & 586 & 71.1 & 98 & 14.9 & 93 & 14.0 \\
\hline 21-25 Yrs & $100.0 \%$ & 1,457 & 62.0 & 544 & 29.1 & 162 & 8.9 \\
\hline 26-34 Yrs & $100.0 \%$ & 3,017 & 64.4 & 1,092 & 29.0 & 250 & 6.6 \\
\hline 35-49 Yrs & $100.0 \%$ & 1,732 & 68.8 & 508 & 25.6 & 112 & 5.6 \\
\hline $50+$ Yrs & $100.0 \%$ & 703 & 81.8 & 115 & 16.7 & 16 & $1.5^{*}$ \\
\hline \multicolumn{8}{|l|}{ GENDER } \\
\hline Male & $100.0 \%$ & 3,286 & 62.4 & 1,419 & 30.7 & 457 & 6.8 \\
\hline Female & $100.0 \%$ & 5,324 & 81.8 & 1,041 & 14.4 & 320 & 3.8 \\
\hline \multicolumn{8}{|l|}{ RACE/ETHNICITY } \\
\hline White (Non-Hispanic) & $100.0 \%$ & 4,140 & 69.6 & 1,689 & 24.8 & 506 & 5.6 \\
\hline Black (Non-Hispanic) & $100.0 \%$ & 2,026 & 81.9 & 310 & 13.4 & 136 & 4.8 \\
\hline Hispanic & $100.0 \%$ & 2,123 & 79.0 & 414 & 16.8 & 118 & 4.3 \\
\hline Other & $100.0 \%$ & 321 & 86.5 & 47 & $9.6^{*}$ & 17 & $4.0^{*}$ \\
\hline \multicolumn{8}{|l|}{ REGION } \\
\hline Northeast & $100.0 \%$ & 1,257 & 73.7 & 379 & 22.0 & 90 & 4.3 \\
\hline North Central & $100.0 \%$ & 1,574 & 66.2 & 680 & 28.4 & 211 & 5.4 \\
\hline South & $100.0 \%$ & 3,671 & 75.0 & 822 & 19.5 & 289 & 5.5 \\
\hline West & $100.0 \%$ & 2,108 & 73.0 & 579 & 21.0 & 187 & 6.0 \\
\hline
\end{tabular}

Note: This table is restricted to people who drove a car or other motor vehicle in the past year.

1 "Non-impaired" drivers are those respondents who drove a motor vehicle in the 12 months prior to the NHSDA interview, but reported that they did not drive within two hours after using drugs and/or alcohol during that same period.

2 Includes marijuana, cocaine, and the medical and non-medical use of tranquilizers, stimulants, and sedatives.

* Denotes low precision.

Office of Applied Studies, SAMHSA, National Household Survey on Drug Abuse, 1996. 
TABLE 3b. Percentage of Drivers Age 16+ within Marital, Educational, Employment, and Personal Income Groups who Drove within Two Hours of Substance Use in the Past Year by Substance Used, 1996

\begin{tabular}{|c|c|c|c|c|c|c|c|}
\hline \multirow[b]{3}{*}{$\begin{array}{l}\text { Demographic } \\
\text { Characteristic }\end{array}$} & \multirow{3}{*}{ 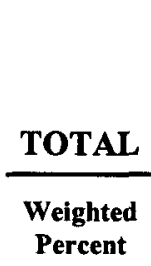 } & & & \multicolumn{4}{|c|}{ Drove within Two Hours of Substance Use } \\
\hline & & \multicolumn{2}{|c|}{$\begin{array}{l}\text { Non-Impaired } \\
\text { Driver }^{1}\end{array}$} & \multicolumn{2}{|c|}{$\begin{array}{l}\text { After Alcohol Use Only } \\
\text { (No Drugs) }\end{array}$} & \multicolumn{2}{|c|}{$\begin{array}{c}\text { After Drug Use }{ }^{2} \\
\text { (With or Without Alcohol) }\end{array}$} \\
\hline & & $\begin{array}{l}\text { Unweighted } \\
\text { Total }\end{array}$ & $\begin{array}{c}\text { Weighted } \\
\text { Percent }\end{array}$ & $\begin{array}{l}\text { Unweighted } \\
\text { Total }\end{array}$ & $\begin{array}{l}\text { Weighted } \\
\text { Percent }\end{array}$ & $\begin{array}{l}\text { Unweighted } \\
\text { Total }\end{array}$ & $\begin{array}{l}\text { Weighted } \\
\text { Percent }\end{array}$ \\
\hline TOTAL & $100.0 \%$ & 8,610 & $72.1 \%$ & 2,460 & $22.6 \%$ & 777 & $5.3 \%$ \\
\hline \multicolumn{8}{|l|}{ MARITAL STATUS } \\
\hline Married & $100.0 \%$ & 3,974 & 74.2 & 1,072 & 22.7 & 181 & 3.1 \\
\hline Div./Sep./Wid. & $100.0 \%$ & 1,120 & 74.4 & 325 & 20.1 & 96 & 5.5 \\
\hline Never Married & $100.0 \%$ & 3,516 & 64.9 & 1,063 & 23.9 & 500 & 11.2 \\
\hline \multicolumn{8}{|l|}{ EDUCATION } \\
\hline$<$ High School & $100.0 \%$ & 1,681 & 82.4 & 240 & 11.3 & 150 & 6.3 \\
\hline High School Grad & $100.0 \%$ & 2,749 & 75.8 & 706 & 18.9 & 251 & 5.3 \\
\hline Some College & $100.0 \%$ & 2,008 & 71.0 & 653 & 23.3 & 189 & 5.7 \\
\hline College Grad & $100.0 \%$ & 1,403 & 61.0 & 809 & 35.0 & 101 & 3.9 \\
\hline \multicolumn{8}{|c|}{ EMPLOYMENT STATUS } \\
\hline Full-Time & $100.0 \%$ & 4,471 & 65.0 & 1,785 & 29.4 & 399 & 5.6 \\
\hline Part-Time & $100.0 \%$ & 1,154 & 74.2 & 294 & 19.4 & 106 & 6.5 \\
\hline Unemployed & $100.0 \%$ & 437 & 68.1 & 99 & 20.8 & 76 & 11.1 \\
\hline Not in Work Force ${ }^{3}$ & $100.0 \%$ & 1,779 & 84.3 & 230 & 12.6 & 110 & 3.1 \\
\hline \multicolumn{8}{|l|}{ PERSONAL INCOME } \\
\hline$<\$ 10,000$ & $100.0 \%$ & 3,786 & 82.5 & 525 & 10.9 & 353 & 6.6 \\
\hline$\$ 10,000-\$ 19,999$ & $100.0 \%$ & 2,257 & 77.3 & 592 & 17.8 & 197 & 4.9 \\
\hline$\$ 20,000-\$ 39,999$ & $100.0 \%$ & 2,017 & 69.3 & 876 & 25.8 & 167 & 4.9 \\
\hline$\$ 40,000-\$ 49,999$ & $100.0 \%$ & 285 & 60.1 & 191 & 34.6 & 32 & $5.3^{*}$ \\
\hline$\$ 50,000-\$ 74,999$ & $100.0 \%$ & 204 & 53.9 & 177 & 42.9 & 17 & $3.3^{*}$ \\
\hline$\$ 75,000+$ & $100.0 \%$ & 61 & 30.5 & 99 & 63.7 & 11 & $5.8^{*}$ \\
\hline
\end{tabular}

Note: This table is restricted to people who drove a car or other motor vehicle in the past year.

1 "Non-impaired" drivers are those respondents who drove a motor vehicle in the 12 months prior to the NHSDA interview, but reported that they did not drive within two hours after using drugs and/or alcohol during that same period.

2 Includes marijuana, cocaine, and the medical and non-medical use of tranquilizers, stimulants, and sedatives.

${ }^{3}$ Includes full-time homemakers, non-working students, the retired, and the disabled.

* Denotes low precision.

Office of Applied Studies, SAMHSA, National Household Survey on Drug Abuse, 1996. 
TABLE 4. Percentage of Drivers Age 16+ within Age by Gender, Racial/Ethnic by Age, and Racial/Ethnic by Gender Groups who Drove within Two Hours of Substance Use in the Past Year by Substance Used, 1996

\begin{tabular}{|c|c|c|c|c|c|c|c|}
\hline \multirow[b]{3}{*}{$\begin{array}{l}\text { Demographic } \\
\text { Characteristic }\end{array}$} & \multirow{3}{*}{$\begin{array}{c}\text { TOTAL } \\
\begin{array}{c}\text { Weighted } \\
\text { Percent }\end{array}\end{array}$} & & & \multicolumn{4}{|c|}{ Drove within Two Hours of Substance Use } \\
\hline & & \multicolumn{2}{|c|}{$\begin{array}{l}\text { Non-Impaired } \\
\text { Driver }^{1}\end{array}$} & \multicolumn{2}{|c|}{$\begin{array}{l}\text { After Alcohol Use Only } \\
\text { (No Drugs) }\end{array}$} & \multicolumn{2}{|c|}{$\begin{array}{c}\text { After Drug Use } \\
\text { (With or Without Alcohol) }\end{array}$} \\
\hline & & $\begin{array}{c}\text { Unweighted } \\
\text { Total }\end{array}$ & $\begin{array}{l}\text { Weighted } \\
\text { Percent }\end{array}$ & $\begin{array}{c}\text { Unweighted } \\
\text { Total }\end{array}$ & $\begin{array}{l}\text { Weighted } \\
\text { Percent }\end{array}$ & $\begin{array}{l}\text { Unweighted } \\
\text { Total }\end{array}$ & $\begin{array}{l}\text { Weighted } \\
\text { Percent }\end{array}$ \\
\hline TOTAL & $100.0 \%$ & 8,610 & $72.1 \%$ & 2,460 & $22.6 \%$ & 777 & $5.3 \%$ \\
\hline \multicolumn{8}{|l|}{ AGE BY GENDER } \\
\hline \multicolumn{8}{|l|}{ 16-20 Years } \\
\hline Male & $100.0 \%$ & 778 & 71.8 & 123 & 13.3 & 145 & 14.8 \\
\hline Female & $100.0 \%$ & 923 & 81.4 & 78 & 8.6 & 92 & 10.0 \\
\hline \multicolumn{8}{|l|}{$21+$ Years } \\
\hline Male & $100.0 \%$ & 2,508 & 61.5 & 1,296 & 32.4 & 312 & 6.1 \\
\hline Female & $100.0 \%$ & 4,401 & 81.8 & 963 & 14.8 & 228 & 3.3 \\
\hline \multicolumn{8}{|c|}{ RACE/ETHNICITY BY AGE } \\
\hline White (Non-Hispanic) & & & & & & & . \\
\hline $16-20$ Years & $100.0 \%$ & 838 & 73.3 & 131 & 12.8 & 152 & 13.9 \\
\hline $21+$ Years & $100.0 \%$ & 3,302 & 69.3 & 1,558 & 25.8 & 354 & 4.9 \\
\hline \multicolumn{8}{|l|}{ Black (Non-Hispanic) } \\
\hline 16-20 Years & $100.0 \%$ & 403 & 83.3 & 25 & $7.1^{*}$ & 36 & $9.6^{*}$ \\
\hline $21+$ Years & $100.0 \%$ & 1,623 & 81.7 & 285 & 14.1 & 100 & 4.2 \\
\hline \multicolumn{8}{|l|}{ Hispanic } \\
\hline 16-20 Years & $100.0 \%$ & 386 & 80.5 & 41 & $8.8^{*}$ & 44 & $10.7^{*}$ \\
\hline $21+$ Years & $100.0 \%$ & 1,737 & 78.8 & 373 & 17.8 & 74 & $3.4^{*}$ \\
\hline \multicolumn{8}{|c|}{$\begin{array}{l}\text { RACE/ETHNICITY BY GENDER } \\
\text { White (Non-Hispanic) }\end{array}$} \\
\hline Male & $100.0 \%$ & 1,485 & 59.0 & 916 & 33.8 & 287 & 7.2 \\
\hline Female & $100.0 \%$ & 2,655 & 80.0 & 773 & 16.0 & 219 & 4.0 \\
\hline \multicolumn{8}{|l|}{ Black (Non-Hispanic) } \\
\hline Male & $100.0 \%$ & 684 & 74.5 & 180 & 19.8 & 76 & 5.7 \\
\hline Female & $100.0 \%$ & 1,342 & 88.6 & 130 & 7.5 & 60 & $3.9^{*}$ \\
\hline \multicolumn{8}{|l|}{ Hispanic } \\
\hline Male & $100.0 \%$ & 978 & 73.0 & 292 & 21.9 & 81 & 5.1 \\
\hline Female & $100.0 \%$ & 1,145 & 87.4 & 122 & 9.5 & 37 & $3.1^{*}$ \\
\hline
\end{tabular}


TABLE 5. Percentage of Drivers Age 16+ Arrested and Not Arrested and on Probation and Not on Probation in the Past Year who Drove within Two Hours of Substance Use in the Past Year by Substance Used, 1996

\begin{tabular}{|c|c|c|c|c|c|c|c|}
\hline \multirow[b]{3}{*}{ During the Past Year } & \multirow{3}{*}{$\begin{array}{c}\text { TOTAL } \\
\text { Weighted } \\
\text { Percent }\end{array}$} & & & \multicolumn{4}{|c|}{ Drove within Two Hours of Substance Use } \\
\hline & & \multicolumn{2}{|c|}{$\begin{array}{l}\text { Non-Impaired } \\
\text { Driver }^{1}\end{array}$} & \multicolumn{2}{|c|}{$\begin{array}{l}\text { After Alcohol Use Only } \\
\text { (No Drugs) }\end{array}$} & \multicolumn{2}{|c|}{$\begin{array}{c}\text { After Drug Use } \\
\text { (With or Without Alcohol) }\end{array}$} \\
\hline & & $\begin{array}{l}\text { Unweighted } \\
\text { Total }\end{array}$ & $\begin{array}{l}\text { Weighted } \\
\text { Percent }\end{array}$ & $\begin{array}{l}\text { Unweighted } \\
\text { Total }\end{array}$ & $\begin{array}{l}\text { Weighted } \\
\text { Percent }\end{array}$ & $\begin{array}{l}\text { Unweighted } \\
\text { Total }\end{array}$ & $\begin{array}{l}\text { Weighted } \\
\text { Percent }\end{array}$ \\
\hline TOTAL & $100.0 \%$ & 8,515 & $\mathbf{7 2 . 0} \%$ & 2,433 & $22.7 \%$ & 762 & $5.3 \%$ \\
\hline \multicolumn{8}{|c|}{ ARRESTED (FOR ANY REASON) } \\
\hline Yes & $100.0 \%$ & 653 & 50.4 & 381 & 32.1 & 244 & 17.5 \\
\hline No & $100.0 \%$ & 7,862 & 74.3 & 2,052 & 21.7 & 518 & 4.0 \\
\hline \multicolumn{8}{|c|}{ ON PROBATION (FOR ANY REASON) } \\
\hline Yes & $100.0 \%$ & 132 & 56.5 & 68 & 21.4 & 65 & 22.1 \\
\hline No & $100.0 \%$ & 8,200 & 72.0 & 2,331 & 22.9 & 690 & 5.1 \\
\hline
\end{tabular}

Note: This table is restricted to people who drove a car or other motor vehicle in the past year.

1 "Non-impaired" drivers are those respondents who drove a motor vehicle in the 12 months prior to the NHSDA interview, but reported that they did not drive within two hours after using drugs and/or alcohol during that same period.

2 Includes marijuana, cocaine, and the medical and non-medical use of tranquilizers, stimulants, and sedatives.

Office of Applied Studies, SAMHSA, National Household Survey on Drug Abuse, 1996. 
TABLE 6a. Age, Gender, Racial/Ethnic, and Regional Distribution of Drivers Age 16+ who Drove within Two Hours of Substance Use in the Past Year by Substance Used, 1996

\begin{tabular}{|c|c|c|c|c|c|c|}
\hline \multirow[b]{3}{*}{$\begin{array}{l}\text { Demographic } \\
\text { Characteristic }\end{array}$} & & & \multicolumn{4}{|c|}{ Drove within Two Hours of Substance Use } \\
\hline & \multicolumn{2}{|c|}{$\begin{array}{l}\text { Non-Impaired } \\
\text { Driver }^{1}\end{array}$} & \multicolumn{2}{|c|}{$\begin{array}{l}\text { After Alcohol Use Only } \\
\text { (No Drugs) }\end{array}$} & \multicolumn{2}{|c|}{$\begin{array}{c}\text { After Drug Use } \\
\text { (With or Without Alcohol) }\end{array}$} \\
\hline & $\begin{array}{l}\text { Unweighted } \\
\text { Total }\end{array}$ & $\begin{array}{l}\text { Weighted } \\
\text { Percent }\end{array}$ & $\begin{array}{l}\text { Unweighted } \\
\text { Total }\end{array}$ & $\begin{array}{l}\text { Weighted } \\
\text { Percent }\end{array}$ & $\begin{array}{l}\text { Unweighted } \\
\text { Total }\end{array}$ & $\begin{array}{c}\text { Weighted } \\
\text { Percent }\end{array}$ \\
\hline TOTAL & 8,610 & $72.1 \%$ & 2,460 & $22.6 \%$ & 777 & $5.3 \%$ \\
\hline AGE & & $100.0 \%$ & & $100.0 \%$ & & $100.0 \%$ \\
\hline 16-18 Yrs & 1,115 & 5.4 & 103 & $1.9^{*}$ & 144 & 10.8 \\
\hline 19-20 Yrs & 586 & 3.1 & 98 & $2.1^{*}$ & 93 & 8.3 \\
\hline 21-25 Yrs & 1,457 & 7.7 & 544 & 11.6 & 162 & 15.0 \\
\hline 26-34 Yrs & 3,017 & 16.7 & 1,092 & 24.0 & 250 & 23.2 \\
\hline 35-49 Yrs & 1,732 & 31.1 & 508 & 37.0 & 112 & 33.9 \\
\hline 50+ Yrs & 703 & 35.9 & 115 & 23.5 & 16 & $8.7^{*}$ \\
\hline GENDER & & $100.0 \%$ & & $100.0 \%$ & & $100.0 \%$ \\
\hline Male & 3,286 & 43.4 & 1,419 & 68.2 & 457 & 64.2 \\
\hline Female & 5,324 & 56.6 & 1,041 & 31.8 & 320 & 35.8 \\
\hline RACE/ETHNICITY & & $100.0 \%$ & & $100.0 \%$ & & $100.0 \%$ \\
\hline White (Non-Hispanic) & 4,140 & 76.6 & 1,689 & 87.2 & 506 & 82.9 \\
\hline Black (Non-Hispanic) & 2,026 & 10.3 & 310 & 5.4 & 136 & 8.0 \\
\hline Hispanic & 2,123 & 8.5 & 414 & 5.7 & 118 & 6.2 \\
\hline Other & 321 & 4.7 & 47 & $1.7^{*}$ & 17 & $2.9^{*}$ \\
\hline REGION & & $100.0 \%$ & & $100.0 \%$ & & $100.0 \%$ \\
\hline Northeast & 1,257 & 18.9 & 379 & 18.1 & 90 & 14.9 \\
\hline North Central & 1,574 & 23.2 & 680 & 31.8 & 211 & 25.5 \\
\hline South & 3,671 & 36.3 & 822 & 30.2 & 289 & 35.6 \\
\hline West & 2,108 & 21.6 & 579 & 19.9 & 187 & 24.0 \\
\hline
\end{tabular}

Note: This table is restricted to people who drove a car or other motor vehicle in the past year.

1 "Non-impaired" drivers are those respondents who drove a motor vehicle in the 12 months prior to the NHSDA interview, but reported that they did not drive within two hours after using drugs and/or alcohol during that same period.

2 Includes marijuana, cocaine, and the medical and non-medical use of tranquilizers, stimulants, and sedatives.

* Denotes low precision.

Office of Applied Studies, SAMHSA, National Household Survey on Drug Abuse, 1996. 
TABLE 6b. Marital, Educational, Employment, and Personal Income Distribution of Drivers Age 16+ who Drove within Two Hours of Substance Use in the Past Year by Substance Used, 1996

\begin{tabular}{|c|c|c|c|c|c|c|}
\hline \multirow[b]{3}{*}{$\begin{array}{l}\text { Demographic } \\
\text { Characteristic }\end{array}$} & & & \multicolumn{4}{|c|}{ Drove within Two Hours of Substance Use } \\
\hline & \multicolumn{2}{|c|}{$\begin{array}{c}\text { Non-Impaired } \\
\text { Driver }^{1}\end{array}$} & \multicolumn{2}{|c|}{$\begin{array}{l}\text { After Alcohol Use Only } \\
\text { (No Drugs) }\end{array}$} & \multicolumn{2}{|c|}{$\begin{array}{c}\text { After Drug Use }{ }^{2} \\
\text { (With or Without Alcohol) }\end{array}$} \\
\hline & $\begin{array}{c}\text { Unweighted } \\
\text { Total }\end{array}$ & $\begin{array}{c}\text { Weighted } \\
\text { Percent }\end{array}$ & $\begin{array}{l}\text { Unweighted } \\
\text { Total }\end{array}$ & $\begin{array}{l}\text { Weighted } \\
\text { Percent }\end{array}$ & $\begin{array}{l}\text { Unweighted } \\
\text { Total }\end{array}$ & $\begin{array}{l}\text { Weighted } \\
\text { Percent }\end{array}$ \\
\hline TOTAL & 8,610 & $72.1 \%$ & 2,460 & $22.6 \%$ & 777 & $5.3 \%$ \\
\hline MARITAL STATUS & & $100.0 \%$ & & $100.0 \%$ & & $100.0 \%$ \\
\hline Married & 3,974 & 63.5 & 1,072 & 62.0 & 181 & 36.1 \\
\hline Div./Sep./Wid. & 1,120 & 15.9 & 325 & 13.7 & 96 & 15.7 \\
\hline Never Married & 3,516 & 20.6 & 1,063 & 24.2 & 500 & 48.2 \\
\hline EDUCATION & & $100.0 \%$ & & $100.0 \%$ & & $100.0 \%$ \\
\hline$<$ High School & 1,681 & 17.1 & 240 & 7.3 & 150 & 18.1 \\
\hline High School Grad & 2,749 & 36.5 & 706 & 28.2 & 251 & 35.6 \\
\hline Some College & 2,008 & 23.7 & 653 & 24.2 & 189 & 26.2 \\
\hline College Grad & 1,403 & 22.6 & 809 & 40.2 & 101 & 20.1 \\
\hline \multicolumn{7}{|l|}{ EMPLOYMENT } \\
\hline STATUS & & $100.0 \%$ & & $100.0 \%$ & & $100.0 \%$ \\
\hline Full-Time & 4,471 & 50.5 & 1,785 & 71.1 & 399 & 60.2 \\
\hline Part-Time Only & 1,154 & 12.4 & 294 & 10.1 & 106 & 14.9 \\
\hline Unemployed & 437 & 3.4 & 99 & 3.3 & 76 & 7.8 \\
\hline Not in Work Force ${ }^{3}$ & 1,779 & 33.6 & 230 & 15.6 & 110 & 17.1 \\
\hline \multicolumn{7}{|l|}{ PERSONAL } \\
\hline INCOME & & $100.0 \%$ & & $100.0 \%$ & & $100.0 \%$ \\
\hline$<\$ 10,000$ & 3,786 & 34.0 & 525 & 14.4 & 353 & 36.6 \\
\hline$\$ 10,000-\$ 19,999$ & 2,257 & 25.7 & 592 & 18.9 & 197 & 22.1 \\
\hline$\$ 20,000$ - $\$ 39,999$ & 2,017 & 28.4 & 876 & 33.8 & 167 & 26.9 \\
\hline$\$ 40,000-\$ 49,999$ & 285 & 5.4 & 191 & 10.0 & 32 & $6.4^{*}$ \\
\hline$\$ 50,000-\$ 74,999$ & 204 & 4.9 & 177 & 12.4 & 17 & $4.0^{*}$ \\
\hline$\$ 75,000+$ & 61 & $1.6^{*}$ & 99 & 10.5 & 11 & $4.1^{*}$ \\
\hline $\begin{array}{l}\text { Note: This table is restrict } \\
\text { "Non-impaired" drivers } \\
\text { reported that they did not } \\
2 \text { Includes marijuana, coca } \\
3 \text { Includes full-time homen } \\
\text { * Denotes low precision. }\end{array}$ & $\begin{array}{l}\text { to people who c } \\
\text { those responde } \\
\text { ive within two } \\
\text { and the medic } \\
\text { cers, non-worki }\end{array}$ & $\begin{array}{l}\text { ve a car or ot } \\
\text { who drove a } \\
\text { urs after usin } \\
\text { and non-med } \\
\text { students, the }\end{array}$ & $\begin{array}{l}\text { Ir motor vehicle } \\
\text { otor vehicle in } \\
\text { drugs and/or alc } \\
\text { l use of tranquil } \\
\text { tired, and the di }\end{array}$ & $\begin{array}{l}n \text { the past year } \\
\text { ne } 12 \text { months } \\
\text { hol during tha } \\
\text { zers, stimulan } \\
\text { abled. }\end{array}$ & $\begin{array}{l}\text { or to the NHSD } \\
\text { ame period. } \\
\text { and sedatives. }\end{array}$ & interview, bu \\
\hline
\end{tabular}


TABLE 7. Age by Gender, Racial/Ethnic by Age, and Racial/Ethnic by Gender Distribution of Drivers Age 16+ who Drove within Two Hours of Substance Use in the Past Year by Substance Used, 1996

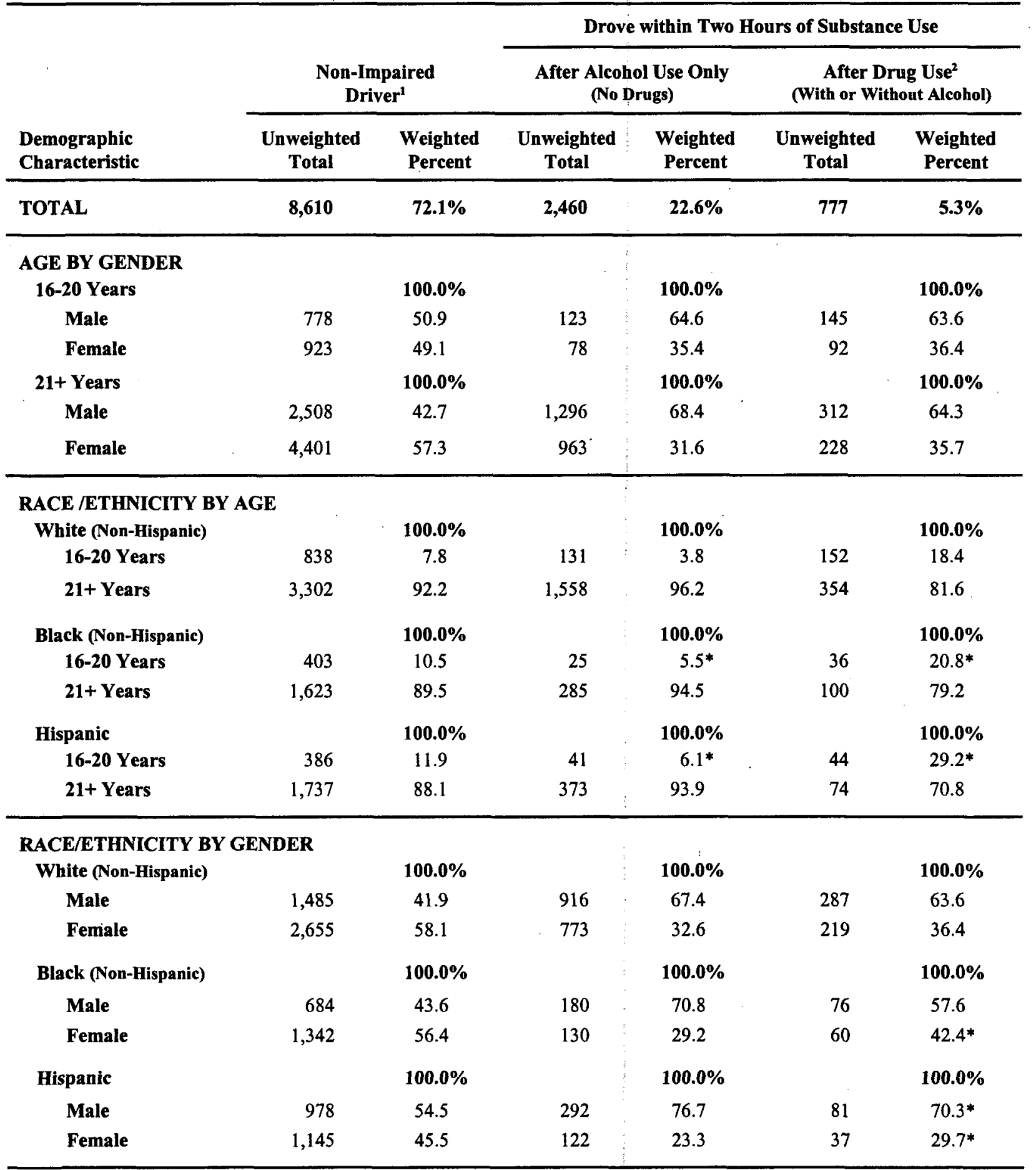

Note: This table is restricted to people who drove a car or other motor vehicle in the past year.

"Non-impaired" drivers are those respondents who drove a motor vehicle in the 12 months prior to the NHSDA interview, but reported that they did not drive within two hours after using drugs and/or alcohol during that same period.

2 Includes marijuana, cocaine, and the medical and non-medical use of tranquilizers, stimulants, and sedatives.

* Denotes low precision.

Office of Applied Studies, SAMHSA, National Household Survey on Drug Abuse, 1996. 
TABLE 8. Past-Year Arrest and Probation Status Distribution of Drivers Age 16+ who Drove within Two Hours of Substance Use in the Past Year by Substance Used, 1996

\begin{tabular}{|c|c|c|c|c|c|c|}
\hline \multirow[b]{3}{*}{ During the Past Year } & \multicolumn{6}{|c|}{ Drove within Two Hours of Substance Use } \\
\hline & \multicolumn{2}{|c|}{$\begin{array}{l}\text { Non-Impaired } \\
\text { Driver' }\end{array}$} & \multicolumn{2}{|c|}{$\begin{array}{c}\text { After Alcohol Use Only } \\
\text { (No Drugs) }\end{array}$} & \multicolumn{2}{|c|}{$\begin{array}{c}\text { After Drug Use }{ }^{2} \\
\text { (With or Without Alcohol) }\end{array}$} \\
\hline & $\begin{array}{l}\text { Unweighted } \\
\text { Total }\end{array}$ & $\begin{array}{l}\text { Weighted } \\
\text { Percent }\end{array}$ & $\begin{array}{l}\text { Unweighted } \\
\text { Total }\end{array}$ & $\begin{array}{l}\text { Weighted } \\
\text { Percent }\end{array}$ & $\begin{array}{l}\text { Unweighted } \\
\text { Total }\end{array}$ & $\begin{array}{l}\text { Weighted } \\
\text { Percent }\end{array}$ \\
\hline TOTAL & 8,515 & $72.0 \%$ & 2,433 & $22.7 \%$ & 762 & $5.3 \%$ \\
\hline \multicolumn{2}{|c|}{ ARRESTED (FOR ANY REASON) } & $100.0 \%$ & & $100.0 \%$ & & $100.0 \%$ \\
\hline Yes & 653 & 6.8 & 381 & 13.6 & 244 & 31.7 \\
\hline No & 7,862 & 93.2 & 2,052 & 86.4 & 518 & 68.3 \\
\hline \multicolumn{2}{|c|}{ ON PROBATION (FOR ANY REASON) } & $100.0 \%$ & & $100.0 \%$ & & $100.0 \%$ \\
\hline Yes & 132 & $1.3^{*}$ & 68 & $1.5^{*}$ & 65 & 6.6 \\
\hline No & 8,200 & 98.7 & 2,331 & 98.5 & 690 & 93.4 \\
\hline
\end{tabular}


TABLE 9. Distribution of Size of Road Driven, Area Driven, Day of Week Driven, and Time of Day Driving Began on Most Recent Occasion of Driving within Two Hours of Marijuana Use for Drivers Age 16+ who Drove Following Marijuana Use in the Past Year by Age Group, 1996

\begin{tabular}{|c|c|c|c|c|c|c|}
\hline \multirow[b]{2}{*}{ Driving Patterns } & \multicolumn{2}{|c|}{ TOTAL } & \multicolumn{2}{|c|}{ 16-20 Years } & \multicolumn{2}{|c|}{$21+$ Years } \\
\hline & $\begin{array}{c}\text { Unweighted } \\
\text { Total }\end{array}$ & $\begin{array}{l}\text { Weighted } \\
\text { Percent }\end{array}$ & $\begin{array}{c}\text { Unweighted } \\
\text { Total } \\
\end{array}$ & $\begin{array}{c}\text { Weighted } \\
\text { Percent } \\
\end{array}$ & $\begin{array}{c}\text { Unweighted } \\
\text { Total } \\
\end{array}$ & $\begin{array}{c}\text { Weighted } \\
\text { Percent } \\
\end{array}$ \\
\hline SIZE OF ROAD & & $100.0 \%$ & & $100.0 \%$ & & $100.0 \%$ \\
\hline Interstate/Highway/Freeway & 235 & 44.6 & 80 & 39.1 & 155 & 46.5 \\
\hline Only on Smaller Roads & 328 & 55.4 & 124 & 60.9 & 204 & 53.5 \\
\hline AREA & & $100.0 \%$ & & $100.0 \%$ & & $100.0 \%$ \\
\hline Rural (open country) & 119 & 23.7 & 37 & $17.9 *$ & 82 & 25.8 \\
\hline Urban (city or town) & 329 & 55.7 & 127 & 61.5 & 202 & 53.7 \\
\hline $\begin{array}{l}\text { Suburban (town just outside of a large } \\
\text { city) }\end{array}$ & 107 & 20.6 & 39 & $20.6 *$ & 68 & 20.5 \\
\hline DAY OF WEEK & & $100.0 \%$ & & $100.0 \%$ & & $100.0 \%$ \\
\hline Weekday $^{1}$ & 158 & 33.5 & 59 & 35.0 & 99 & 32.9 \\
\hline Weekend $^{2}$ & 334 & 66.5 & 122 & 65.0 & 212 & 67.1 \\
\hline TIME OF DAY BEGAN & ... & $100.0 \%$ & $\cdots$ & $100.0 \%$ & . & $100.0 \%$ \\
\hline $12: 00$ a.m. to $5: 59$ a.m. & 135 & 20.5 & 59 & 31.5 & 76 & 16.7 \\
\hline 6:00 a.m. to $11: 59$ a.m. & 46 & $8.2^{*}$ & 10 & $5.6^{*}$ & 36 & $9.1^{*}$ \\
\hline 12:00 p.m. to 5:59 p.m. & 120 & 22.5 & 37 & $15.9 *$ & 83 & 24.8 \\
\hline 6:00 p.m. to $11: 59$ p.m. & 242 & 48.8 & 91 & 47.0 & 151 & 49.4 \\
\hline
\end{tabular}

Note: This table is restricted to people who drove a car or other motor vehicle in the past year.

1 Monday, Tuesday, Wednesday, or Thursday.

2 Friday, Saturday, or Sunday.

* Denotes low precision.

Office of Applied Studies, SAMHSA, National Household Survey on Drug Abuse, 1996. 
TABLE 10. Distribution of Starting Point and Destination on Most Recent Occasion of Driving within Two Hours of Marijuana Use for Drivers Age 16+ who Drove Following Marijuana Use in the Past Year by Age Group, 1996

\begin{tabular}{|c|c|c|c|c|c|c|}
\hline \multirow[b]{2}{*}{ Starting Point and Destination } & \multicolumn{2}{|c|}{ TOTAL } & \multicolumn{2}{|c|}{ 16-20 Years } & \multicolumn{2}{|c|}{ 21+ Years } \\
\hline & $\begin{array}{c}\text { Unweighted } \\
\text { Total } \\
\end{array}$ & $\begin{array}{c}\text { Weighted } \\
\text { Percent }\end{array}$ & $\begin{array}{c}\text { Unweighted } \\
\text { Total }\end{array}$ & $\begin{array}{c}\text { Weighted } \\
\text { Percent }\end{array}$ & $\begin{array}{c}\text { Unweighted } \\
\text { Total } \\
\end{array}$ & $\begin{array}{c}\text { Weighted } \\
\text { Percent } \\
\end{array}$ \\
\hline STARTING POINT & & $100.0 \%$ & & $100.0 \%$ & & $100.0 \%$ \\
\hline Home & 161 & 35.9 & 41 & $22.3^{*}$ & 120 & 40.7 \\
\hline Friend/Relative's Home & 265 & 44.7 & 118 & 60.3 & 147 & 39.2 \\
\hline Public Location $^{1}$ & 111 & 19.4 & 38 & $17.4^{*}$ & 73 & 20.1 \\
\hline DESTINATION & & $100.0 \%$ & & $100.0 \%$ & & $100.0 \%$ \\
\hline Home & 247 & 47.2 & 83 & 43.4 & 164 & 48.6 \\
\hline Friend/Relative's Home & 131 & 20.3 & 58 & 27.9 & 73 & 17.7 \\
\hline Public Location' & 159 & 32.5 & 55 & 28.7 & 104 & 33.8 \\
\hline
\end{tabular}

Note: This table is restricted to people who drove a car or other motor vehicle in the past year.

1 Includes bar or nightclub, restaurant, sporting event, concert, workplace, no place in particular, or unspecified.

* Denotes low precision.

Office of Applied Studies, SAMHSA, National Household Survey on Drug Abuse, 1996. 
TABLE 11. Percentage of Drivers Age 16+ who Drove within Two Hours of Marijuana Use in the Past Year Reporting Reasons for Driving on Most Recent Occasion of Driving Following Marijuana Use by Age Group, 1996

\begin{tabular}{lcccc}
\hline & \multicolumn{2}{c}{ 16-20 Years } & \multicolumn{2}{c}{ 21+Years } \\
\cline { 2 - 5 } Reported Reason for Driving & $\begin{array}{c}\text { Unweighted } \\
\text { Total }\end{array}$ & $\begin{array}{c}\text { Weighted } \\
\text { Percent }\end{array}$ & $\begin{array}{c}\text { Unweighted } \\
\text { Total }\end{array}$ & $\begin{array}{c}\text { Weighted } \\
\text { Percent }\end{array}$ \\
\hline No other way to get there & 125 & 68.5 & 191 & 58.6 \\
Not high enough to cause a crash & 104 & 57.3 & 196 & 60.4 \\
Police not likely to catch me & 68 & 36.9 & 113 & 37.9 \\
No one else available to drive & 86 & 48.2 & 134 & 45.0 \\
Had an appointment or curfew & 61 & 31.4 & 41 & $15.5 *$ \\
Other reason & 57 & 29.9 & 69 & 28.3 \\
\hline $\begin{array}{l}\text { Note: This table restricted to people who drove a car or other motor vehicle in the past year. Responses do not sum to } 100 \% \\
\text { because respondents could mark more than one answer. }\end{array}$ \\
$\begin{array}{l}\text { * Denotes low precision. } \\
\text { Office of Applied Studies, SAMHSA, National Household Survey on Drug Abuse, } 1996 .\end{array}$
\end{tabular}


TABLE 12. Distribution of Perceived Extent to which Marijuana Affected Ability to Drive Safely on Most Recent Occasion of Driving within Two Hours of Marijuana Use for Drivers Age 16+ who Drove Following Marijuana Use in the Past Year by Age Group, 1996

Amount Marijuana Affected Ability to Drive Safely

\begin{tabular}{lcccccc}
\cline { 3 - 6 } & \multicolumn{2}{c}{ TOTAL } & \multicolumn{2}{c}{ A Lot/A Little } & \multicolumn{2}{c}{ Not at All } \\
\cline { 2 - 7 } & $\begin{array}{c}\text { Unweighted } \\
\text { Total }\end{array}$ & $\begin{array}{c}\text { Weighted } \\
\text { Percent }\end{array}$ & $\begin{array}{c}\text { Unweighted } \\
\text { Total }\end{array}$ & $\begin{array}{c}\text { Weighted } \\
\text { Percent }\end{array}$ & $\begin{array}{c}\text { Unweighted } \\
\text { Total }\end{array}$ & $\begin{array}{c}\text { Weighted } \\
\text { Percent }\end{array}$ \\
\hline TOTAL & $\mathbf{5 7 1}$ & $\mathbf{1 0 0 . 0} \%$ & $\mathbf{2 7 3}$ & $\mathbf{4 4 . 2}$ & $\mathbf{2 9 8}$ & $\mathbf{5 5 . 8}$ \\
$\mathbf{1 6 - 2 0}$ Years & $\mathbf{2 0 8}$ & $\mathbf{1 0 0 . 0} \%$ & 107 & 48.2 & 101 & 51.8 \\
$\mathbf{2 1 +}$ Years & $\mathbf{3 6 3}$ & $\mathbf{1 0 0 . 0} \%$ & 166 & 42.8 & 197 & $\mathbf{5 7 . 2}$ \\
\hline
\end{tabular}

Note: This table is restricted to people who drove a car or other motor vehicle in the past year.

Office of Applied Studies, SAMHSA, National Household Survey on Drug Abuse, 1996.

TABLE 13. Distribution of Perceived Likelihood of Being Stopped by the Police when Driving Following Marijuana Use Compared to when Driving on Other Occasions for Drivers Age 16+ who Drove within Two Hours of Marijuana Use in the Past Year by Age Group, 1996

\begin{tabular}{|c|c|c|c|c|c|c|}
\hline & & & \multicolumn{4}{|c|}{$\begin{array}{l}\text { How Likely Stopped by Police } \\
\text { If Use Marijuana and Drive }\end{array}$} \\
\hline & \multirow{2}{*}{\multicolumn{2}{|c|}{ TOTAL }} & \multirow{2}{*}{\multicolumn{2}{|c|}{$\begin{array}{c}\text { A Lot/A Little More } \\
\text { Likely }\end{array}$}} & \multirow{2}{*}{\multicolumn{2}{|c|}{ No More Likely }} \\
\hline & & & & & & \\
\hline & $\begin{array}{l}\text { Unweighted } \\
\text { Total }\end{array}$ & $\begin{array}{l}\text { Weighted } \\
\text { Percent }\end{array}$ & $\begin{array}{l}\text { Unweighted } \\
\text { Total }\end{array}$ & $\begin{array}{l}\text { Weighted } \\
\text { Percent }\end{array}$ & $\begin{array}{l}\text { Unweighted } \\
\text { Total }\end{array}$ & $\begin{array}{c}\text { Weighted } \\
\text { Percent }\end{array}$ \\
\hline TOTAL & 565 & $100.0 \%$ & 218 & 34.9 & 347 & 65.1 \\
\hline 16-20 Years & 208 & $100.0 \%$ & 95 & 45.7 & 113 & $54.3 \quad \vdots$ \\
\hline $21+$ Years & 357 & $100.0 \%$ & 123 & 31.1 & 234 & 68.9 \\
\hline
\end{tabular}

Note: This table is restricted to people who drove a car or other motor vehicle in the past year.

Office of Applied Studies, SAMHSA, National Household Survey on Drug Abuse, 1996. 
TABLE 14. Distribution of Number of Days in Past Month Drove within Two Hours of Alcohol or Marijuana Use, for All Ages and within Age Groups, for Drivers Age 16+ who Drove Following Alcohol Use Only or Marijuana Use in the Past Year by Substance Type, 1996

\begin{tabular}{lcccc}
\hline & \multicolumn{2}{c}{ Alcohol } & \multicolumn{2}{c}{ Marijuana } \\
\cline { 2 - 5 } Number of Days & $\begin{array}{c}\text { Unweighted } \\
\text { Total }\end{array}$ & $\begin{array}{c}\text { Weighted } \\
\text { Percent }\end{array}$ & $\begin{array}{c}\text { Unweighted } \\
\text { Total }\end{array}$ & $\begin{array}{c}\text { Weighted } \\
\text { Percent }\end{array}$ \\
\hline TOTAL & $\mathbf{2 , 3 9 0}$ & $\mathbf{1 0 0 . 0} \%$ & $\mathbf{5 7 8}$ & $\mathbf{1 0 0 . 0 \%}$ \\
None & 903 & 36.5 & 178 & 31.5 \\
1-5 Days & 1,311 & 56.5 & 250 & 44.0 \\
6+ Days & 176 & 7.0 & 150 & 24.5 \\
\hline 16-20 YEARS & 195 & $100.0 \%$ & 207 & $\mathbf{1 0 0 . 0} \%$ \\
None & 84 & 44.3 & 59 & 26.6 \\
1-5 Days & 93 & 45.7 & 92 & 44.2 \\
6+ Days & 18 & $10.0 *$ & 56 & 29.2 \\
\hline 21+ YEARS & $\mathbf{2 , 1 9 5}$ & $100.0 \%$ & 371 & $\mathbf{1 0 0 . 0 \%}$ \\
None & 819 & 36.2 & 119 & 33.1 \\
1-5 Days & 1,218 & 56.9 & 158 & 43.9 \\
6+ Days & 158 & 6.9 & 94 & 23.0 \\
\hline
\end{tabular}

Note: This table is restricted to people who drove a car or other motor vehicle in the past year.

* Denotes low precision.

Office of Applied Studies, SAMHSA, National Household Survey on Drug Abuse, 1996. 
TABLE 15. Distribution of Level of Past-Month Alcohol Use or Past-Year Marijuana Use for Drivers Age 16+ who Drove within Two Hours of Alcohol Use Only or Marijuana Use in the Past Year by Age Group, 1996

\begin{tabular}{|c|c|c|c|c|c|c|c|c|c|c|}
\hline & \multirow{3}{*}{$\begin{array}{l}\text { TOTAL } \\
\text { Percent }\end{array}$} & \multicolumn{4}{|c|}{ ALCOHOL ${ }^{1}$} & \multirow{3}{*}{$\begin{array}{l}\text { TOTAL } \\
\text { Percent }\end{array}$} & \multicolumn{4}{|c|}{ MARIJUANA ${ }^{2}$} \\
\hline & & \multicolumn{2}{|c|}{ Heavy Use } & \multicolumn{2}{|c|}{ Medium/Low Use } & & \multicolumn{2}{|c|}{ Heavy Use } & \multicolumn{2}{|c|}{ Medium/Low Use } \\
\hline & & $\begin{array}{c}\text { Unweighted } \\
\text { Total }\end{array}$ & $\begin{array}{c}\text { Weighted } \\
\text { Percent }\end{array}$ & $\begin{array}{c}\text { Unweighted } \\
\text { Total }\end{array}$ & $\begin{array}{c}\text { Weighted } \\
\text { Percent }\end{array}$ & & $\begin{array}{c}\text { Unweighted } \\
\text { Total }\end{array}$ & $\begin{array}{c}\text { Weighted } \\
\text { Percent }\end{array}$ & $\begin{array}{c}\text { Unweighted } \\
\text { Total }\end{array}$ & $\begin{array}{c}\text { Weighted } \\
\text { Percent }\end{array}$ \\
\hline TOTAL & $100.0 \%$ & 377 & 14.1 & 1,808 & 85.9 & $100.0 \%$ & 340 & 59.7 & 228 & 40.3 \\
\hline 16-20 Years & $100.0 \%$ & 52 & $32.0^{*}$ & 110 & 68.0 & $100.0 \%$ & 128 & 63.1 & 79 & 36.9 \\
\hline $21+$ Years & $100.0 \%$ & 325 & 13.5 & 1,698 & 86.5 & $100.0 \%$ & 212 & 58.5 & 149 & 41.5 \\
\hline
\end{tabular}

Note: This table is restricted to people who drove a car or other motor vehicle in the past year.

1 Heavy = Had at least five drinks on at least five occasions in the past 30 days; Medium = Had at least five drinks on at least one, but no more than four occasions during the past 30 days (i.e., binge drinking); Low = Used alcohol, but had at least one, but no more than four drinks on any occasion during the past 30 days.

2 Heavy = Used weekly; Medium = Used monthly, but not weekly; Low = Used in past year, but not weekly or monthly.

* Denotes low precision.

Office of Applied Studies, SAMHSA, National Household Survey on Drug Abuse, 1996. 
TABLE 16. Distribution of Whether or Not Other Substances Were Also Used on Most Recent Occasion of Driving within Two Hours of Marijuana Use for Drivers Age 16+ who Drove Following Marijuana Use in the Past Year by Age Group, 1996

\begin{tabular}{|c|c|c|c|c|c|c|c|}
\hline & \multirow{2}{*}{$\begin{array}{c}\text { TOTAL } \\
\begin{array}{c}\text { Weighted } \\
\text { Percent }\end{array}\end{array}$} & \multicolumn{2}{|c|}{ Alone } & \multicolumn{2}{|c|}{ With Alcohol } & \multicolumn{2}{|c|}{ With Other Drug } \\
\hline & & $\begin{array}{c}\text { Unweighted } \\
\text { Total }\end{array}$ & $\begin{array}{c}\text { Weighted } \\
\text { Percent }\end{array}$ & $\begin{array}{c}\text { Unweighted } \\
\text { Total }\end{array}$ & $\begin{array}{c}\text { Weighted } \\
\text { Percent }\end{array}$ & $\begin{array}{c}\text { Unweighted } \\
\text { Total }\end{array}$ & $\begin{array}{c}\text { Weighted } \\
\text { Percent }\end{array}$ \\
\hline TOTAL & $100.0 \%$ & 332 & 62.0 & 184 & 33.2 & 34 & 4.8 \\
\hline 16-20 Years & $100.0 \%$ & 137 & 70.1 & 55 & 24.1 & 13 & $5.9^{*}$ \\
\hline $21+$ Years & $100.0 \%$ & 195 & 59.1 & 129 & 36.5 & 21 & $4.4^{*}$ \\
\hline
\end{tabular}

Note: This table is restricted to people who drove a car or other motor vehicle in the past year.

* Denotes low precision.

Office of Applied Studies, SAMHSA, National Household Survey on Drug Abuse, 1996.

TABLE 17. Percentage of Drivers Age 16+ who Drove within Two Hours of Using Marijuana and Another Substance in the Past Year by Age Group, 1996

\begin{tabular}{lcccc}
\hline & \multicolumn{2}{c}{ 16-20 Years } & \multicolumn{2}{c}{$21+$ Years } \\
\cline { 2 - 5 } Drove after Using Marijuana and... & $\begin{array}{c}\text { Unweighted } \\
\text { Total }\end{array}$ & $\begin{array}{c}\text { Weighted } \\
\text { Percent }\end{array}$ & $\begin{array}{c}\text { Unweighted } \\
\text { Total }\end{array}$ & $\begin{array}{c}\text { Weighted } \\
\text { Percent }\end{array}$ \\
\hline Alcohol & 167 & 77.7 & 329 & 85.5 \\
Any Other Drug & 79 & 39.7 & 107 & 24.5 \\
\hline
\end{tabular}

Note: This table is restricted to people who drove a car or other motor vehicle in the past year. Responses do not sum to $100 \%$ because respondents can fall into more than one category.

Includes cocaine, heroin, hallucinogens, inhalants, and the medical and non-medical use of tranquilizers, analgesics, stimulants, and sedatives.

Office of Applied Studies, SAMHSA, National Household Survey on Drug Abuse, 1996. 
TABLE 18. Distribution of Number of Drinks Consumed, Number of Hours between First and Last Drink, and Time between Last Drink and when Driving Began on Most Recent Occasion of Driving within Two Hours of Alcohol Use for Drivers Age 16+ who Drove Following Alcohol Use in the Past Year by Age Group, 1996

\begin{tabular}{|c|c|c|c|c|c|c|}
\hline & \multicolumn{2}{|c|}{ TOTAL } & \multicolumn{2}{|c|}{ 16-20 Years } & \multicolumn{2}{|c|}{$21+$ Years } \\
\hline & $\begin{array}{c}\text { Unweighted } \\
\text { Total }\end{array}$ & $\begin{array}{c}\text { Weighted } \\
\text { Percent }\end{array}$ & $\begin{array}{c}\text { Unweighted } \\
\text { Total }\end{array}$ & $\begin{array}{l}\text { Weighted } \\
\text { Percent }\end{array}$ & $\begin{array}{c}\text { Unweighted } \\
\text { Total }\end{array}$ & $\begin{array}{c}\text { Weighted } \\
\text { Percent }\end{array}$ \\
\hline NUMBER OF DRINKS & & $100.0 \%$ & & $100.0 \%$ & & $100.0 \%$ \\
\hline 1-2 Drinks & 945 & 58.8 & 84 & 36.3 & 861 & 60.1 \\
\hline 3-4 Drinks & 542 & 26.4 & 56 & 24.6 & 486 & 26.5 \\
\hline 5+ Drinks & 404 & 14.8 & 77 & 39.1 & 327 & 13.5 \\
\hline \multicolumn{7}{|c|}{ HOURS BETWEEN FIRST AND LAST } \\
\hline DRINK & & $100.0 \%$ & & $100.0 \%$ & & $100.0 \%$ \\
\hline 4+ Hours & 494 & 22.7 & 55 & 25.1 & 439 & 22.6 \\
\hline 2-4 Hours & 555 & 27.6 & 55 & 25.7 & 500 & 27.7 \\
\hline 1-2 Hours & 359 & 22.4 & 41 & $16.1^{*}$ & 318 & 22.8 \\
\hline$<1$ Hour & 310 & 16.0 & 59 & 29.8 & 251 & 15.2 \\
\hline Only Had 1 Drink & 192 & 11.3 & 10 & $3.2^{*}$ & 182 & 11.7 \\
\hline \multicolumn{6}{|c|}{ TIME BETWEEN LAST DRINK AND } & $100.0 \%$ \\
\hline 1-2 Hours & 891 & 42.4 & 103 & 40.8 & 788 & 42.5 \\
\hline$<1$ Hour & 1030 & 57.6 & 117 & 59.2 & 913 & 57.5 \\
\hline
\end{tabular}

Note: This table is restricted to people who drove a car or other motor vehicle in the past year.

* Denotes low precision.

Office of Applied Studies, SAMHSA, National Household Survey on Drug Abuse, 1996. 
TABLE 19. Distribution of Estimated Blood Alcohol Concentration (BAC) Levels ${ }^{1}$ on Most Recent Occasion of Driving within Two Hours of Alcohol Use for Drivers Age 16+ who Drove Following Alcohol Use in the Past Year by Age within Gender, 1996

\begin{tabular}{|c|c|c|c|c|c|c|c|c|c|c|c|}
\hline \multirow[b]{3}{*}{$\begin{array}{c}\text { BAC } \\
\text { Level } \\
\end{array}$} & \multirow{3}{*}{$\begin{array}{c}\text { TOTAL } \\
\text { Weighted } \\
\text { Percent }\end{array}$} & \multicolumn{5}{|c|}{ Males } & \multicolumn{5}{|c|}{ Females } \\
\hline & & \multirow{2}{*}{$\begin{array}{c}\text { Total } \\
\begin{array}{c}\text { Weighted } \\
\text { Percent }\end{array}\end{array}$} & \multicolumn{2}{|c|}{$16-20$ Years } & \multicolumn{2}{|c|}{ 21+ Years } & \multirow{2}{*}{$\begin{array}{c}\text { Total } \\
\text { Weighted } \\
\text { Percent } \\
\end{array}$} & \multicolumn{2}{|c|}{$16-20$ Years } & \multicolumn{2}{|c|}{ 21+ Years } \\
\hline & & & $\begin{array}{c}\text { Unweighted } \\
\text { Total } \\
\end{array}$ & $\begin{array}{c}\text { Weighted } \\
\text { Percent }\end{array}$ & $\begin{array}{c}\begin{array}{c}\text { Unweighted } \\
\text { Total }\end{array} \\
\end{array}$ & $\begin{array}{c}\text { Weighted } \\
\text { Percent } \\
\end{array}$ & & $\begin{array}{c}\text { Unweighted } \\
\text { Total } \\
\end{array}$ & $\begin{array}{c}\text { Weighted } \\
\text { Percent }\end{array}$ & $\begin{array}{c}\text { Unweighted } \\
\text { Total } \\
\end{array}$ & $\begin{array}{c}\text { Weighted } \\
\text { Percent }\end{array}$ \\
\hline TOTAL & $100.0 \%$ & $100.0 \%$ & 137 & $100.0 \%$ & 1,019 & $100.0 \%$ & $100.0 \%$ & 67 & $100.0 \%$ & 599 & $100.0 \%$ \\
\hline$<.02$ & 62.0 & 66.3 & 44 & $29.9^{*}$ & 633 & 68.3 & 50.7 & 26 & $31.2^{*}$ & 299 & 51.8 \\
\hline $.02-.079$ & 30.1 & 26.8 & 48 & $34.8^{*}$ & 282 & 26.3 & .39 .0 & 19 & $32.1^{*}$ & 219 & 39.4 \\
\hline $.08+$ & 7.8 & 6.9 & 45 & $35.2 *$ & 104 & 5.3 & 10.3 & 22 & $36.7^{*}$ & 81 & 8.8 \\
\hline
\end{tabular}

Note: This table is restricted to people who drove a car or other motor vehicle in the past year.

1 See Appendix D for method used to estimate BAC levels. BAC levels are reported in grams per deciliter.

* Denotes low precision.

Office of Applied Studies, SAMHSA, National Household Survey on Drug Abuse, 1996. 
TABLE 20. Average Estimated Blood Alcohol Concentration (BAC) Level ${ }^{1}$ on Most Recent Occasion of Driving within Two Hours of Alcohol Use for Drivers Age 16+ who Drove Following Alcohol Use in the Past Year by Gender and Age, 1996

\begin{tabular}{lcccccc}
\hline & \multicolumn{2}{c}{ TOTAL } & \multicolumn{2}{c}{ Males } & \multicolumn{2}{c}{ Females } \\
\cline { 2 - 7 } Age & $\begin{array}{c}\text { Unweighted } \\
\text { Total }\end{array}$ & $\begin{array}{c}\text { Weighted } \\
\text { Mean }\end{array}$ & $\begin{array}{c}\text { Unweighted } \\
\text { Total }\end{array}$ & $\begin{array}{c}\text { Weighted } \\
\text { Mean }\end{array}$ & $\begin{array}{c}\text { Unweighted } \\
\text { Total }\end{array}$ & $\begin{array}{c}\text { Weighted } \\
\text { Mean }\end{array}$ \\
\hline TOTAL & 1822 & .026 & 1156 & .024 & 666 & .033 \\
\hline 16-20 YRS & 204 & .087 & 137 & .087 & 67 & .087 \\
21-25 YRS & 418 & .038 & 252 & .038 & 166 & .039 \\
26-34 YRS & 770 & .030 & 468 & .027 & 302 & .035 \\
35-49 YRS & 357 & .018 & 247 & .016 & 110 & .026 \\
50+ YRS & 73 & .015 & 52 & .012 & 21 & $.023 *$ \\
\hline
\end{tabular}

Note: This table is restricted to people who drove a car or other motor vehicle in the past year.

1 See Appendix D for method used to estimate BAC levels. BAC levels are reported in grams per deciliter.

* Denotes low precision.

Office of Applied Studies, SAMHSA, National Household Survey on Drug Abuse, 1996. 


\section{APPENDIX B: STANDARD ERROR TABLES}

As stated earlier, this report presents results of tests of statistical significance for comparisons of prevalence estimates. Differences were tested for statistical significance using $Z$ tests. The $\mathrm{Z}$ test takes into account the sizes of the subsamples being compared and the degree of variation among sample members. Statistical significance refers to the probability that a difference as large as that observed would occur due to random error in the estimates if there were no difference in the prevalence rates in the groups being compared. Unless otherwise noted, differences discussed in the text were statistically significant at the .05 level or lower. That is, a sample difference equal to or larger than the observed sample difference is likely to occur fewer than 5 times in 100 by chance alone (.05 level). Analogous definitions apply to significance at the .01 and .001 levels.

Standard errors of the estimates are not presented in the main text of this report. However, this appendix contains standard errors for the estimates presented in this report. These standard errors were calculated using SUDAAN ${ }^{1}$. The reader may use these standard errors to perform additional hypothesis testing. The difference in prevalence rates may be determined using the standard difference in percentages test expressed as

$$
z=\frac{\left|p_{1}-p_{2}\right|}{\sqrt{S E\left(p_{1}\right)^{2}+S E\left(p_{2}\right)^{2}}}
$$

where $p_{1}$ is the estimated percentage of the first subgroup (e.g., the estimated percentage of males who drove within two hours of drug use in the past year), $\mathrm{p}_{2}$ is the corresponding estimate of the second group (e.g., females), $S E\left(p_{1}\right)$ is the standard error of $p_{1}$, and $S E\left(p_{2}\right)$ is the standard error of $\mathrm{p}_{2}$. So, using our example, as shown in Table 3a., 6.8 percent of males reported driving within two hours of drug use in the past year and 3.8 percent of females reported the same behavior. As shown in Table SE3a., the standard errors for these estimates are 0.47 and 0.32 , respectively. Therefore, using the above equation it follows that $\mathrm{Z}=5.28$, which is greater than the critical value of 1.96. Therefore, the difference in the two percentages is significant at the .05 level; in fact, it is significant at the .001 level.

The standard error tables are numbered to correspond with the detailed data tables. For example the standard errors for Table 2 are found in Table SE2.

${ }^{1}$ See Shah, B.V., Barnwell, B.G., Hunt, P.N., \& LaVange, L.M. (1994). SUDAAN user's manual: Release 6.4. Research Triangle Park, NC: Research Triangle Institute. 
TABLE SE2. Percentage of Drivers Age 16+ in Age, Gender, and Regional Groups who Drove Within Two Hours of Substance Use by Substance Used, STANDARD ERRORS, 1996

Drove within Two Hours of Substance Use

\begin{tabular}{|c|c|c|c|}
\hline $\begin{array}{l}\text { Demographic } \\
\text { Characteristic }\end{array}$ & $\begin{array}{c}\text { After } \\
\text { Alcohol Use }\end{array}$ & $\begin{array}{c}\text { After } \\
\text { Marijuana Use }\end{array}$ & $\begin{array}{c}\text { After Other } \\
\text { Drug Use }^{1}\end{array}$ \\
\hline TOTAL & 0.92 & 0.22 & 0.21 \\
\hline \multicolumn{4}{|l|}{ AGE } \\
\hline 16-20 Yrs & 1.42 & 1.03 & 0.48 \\
\hline 21-34 Yrs & 1.34 & 0.36 & 0.31 \\
\hline $35+$ Yrs & 1.13 & 0.27 & 0.29 \\
\hline \multicolumn{4}{|l|}{ GENDER } \\
\hline Male & 1.46 & 0.37 & 0.32 \\
\hline Female & 0.76 & 0.18 & 0.28 \\
\hline \multicolumn{4}{|l|}{ REGION } \\
\hline Northeast & 1.73 & 0.47 & 0.37 \\
\hline North Central & 2.46 & 0.51 & 0.25 \\
\hline South & 1.46 & 0.36 & 0.44 \\
\hline West & 1.95 & 0.60 & 0.51 \\
\hline
\end{tabular}

Note: This table is restricted to people who drove a car or other motor vehicle in the past year.

1 Includes cocaine, and the medical and non-medical use of tranquilizers, stimulants, and sedatives.

Office of Applied Studies, SAMHSA, National Household Survey on Drug Abuse, 1996. 
TABLE SE3a. Percentage of Drivers 16+ within Age, Gender, Racial/Ethnic, and Regional Groups Age who Drove within Two Hours of Substance Use in the Past Year by Substance Used, STANDARD ERRORS, 1996

\begin{tabular}{|c|c|c|c|}
\hline \multirow[b]{2}{*}{$\begin{array}{l}\text { Demographic } \\
\text { Characteristic }\end{array}$} & \multirow[b]{2}{*}{$\underset{\text { Driver }^{1}}{\text { Non-Impaired }}$} & \multicolumn{2}{|c|}{ Drove within Two Hours of Substance Use } \\
\hline & & After Alcohol Use Only & $\begin{array}{l}\text { After Drug Use } \\
\text { (With or Without Alcohol) }\end{array}$ \\
\hline TOTAL & 0.97 & 0.94 & 0.28 \\
\hline \multicolumn{4}{|l|}{ AGE } \\
\hline 16-18 Yrs & 1.38 & 1.03 & 1.05 \\
\hline 19-20 Yrs & 2.71 & 2.10 & 1.89 \\
\hline 21-25 Yrs & 2.11 & 1.96 & 0.80 \\
\hline 26-34 Yrs & 1.27 & 1.09 & 0.46 \\
\hline 35-49 Yrs & 1.54 & 1.32 & 0.73 \\
\hline $50+$ Yrs & 1.85 & 1.79 & 0.44 \\
\hline \multicolumn{4}{|l|}{ GENDER } \\
\hline Male & 1.52 & 1.48 & 0.47 \\
\hline Female & 0.81 & 0.77 & 0.32 \\
\hline \multicolumn{4}{|l|}{ RACE/ETHNICITY } \\
\hline White (Non-Hispanic) & 1.19 & 1.18 & 0.34 \\
\hline Black (Non-Hispanic) & 1.14 & 0.96 & 0.53 \\
\hline Hispanic & 1.19 & 1.10 & 0.44 \\
\hline Other & 2.78 & 2.22 & 1.57 \\
\hline \multicolumn{4}{|l|}{ REGION } \\
\hline Northeast & 1.91 & 1.90 & 0.51 \\
\hline North Central & 2.42 & 2.29 & 0.54 \\
\hline South & 1.53 & 1.53 & 0.57 \\
\hline West & 2.17 & 1.78 & 0.66 \\
\hline
\end{tabular}

Note: This table is restricted to people who drove a car or other motor vehicle in the past year.

1 "Non-impaired" drivers are those respondents who drove a motor vehicle in the 12 months prior to the NHSDA interview, but reported that they did not drive within two hours after using drugs and/or alcohol during that same period.

2 Includes marijuana, cocaine, and the medical and non-medical use of tranquilizers, stimulants, and sedatives.

Office of Applied Studies, SAMHSA, National Household Survey on Drug Abuse, 1996. 
TABLE SE3b. Percentage of Drivers Age 16+ within Marital, Educational, Employment, ana rersumaı Income Groups who Drove within Two Hours of Substance Use in the Past Year by Substance Used, STANDARD ERRORS, 1996

\begin{tabular}{|c|c|c|c|}
\hline \multirow[b]{2}{*}{$\begin{array}{l}\text { Demographic } \\
\text { Characteristic }\end{array}$} & \multirow[b]{2}{*}{$\begin{array}{l}\text { Non-Impaired } \\
\text { Driver }^{1}\end{array}$} & \multicolumn{2}{|c|}{ Drove within Two Hours of Substance Use } \\
\hline & & $\begin{array}{l}\text { After Alcohol Use Only } \\
\text { (No Drugs) }\end{array}$ & $\begin{array}{c}\text { After Drug Use }{ }^{2} \\
\text { (With or Without Alcohol) }\end{array}$ \\
\hline TOTAL & 0.97 & 0.94 & 0.28 \\
\hline \multicolumn{4}{|l|}{ MARITAL STATUS } \\
\hline Married & 1.15 & 1.17 & 0.35 \\
\hline Div./Sep./Wid. & 1.95 & 1.72 & 0.78 \\
\hline Never Married & 1.31 & 1.22 & 0.67 \\
\hline \multicolumn{4}{|l|}{ EDUCATION } \\
\hline$<$ High School & 1.82 & 1.37 & 1.01 \\
\hline High School Grad & 1.35 & 1.16 & 0.57 \\
\hline Some College & 1.73 & 1.67 & 0.59 \\
\hline College Grad & 1.87 & 1.87 & 0.54 \\
\hline \multicolumn{4}{|c|}{ EMPLOYMENT STATUS } \\
\hline Full-Time & 1.23 & 1.18 & 0.38 \\
\hline Part-Time & 1.77 & 1.66 & 0.97 \\
\hline Unemployed & 3.22 & 3.31 & 1.72 \\
\hline Not in Work Force ${ }^{3}$ & 1.93 & 1.82 & 0.44 \\
\hline \multicolumn{4}{|l|}{ PERSONAL INCOME } \\
\hline$<\$ 10,000$ & 1.12 & 0.92 & 0.61 \\
\hline$\$ 10,000$ - \$19,999 & 1.46 & 1.35 & 0.51 \\
\hline$\$ 20,000-\$ 39,999$ & 1.56 & 1.54 & 0.58 \\
\hline$\$ 40,000$ - $\$ 49,999$ & 3.17 & 2.85 & 1.25 \\
\hline$\$ 50,000$ - $\$ 74,999$ & 3.55 & 3.45 & 0.70 \\
\hline$\$ 75,000+$ & 5.26 & 5.29 & 2.09 \\
\hline
\end{tabular}

Note: This table is restricted to people who drove a car or other motor vehicle in the past year.

1 "Non-impaired" drivers are those respondents who drove a motor vehicle in the 12 months prior to the NHSDA interview, but reported that they did not drive within two hours after using drugs and/or alcohol during that same period.

2 Includes marijuana, cocaine, and the medical and non-medical use of tranquilizers, stimulants, and sedatives.

3 Includes full-time homemakers, non-working students, the retired, and the disabled.

Office of Applied Studies, SAMHSA, National Household Survey on Drug Abuse, 1996. 
TABLE SE4. Percentage of Drivers Age 16+ within Age by Gender, Racial/Ethnic by Age, and Racial/Ethnic by Gender Groups who Drove within Two Hours of Substance Use in the Past Year by Substance Used, STANDARD ERRORS, 1996

\begin{tabular}{|c|c|c|c|}
\hline \multirow[b]{2}{*}{$\begin{array}{l}\text { Demographic } \\
\text { Characteristic }\end{array}$} & \multirow[b]{2}{*}{$\begin{array}{c}\text { Non-Impaired } \\
\text { Driver }^{1}\end{array}$} & \multicolumn{2}{|c|}{ Drove within Two Hours of Substance Use } \\
\hline & & $\begin{array}{l}\text { After Alcohol Use Only } \\
\text { (No Drugs) }\end{array}$ & $\begin{array}{c}\text { After Drug Use } \\
\text { (With or Without Alcohol) }\end{array}$ \\
\hline TOTAL & 0.97 & 0.94 & 0.28 \\
\hline \multicolumn{4}{|l|}{ AGE BY GENDER } \\
\hline \multicolumn{4}{|l|}{ 16-20 Years } \\
\hline Male & 2.15 & 1.68 & 1.44 \\
\hline Female & 1.82 & 1.22 & 1.33 \\
\hline \multicolumn{4}{|l|}{$21+$ Years } \\
\hline Male & 1.64 & 1.63 & 0.51 \\
\hline Female & 0.83 & 0.79 & 0.34 \\
\hline \multicolumn{4}{|c|}{$\begin{array}{l}\text { RACE/ETHNICITY BY AGE } \\
\text { White (Non-Hispanic) }\end{array}$} \\
\hline 16-20 Years & 2.00 & 1.45 & 1.31 \\
\hline $21+$ Years & 1.23 & 1.24 & 0.35 \\
\hline \multicolumn{4}{|c|}{ Black (Non-Hispanic) } \\
\hline 16-20 Years & 2.15 & 1.58 & 1.86 \\
\hline $21+$ Years & 1.23 & 1.05 & 0.55 \\
\hline \multicolumn{4}{|l|}{ Hispanic } \\
\hline 16-20 Years & 2.11 & 1.60 & 1.49 \\
\hline $21+$ Years & 1.38 & 1.27 & 0.49 \\
\hline \multicolumn{4}{|c|}{$\begin{array}{l}\text { RACE/ETHNICITY BY GENDER } \\
\text { White (Non-Hispanic) }\end{array}$} \\
\hline Male & 1.87 & 1.85 & 0.57 \\
\hline Female & 0.98 & 0.94 & 0.39 \\
\hline \multicolumn{4}{|c|}{ Black (Non-Hispanic) } \\
\hline Male & 1.88 & 1.72 & 0.80 \\
\hline Female & 1.21 & 0.88 & 0.74 \\
\hline \multicolumn{4}{|l|}{ Hispanic } \\
\hline Male & 1.60 & 1.44 & 0.69 \\
\hline Female & 1.27 & 1.24 & 0.74 \\
\hline
\end{tabular}

Note: This table is restricted to people who drove a car or other motor vehicle in the past year.

"Non-impaired" drivers are those respondents who drove a motor vehicle in the 12 months prior to the NHSDA interview, but reported that they did not drive within two hours after using drugs and/or alcohol during that same period.

2 Includes marijuana, cocaine, and the medical and non-medical use of tranquilizers, stimulants, and sedatives.

Office of Applied Studies, SAMHSA, National Household Survey on Drug Abuse, 1996. 
TABLE SE5. Percentage of Drivers Age 16+ Arrested and Not Arrested and on Probation and Not on Probation in the Past Year who Drove within Two Hours of Substance Use in the Past Year by Substance Used, STANDARD ERRORS, 1996

\begin{tabular}{|c|c|c|c|}
\hline \multirow[b]{2}{*}{ During the Past Year } & \multirow[b]{2}{*}{$\begin{array}{l}\text { Non-Impaired } \\
\text { Driver }^{1}\end{array}$} & \multicolumn{2}{|c|}{ Drove within Two Hours of Substance Use } \\
\hline & & $\begin{array}{l}\text { After Alcohol Use Only } \\
\text { (No Drugs) }\end{array}$ & $\begin{array}{c}\text { After Drug Use } \\
\text { (With or Without Alcohol) }\end{array}$ \\
\hline TOTAL & 0.97 & 0.95 & 0.29 \\
\hline \multicolumn{4}{|c|}{ ARRESTED (FOR ANY REASON) } \\
\hline Yes & 2.67 & 2.37 & 1.62 \\
\hline No & 1.01 & 0.98 & 0.28 \\
\hline \multicolumn{4}{|c|}{ ON PROBATION (FOR ANY REASON) } \\
\hline Yes & 5.36 & 3.32 & 4.09 \\
\hline No & 1.00 & 0.97 & 0.27 \\
\hline
\end{tabular}


TABLE SE6a. Age, Gender, Racial/Ethnic, and Regional Distribution of Drivers Age $16+$ who Drove within Two Hours of Substance Use in the Past Year by Substance Used, 1996

\begin{tabular}{|c|c|c|c|}
\hline \multirow[b]{2}{*}{$\begin{array}{l}\text { Demographic } \\
\text { Characteristic }\end{array}$} & \multirow[b]{2}{*}{$\begin{array}{c}\text { Non-Impaired } \\
\text { Driver }^{1}\end{array}$} & \multicolumn{2}{|c|}{ Drove within Two Hours of Substance Use } \\
\hline & & $\begin{array}{l}\text { After Alcohol Use Only } \\
\text { (No Drugs) }\end{array}$ & $\begin{array}{c}\text { After Drug Use } \\
\text { (With or Without Alcohol) }\end{array}$ \\
\hline TOTAL & 0.97 & 0.94 & 0.28 \\
\hline AGE & & & \\
\hline 16-18 Yrs & 0.22 & 0.26 & 1.01 \\
\hline 19-20 Yrs & 0.18 & 0.32 & 1.29 \\
\hline 21-25 Yrs & 0.44 & 0.73 & 1.38 \\
\hline 26-34 Yrs & 0.58 & 1.14 & 1.89 \\
\hline 35-49 Yrs & 1.06 & 1.66 & 3.24 \\
\hline 50+ Yrs & 1.46 & 2.18 & 2.59 \\
\hline \multicolumn{4}{|l|}{ GENDER } \\
\hline Male & 1.22 & 1.22 & 2.56 \\
\hline Female & 1.22 & 1.22 & 2.56 \\
\hline \multicolumn{4}{|l|}{ RACE/ETHNICITY } \\
\hline White (Non-Hispanic) & 1.20 & 0.85 & 1.99 \\
\hline Black (Non-Hispanic) & 0.76 & 0.55 & 0.98 \\
\hline Hispanic & 0.46 & 0.49 & 0.73 \\
\hline Other & 0.69 & 0.36 & 1.21 \\
\hline \multicolumn{4}{|l|}{ REGION } \\
\hline Northeast & 1.51 & 1.94 & 2.40 \\
\hline North Central & 1.82 & 2.67 & 3.12 \\
\hline South & 1.50 & 2.37 & 3.14 \\
\hline West & 1.49 & 1.67 & 2.88 \\
\hline
\end{tabular}

Note: This table is restricted to people who drove a car or other motor vehicle in the past year.

1 "Non-impaired" drivers are those respondents who drove a motor vehicle in the 12 months prior to the NHSDA interview, but reported that they did not drive within two hours after using drugs and/or alcohol during that same period.

2 Includes marijuana, cocaine, and the medical and non-medical use of tranquilizers, stimulants, and sedatives.

Office of Applied Studies, SAMHSA, National Household Survey on Drug Abuse, 1996. 
TABLE SE6b. Marital, Educational, Employment, and Personal Income Distribution of Drivers Age 16+ who Drove within Two Hours of Substance Use in the Past Year by Substance Used, STANDARD ERRORS, 1996

\begin{tabular}{lccc}
\hline & & \multicolumn{2}{c}{ Drove within Two Hours of Substance Use } \\
\cline { 3 - 4 } $\begin{array}{l}\text { Demographic } \\
\text { Characteristic }\end{array}$ & $\begin{array}{c}\text { Non-Impaired } \\
\text { Driver }^{1}\end{array}$ & $\begin{array}{c}\text { After Alcohol Use Only } \\
\text { (No Drugs) }\end{array}$ & $\begin{array}{c}\text { After Drug Use } \\
\text { (With or Without Alcohol) }\end{array}$ \\
\hline TOTAL & $\mathbf{0 . 9 7}$ & $\mathbf{0 . 9 4}$ & $\mathbf{0 . 2 8}$ \\
\hline MARITAL STATUS & & & \\
Married & 1.00 & 1.64 & 3.26 \\
Div./Sep./Wid. & 0.62 & 1.25 & 2.20 \\
Never Married & 0.75 & 1.18 & 2.98 \\
\hline EDUCATION & & & 2.78 \\
<High School & 1.14 & 0.90 & 3.09 \\
High School Grad & 1.30 & 1.65 & 2.18 \\
Some College & 1.04 & 1.57 & 2.70 \\
College Grad & 1.23 & 2.02 & \\
\hline EMPLOYMENT & & & 2.65 \\
STATUS & & & 2.17 \\
Full-Time & 1.28 & 2.17 & 1.14 \\
Part-Time Only & 0.70 & 1.06 & 2.11 \\
Unemployed & 0.29 & 0.59 & \\
Not in Work Force & 1.18 & 2.00 & \\
\hline PNT & & & \\
\hline
\end{tabular}

PERSONAL

INCOME

$\begin{array}{llll}\mathbf{\$} \mathbf{1 0 , 0 0 0} & 1.17 & 0.96 & 2.82 \\ \mathbf{\$ 1 0 , 0 0 0}-\mathbf{\$ 1 9 , 9 9 9} & 0.87 & 1.35 & 2.06 \\ \mathbf{\$ 2 0 , 0 0 0}-\mathbf{\$ 3 9 , 9 9 9} & 1.07 & 1.82 & 2.79 \\ \mathbf{\$ 4 0 , 0 0 0}-\mathbf{\$ 4 9 , 9 9 9} & 0.42 & 0.91 & 1.61 \\ \mathbf{\$ 5 0 , 0 0 0}-\mathbf{\$ 7 4 , 9 9 9} & 0.53 & 1.20 & 0.92 \\ \mathbf{\$ 7 5 , 0 0 0 +} & 0.35 & 1.52 & 1.46\end{array}$

Note: This table is restricted to people who drove a car or other motor vehicle in the past year.

1 "Non-impaired" drivers are those respondents who drove a motor vehicle in the 12 months prior to the NHSDA interview, but reported that they did not drive within two hours after using drugs and/or alcohol during that same period.

2 Includes marijuana, cocaine, and the medical and non-medical use of tranquilizers, stimulants, and sedatives.

3 Includes full-time homemakers, non-working students, the retired, and the disabled.

Office of Applied Studies, SAMHSA, National Household Survey on Drug Abuse, 1996. 
TABLE SE7. Age by Gender, Racial/Ethnic by Age, and Racial/Ethnic by Gender Distribution of Drivers Age 16+ who Drove within Two Hours of Substance Use in the Past Year by Substance Used, STANDARD ERRORS, 1996

\begin{tabular}{|c|c|c|c|}
\hline \multirow[b]{2}{*}{$\begin{array}{l}\text { Demographic } \\
\text { Characteristic }\end{array}$} & \multirow[b]{2}{*}{$\begin{array}{c}\text { Non-Impaired } \\
\text { Driver }^{1}\end{array}$} & \multicolumn{2}{|c|}{ Drove within Two Hours of Substance Use } \\
\hline & & $\begin{array}{l}\text { After Alcohol Use Only } \\
\text { (No Drugs) }\end{array}$ & $\begin{array}{c}\text { After Drug Use }{ }^{2} \\
\text { (With or Without Alcohol) }\end{array}$ \\
\hline TOTAL & 0.97 & 0.94 & 0.28 \\
\hline \multicolumn{4}{|l|}{$\begin{array}{l}\text { AGE BY GENDER } \\
\text { 16-20 Years }\end{array}$} \\
\hline Male & 1.52 & 4.56 & 3.85 \\
\hline Female & 1.52 & 4.56 & 3.85 \\
\hline \multicolumn{4}{|l|}{$21+$ Years } \\
\hline Male & 1.35 & 1.24 & 3.22 \\
\hline Female & 1.35 & 1.24 & 3.22 \\
\hline \multicolumn{4}{|c|}{ RACE /ETHNICITY BY AGE } \\
\hline 16-20 Years & 0.40 & 0.48 & 1.98 \\
\hline $21+$ Years & 0.40 & 0.48 & 1.98 \\
\hline \multicolumn{4}{|c|}{ Black (Non-Hispanic) } \\
\hline 16-20 Years & 0.66 & 1.27 & 4.07 \\
\hline $21+$ Years & 0.66 & 1.27 & 4.07 \\
\hline \multicolumn{4}{|l|}{ Hispanic } \\
\hline 16-20 Years & 0.75 & 1.36 & 4.57 \\
\hline $21+$ Years & 0.75 & 1.36 & 4.57 \\
\hline \multicolumn{4}{|c|}{ RACE/ETHINICITY BY GENDER } \\
\hline \multicolumn{4}{|c|}{ White (Non-Hispanic) } \\
\hline Male & 1.47 & 1.31 & 2.89 \\
\hline Female & 1.47 & 1.31 & 2.89 \\
\hline \multicolumn{4}{|c|}{ Black (Non-Hispanic) } \\
\hline Male & 1.97 & 2.73 & 5.48 \\
\hline Female & 1.97 & 2.73 & 5.48 \\
\hline \multicolumn{4}{|l|}{ Hispanic } \\
\hline Male & 1.73 & 2.52 & 6.59 \\
\hline Female & 1.73 & 2.52 & 6.59 \\
\hline
\end{tabular}

Note: This table is restricted to people who drove a car or other motor vehicle in the past year.

"Non-impaired" drivers are those respondents who drove a motor vehicle in the 12 months prior to the NHSDA interview, but reported that they did not drive within two hours after using drugs and/or alcohol during that same period.

2 . Includes marijuana, cocaine, and the medical and non-medical use of tranquilizers, stimulants, and sedatives.

Office of Applied Studies, SAMHSA, National Household Survey on Drug Abuse, 1996. 
TABLE SE8. Past-Year Arrest and Probation Status Distribution of Drivers Age 16+ Arrested who Drove within Two Hours of Substance Use in the Past Year by Substance Used, STANDARD ERRORS, 1996

\begin{tabular}{|c|c|c|c|}
\hline \multirow[b]{2}{*}{ During the Past Year } & \multicolumn{3}{|c|}{ Drove within Two Hours of Substance Use } \\
\hline & $\begin{array}{c}\text { Non-Impaired } \\
\text { Driver }^{1}\end{array}$ & $\begin{array}{l}\text { After Alcohol Use Only } \\
\text { (No Drugs) }\end{array}$ & $\begin{array}{c}\text { After Drug Use } \\
\text { (With or Without Alcohol) }\end{array}$ \\
\hline TOTAL & 0.97 & 0.95 & 0.29 \\
\hline \multicolumn{4}{|c|}{ ARRESTED (FOR ANY REASON) } \\
\hline Yes & 0.58 & 1.11 & 2.86 \\
\hline No & 0.58 & 1.11 & 2.86 \\
\hline \multicolumn{4}{|c|}{ ON PROBATION (FOR ANY REASON) } \\
\hline Yes & 0.22 & 0.22 & 1.30 \\
\hline No & 0.22 & 0.22 & 1.30 \\
\hline
\end{tabular}


TABLE SE9. Distribution of Size of Road Driven, Area Driven, Day of Week Driven, and Time of Day Driving Began on Most Recent Occasion of Driving within Two Hours of Marijuana Use for Drivers Age 16+ who Drove Following Marijuana Use in the Past Year by Age Group, STANDARD ERRORS, 1996

\begin{tabular}{llll}
\hline Driving Patterns & TOTAL & 16-20 Years & 21+ Years \\
\hline SIZE OF ROAD & & & \\
Interstate/Highway/Freeway & 2.85 & 3.77 & 3.43 \\
Only on Smaller Roads & 2.85 & 3.77 & 3.43 \\
\hline AREA & 2.96 & 3.36 & 3.44 \\
Rural (open country) & 2.99 & 4.25 & 3.48 \\
Urban (city or town) & 2.30 & 2.57 & 3.14 \\
Suburban (town just outside of a large city) & & & \\
\hline DAY OF WEEK & 3.01 & 4.28 & 3.70 \\
Weekday & 3.01 & 4.28 & 3.70 \\
Weekend & & & \\
\hline TIME OF DAY BEGAN & 2.20 & 4.22 & 2.15 \\
12:00 a.m. to 5:59 a.m. & 1.44 & 2.33 & 1.66 \\
6:00 a.m. to 11:59 a.m. & 3.16 & 3.09 & 3.83 \\
12:00 p.m. to 5:59 p.m. & 2.92 & 3.64 & 3.78 \\
6:00 p.m. to 11:59 p.m. & & & \\
\hline
\end{tabular}

Note: This table is restricted to people who drove a car or other motor vehicle in the past year.

1 Monday, Tuesday, Wednesday, or Thursday.

2 Friday, Saturday, or Sunday.

Office of Applied Studies, SAMHSA, National Household Survey on Drug Abuse, 1996. 
TABLE SE10. Distribution of Starting Point and Destination on Most Recent Occasion of Driving within Two Hours of Marijuana Use for Drivers Age 16+ who Drove Following Marijuana Use in the Past Year by Age Group, STANDARD ERRORS, 1996

\begin{tabular}{lccc}
\hline Starting Point and Destination & TOTAL & 16-20 Years & 21+ Years \\
\hline STARTING POINT & & & \\
Home & 3.61 & 3.68 & 4.40 \\
Friend/Relative's Home & 3.74 & 4.70 & 4.44 \\
Public Location' & 2.36 & 3.31 & 3.22 \\
\hline DESTINATION & & & \\
Home & 3.01 & 5.28 & 3.66 \\
Friend/Relative's Home & 1.87 & 3.35 & 2.16 \\
Public Location' & 3.19 & 4.45 & 3.95 \\
\hline
\end{tabular}

Note: This table is restricted to people who drove a car or other motor vehicle in the past year.

1 Includes bar or nightclub, restaurant, sporting event, concert, workplace, no place in particular, or unspecified.

Office of Applied Studies, SAMHSA, National Household Survey on Drug Abuse, 1996. 
TABLE SE11. Percentage of Drivers Age 16+ who Drove within Two Hours of Marijuana Use in the Past Year Reporting Reasons for Driving on Most Recent Occasion of Driving Following Marijuana Use by Age Group, STANDARD ERRORS, 1996

\begin{tabular}{lcc}
\hline Reported Reason for Driving & 16-20 Years & 21+ Years \\
\hline No other way to get there & 3.42 & 4.08 \\
Not high enough to cause a crash & 5.52 & 4.47 \\
Police not likely to catch me & 3.65 & 4.42 \\
No one else available to drive & 4.50 & 4.41 \\
Had an appointment or curfew & 3.99 & 3.08 \\
Other reason & 3.76 & 4.17 \\
\hline
\end{tabular}

Note: This table restricted to people who drove a car or other motor vehicle in the past year. Responses do not sum to $100 \%$ because respondents could mark more than one answer.

Office of Applied Studies, SAMHSA, National Household Survey on Drug Abuse, 1996. 
TABLE SE12. Distribution of Perceived Extent to which Marijuana Affected Ability to Drive Safely on Most Recent Occasion of Driving within Two Hours of Marijuana Use for Drivers Age 16+ who Drove Following Marijuana Use in the Past Year by Age Group, STANDARD ERRORS, 1996

\begin{tabular}{lcc}
\hline & \multicolumn{2}{c}{$\begin{array}{c}\text { Amount Marijuana Affected Ability } \\
\text { to Drive Safely }\end{array}$} \\
\cline { 2 - 3 } & A Lot/A Little & Not at All \\
\hline TOTAL & $\mathbf{2 . 5 9}$ & $\mathbf{2 . 5 9}$ \\
16-20 Years & 5.37 & 5.37 \\
21+ Years & 3.46 & 3.46 \\
\hline
\end{tabular}

Note: This table is restricted to people who drove a car or other motor vehicle in the past year.

Office of Applied Studies, SAMHSA, National Household Survey on Drug Abuse, 1996.

TABLE SE13. Distribution of Perceived Likelihood of Being Stopped by the Police when Driving Following Marijuana Use Compared to when Driving on Other Occasions for Drivers Age 16+ who Drove within Two Hours of Marijuana Use in the Past Year by Age Group, STANDARD ERRORS, 1996

\begin{tabular}{lcc}
\hline & \multicolumn{2}{c}{$\begin{array}{c}\text { How Likely Stopped by Police } \\
\text { If Use Marijuana and Drive }\end{array}$} \\
\cline { 2 - 3 } & $\begin{array}{c}\text { A Lot/A Little More } \\
\text { Likely }\end{array}$ & No More Likely \\
\hline TOTAL & $\mathbf{2 . 6 8}$ & $\mathbf{2 . 6 8}$ \\
16-20 Years & 4.93 & 4.93 \\
21+ Years & 3.11 & 3.11 \\
\hline
\end{tabular}

Note: This table is restricted to people who drove a car or other motor vehicle in the past year.

Office of Applied Studies, SAMHSA, National Household Survey on Drug Abuse, 1996. 
TABLE SE14. Distribution of Number of Days in Past Month Drove within Two Hours of Alcohol or Marijuana Use, for All Ages and within Age Groups, for Drivers Age 16+ who Drove Following Alcohol Use Only or Marijuana Use in the Past Year by Substance Type, STANDARD ERRORS, 1996

\begin{tabular}{lcc}
\hline Number of Days & Alcohol & Marijuana \\
\hline TOTAL & 1.57 & \\
None & 1.66 & 3.43 \\
1-5 Days & 0.70 & 3.56 \\
6+ Days & & 2.22 \\
\hline 16-20 YEARS & 4.46 & \\
None & 4.30 & 3.68 \\
1-5 Days & 2.57 & 4.82 \\
6+ Days & & 3.79 \\
\hline 21+ YEARS & & \\
None & 1.62 & 4.10 \\
1-5 Days & 1.72 & 4.35 \\
6+ Days & 0.73 & 2.90 \\
\hline
\end{tabular}

Note: This table is restricted to people who drove a car or other motor vehicle in the past year.

Office of Applied Studies, SAMHSA, National Household Survey on Drug Abuse, 1996. 
TABLE SE15. Distribution of Level of Past-Month Alcohol Use or Past-Year Marijuana Use for Drivers Age 16+ who Drove within Two Hours of Alcohol Use Only or Marijuana Use in the Past Year by Age Group, STANDARD ERRORS, 1996

\begin{tabular}{|c|c|c|c|c|}
\hline & \multicolumn{2}{|c|}{ ALCOHOL } & \multicolumn{2}{|c|}{ MARIJUANA ${ }^{2}$} \\
\hline & $\begin{array}{c}\text { Heavy } \\
\text { Use }\end{array}$ & $\begin{array}{l}\text { Medium/Low } \\
\text { Use }\end{array}$ & $\begin{array}{l}\text { Heavy } \\
\text { Use }\end{array}$ & $\begin{array}{c}\text { Medium/Low } \\
\text { Use }\end{array}$ \\
\hline TOTAL & 0.96 & 0.96 & 3.16 & 3.16 \\
\hline 16-20 Years & 4.34 & 4.34 & 4.39 & 4.39 \\
\hline 21+ Years & 0.99 & 0.99 & 3.91 & 3.91 \\
\hline $\begin{array}{l}\text { Note: This table is } \\
1 \text { Heavy = Had at } \\
\text { one, but no more } \\
\text { but no more than } \\
2 \text { Heavy = Used w }\end{array}$ & $\begin{array}{l}\text { ar or othe } \\
\text { sions in } \\
30 \text { days } \\
\text { the past } \\
\text { t not wee }\end{array}$ & $\begin{array}{l}\text { r vehicle in the pa } \\
\text { t } 30 \text { days; Mediun } \\
\text { inge drinking); Lo } \\
\text { s. } \\
\text { ow = Used in past }\end{array}$ & $\begin{array}{l}\text { r. } \\
\text { ad at least } \\
\text { Jsed alcoh } \\
\text { but not we }\end{array}$ & $\begin{array}{l}\text { lrinks on at least } \\
\text { tt had at least one, } \\
\text { or monthly. }\end{array}$ \\
\hline
\end{tabular}


TABLE SE16. Distribution of Whether or Not Other Substances Were Also Used on Most Recent Occasion of Driving within Two Hours of Marijuana Use for Drivers Age 16+ who Drove Following Marijuana Use in the Past Year by Age Group, STANDARD ERRORS, 1996

\begin{tabular}{lccc} 
& & & \multicolumn{2}{c}{ With Other } \\
\hline TOTAL & Alone & With Alcohol & Drug \\
16-20 Years & $\mathbf{2 . 8 0}$ & $\mathbf{2 . 8 3}$ & $\mathbf{0 . 8 8}$ \\
21+ Years & 3.98 & 3.73 & 1.63 \\
\hline
\end{tabular}

Note: This table is restricted to people who drove a car or other motor vehicle in the past year.

Office of Applied Studies, SAMHSA, National Household Survey on Drug Abuse, 1996.

TABLE SE17. Percentage of Drivers Age 16+ who Drove within Two Hours of Using Marijuana and Another Substance in the Past Year by Age Group, STANDARD ERRORS, 1996

\begin{tabular}{lccc}
\hline Drove after Using Marijuana and... & 16-20 Years & 21+ Years \\
\hline Alcohol & 3.93 & 2.91 \\
Any Other Drug & 3.87 & 3.02 \\
\hline
\end{tabular}

Note: This table is restricted to people who drove a car or other motor vehicle in the past year. Responses do not sum to $100 \%$ because respondents can fall into more than one category.

1 Includes cocaine, heroin, hallucinogens, inhalants, and the medical and non-medical use of tranquilizers, analgesics, stimulants, and sedatives.

Office of Applied Studies, SAMHSA, National Household Survey on Drug Abuse, 1996. 
TABLE SE18. Distribution of Number of Drinks Consumed, Number of Hours between First and Last Drink, and Time between Last Drink and when Driving Began on Most Recent Occasion of Driving within Two Hours of Alcohol Use for Drivers Age 16+ who Drove Following Alcohol Use in the Past Year by Age Group, STANDARD ERRORS, 1996

\begin{tabular}{lccc}
\hline & TOTAL & 16-20 Years & 21+ Years \\
\hline NUMBER OF DRINKS & & & \\
1-2 Drinks & 1.69 & 4.27 & 1.74 \\
3-4 Drinks & 1.74 & 3.58 & 1.84 \\
5+ Drinks & 1.18 & 3.93 & 1.21 \\
\hline HOURS BETWEEN FIRST AND LAST DRINK & & & \\
4+ Hours & 1.36 & 3.95 & 1.42 \\
2-4 Hours & 1.77 & 3.45 & 1.92 \\
1-2 Hours & 1.80 & 3.04 & 1.92 \\
< Hour & 1.41 & 4.24 & 1.49 \\
Only Had 1 Drink & 1.42 & 1.28 & 1.49 \\
\hline TIME BETWEEN LAST DRINK AND WHEN & & & \\
DRIVING BEGAN & & & 1.88 \\
1-2 Hours & 1.75 & 3.80 & 1.88 \\
\hline < Hour & 1.75 & 3.80 & \\
\hline
\end{tabular}

Note: This table is restricted to people who drove a car or other motor vehicle in the past year.

Office of Applied Studies, SAMHSA, National Household Survey on Drug Abuse, 1996. 
TABLE SE19. Distribution of Estimated Blood Alcohol Concentration (BAC) Levels ${ }^{1}$ on Most Recent Occasion of Driving within Two Hours of Alcohol Use for Drivers Age 16+ who Drove Following Alcohol Use in the Past Year by Age within Gender, STANDARD ERRORS, 1996

\begin{tabular}{lccccccc} 
& & \multicolumn{3}{c}{ Males } & \multicolumn{3}{c}{ Females } \\
\cline { 3 - 8 } \multicolumn{1}{c}{$\begin{array}{c}\text { BAC } \\
\text { Level }\end{array}$} & TOTAL & Total & $\begin{array}{c}\mathbf{1 6 - 2 0} \\
\text { Years }\end{array}$ & $\begin{array}{c}\mathbf{2 1 +} \\
\text { Years }\end{array}$ & Total & $\begin{array}{c}\mathbf{1 6 - 2 0} \\
\text { Years }\end{array}$ & $\begin{array}{c}\text { 21+ } \\
\text { Years }\end{array}$ \\
\hline$<.02$ & 1.74 & 2.22 & 4.62 & 2.28 & 2.84 & 6.55 & 3.06 \\
$\mathbf{0 2 - . 0 7 9}$ & 1.73 & 1.97 & 5.74 & 2.04 & 3.17 & 7.28 & 3.35 \\
$\mathbf{0 8 +}$ & 0.67 & 0.80 & 4.91 & 0.76 & 1.28 & 7.74 & 1.27 \\
\hline Nonyyyyyyy
\end{tabular}

Note: This table is restricted to people who drove a car or other motor vehicle in the past year.

1 See Appendix D for method used to estimate BAC levels. BAC levels are reported in grams per deciliter.

Office of Applied Studies, SAMHSA, National Household Survey on Drug Abuse, 1996. 
TABLE SE20. Average Estimated Blood Alcohol Concentration (BAC) Level ${ }^{1}$ on Most Recent Occasion of Driving within Two Hours of Alcohol Use for Drivers Age 16+ who Drove Following Alcohol Use in the Past Year by Gender and Age, STANDARD ERRORS, 1996

\begin{tabular}{lccc}
\hline & & \multicolumn{2}{c}{ Gender } \\
\cline { 3 - 4 } Age & TOTAL & Males & Females \\
\hline TOTAL & 0.001 & 0.002 & 0.002 \\
\hline 16-20 YRS & 0.011 & 0.013 & 0.023 \\
21-25 YRS & 0.003 & 0.004 & 0.005 \\
26-34 YRS & 0.002 & 0.002 & 0.004 \\
35-49 YRS & 0.002 & 0.002 & 0.004 \\
50+ YRS & 0.002 & 0.002 & 0.005 \\
\hline
\end{tabular}

Note: This table is restricted to people who drove a car or other motor vehicle in the past year.

1 See Appendix D for method used to estimate BAC levels. BAC levels are reported in grams per deciliter.

Office of Applied Studies, SAMHSA, National Household Survey on Drug Abuse, 1996. 


\section{APPENDIX C: NHSDA METHODOLOGY AND LIMITATIONS OF THE DATA}

\section{Sample Design}

The sample design of the NHSDA has changed over time, but it has always been representative of the U.S. general population age 12 and older and has always oversampled youths and young adults. The 1996 NHSDA employed a multistage area probability sample of 18,269 persons interviewed January-December 1996. Response rates for household screening and for interviewing were 93 percent and 79 percent, respectively. Blacks, Hispanics, and young people were oversampled to improve the accuracy of estimates for those populations.

The first stage of sampling in the NHSDA is the selection of 115 primary sampling units (PSUs), each consisting of counties (i.e., administrative subdivisions of States) or groups of counties (e.g., metropolitan areas). Within these PSUs, segments (e.g., city blocks or enumeration districts) are selected. In each of the segments, a listing of all dwellings is made. From the eligible sample units, which can be either households or units within group quarters, sample persons are randomly selected, with unequal probabilities, using a screening procedure carried out by interviewers. Oversampling of certain subpopulations is accomplished, by assigning the appropriate selection probabilities at the PSU, segment, and person levels. In 1996, these subpopulations were young people (i.e., age 12-34), blacks, and Hispanics.

In 1996, the NHSDA sampled segments were allocated equally into four separate samples, one for each 3-month period during the year, so that the survey was essentially continuously in the field. A more complete description of the 1996 NHSDA sample design can be found in the 1996 National Household Survey on Drug Abuse Methodological Resource Book (Office of Applied Studies, SAMHSA, 1997).

\section{Selection of Primary Sampling Units (PSUs)}

The 1996 NHSDA used the same 115 PSUs that were selected for the 1995 NHSDA. These 115 PSUs were selected to represent the Nation's total eligible population, including areas of high Hispanic concentration. The PSUs were metropolitan areas, counties, groups of counties, and independent cities. The 115 PSUs comprised 43 certainty PSUs and 72 noncertainty PSUs. The 43 certainty PSUs were metropolitan areas with high Hispanic concentration that have been included in the NHSDA with certainty since 1988. The 72 noncertainty PSUs were selected with probabilities proportional to size and minimal replacement to represent the balance of the Nation outside the 43 certainty PSUs.

The noncertainty PSUs were selected with probabilities proportional to a composite size measure. The composite size measure was defined as the sum of racial/ethnic group dwelling counts weighted by the specified racial/ethnic sampling rates. This selection scheme allowed for 
targeting particular racial/ethnic subpopulation sample sizes. The use of a composite size measure ensured: (1) roughly equal sample sizes per sample subarea (the second stage unit of selection) and (2) roughly equal probabilities of selecting eligible individuals (the fifth or finalstage unit of selection) within race/ethnicity, and age group.

\section{Selection of the Second-Stage Sample: Subareas within PSUs}

About 96 percent of the subareas (i.e., area segments) selected in the 1996 NHSDA, or 1,860 out of 1,940 total selected segments, were previously used in the 1995 NHSDA. The remaining four percent were new subareas that had to be selected in 1996 because there were insufficient unused listing units in some 1995 subareas to provide the required number of sample listing units per subarea.

Both the 1995 NHSDA sample subareas and the new subareas selected in 1996 were drawn from the 1990 Census files. Within each sample PSU, subareas were defined by combining adjacent blocks to create non-overlapping area segments that contained at least 90 occupied dwellings. The area segments from each stratum of each of the PSUs were selected with probabilities proportional to a composite size measure. For each stratum, a composite size measure equaled a weighted average of the numbers of Hispanic, non-Hispanic black, and nonHispanic non-black dwelling units with weights proportional to the desired racial/ethnic sampling rates.

\section{Selection of the Third-Stage Sample: Listing Units within Subareas}

Projections indicated that screenings had to be completed for approximately 50,000 dwelling units in order to identify sufficient dwelling units to yield Hispanic, non-Hispanic black, and age domain samples of the desired size. Assuming an average 93 percent screening completion rate and a projected average 85 percent listing unit eligibility rate, approximately 63,000 listings had to be selected. A listing unit was ineligible for the study if it was: (a) vacant; (b) a vacation, second, or temporary home; (c) not a dwelling unit; (d) a military facility whose occupants were only military personnel; or (e) an institutional housing facility. A sample of 67,049 dwelling units was selected; of these, 56,912 were to determined to be eligible sample units.

Dwelling unit listings were selected using systematic sampling. The sampled listings were then sent to the field for screening. After first determining that a sampled listing was eligible for the study, the interviewer completed a dwelling roster that listed all residents age 12 and older with their age and race/ethnicity. This roster formed the basis for the within-dwelling sampling of individuals.

\section{Within-Dwelling Unit Sampling}

The 1996 NHSDA used a within-dwelling unit sample selection approach in which each dwelling was classified according to the race/ethnicity of the head of the dwelling. The 
interviewers also determined the age domains represented by individuals residing in each dwelling in terms of the presence or absence of individuals age 12-17, 18-25, 26-34, 35-49, and 50 and older.

\section{Data Collection Methodology}

NHSDA data are collected through in-person interviews with sample persons, incorporating procedures to maximize respondents' cooperation and willingness to report honestly about their illicit drug use behavior. Introductory letters are sent to sampled addresses, followed by an interviewer visit. A five-minute screening procedure involves listing all household members along with their basic demographic data and possible selection of sample person(s). This selection process is designed to provide the necessary sample sizes for specified population groups by selecting up to two persons per household, depending on the composition of the household.

Interviewers attempt to conduct the survey in a private place, away from other household members. The administration of the interview averages about an hour in length, and includes a combination of interviewer-administered and self-administered questions. In the latter, the answers to sensitive questions, such as those dealing with illicit drug use, are recorded by the respondent and not seen or reviewed by the interviewer. After the self-administered answer sheets are completed, they are placed by the respondent in an envelope, which is sealed and mailed to the contractor with no personal identifying information attached.

\section{Data Processing}

Upon receipt, questionnaires are checked for critical identification and demographic data, then keyed to disk. This creates a file consisting of one record for each completed interview. Extensive within-record consistency checks and resolution of most inconsistencies and missing data are done using machine editing routines, called logical imputation. For some key variables that still have missing values after the application of logical imputation, statistical imputation is used to replace the missing data with appropriate valid response codes.

Two types of statistical imputation procedures are used. Hot-deck imputation involves the replacement of a missing value with a valid code taken from another respondent who is "similar" and has complete data. Logistic regression models are also used to determine replacement values for some variables.

\section{Weighting Procedures}

The population estimates in this report are based on sample survey data rather than on complete data for the population. Therefore, the data were weighted to obtain unbiased estimates of drug use in the population represented by the 1996 NHSDA. The basic sampling weights for the 1996 NHSDA are equal to the inverse of the probabilities of selection of sample respondents. 
In other words, the smaller a respondent's chance of entering the sample, the larger the weight of that respondent in the calculation of unbiased estimates for the target population.

The probability of selection of a respondent can be computed as the product of four stagewise sampling probabilities. The probability of selecting a respondent equals the product of the following: (1) the probability of selecting the respondent's PSU, (2) the probability of selecting the respondent's subarea given selection of his/her PSU, (3) the probability of selecting the respondent's dwelling unit given selection of his/her subarea, and 4) the probability of selecting the respondent given selection of his/her dwelling unit.

To obtain the final NHSDA weights, the basic sampling weights were adjusted to account for dwelling unit-level and individual-level nonresponse and subsampling of individuals within dwelling units, and further adjusted to ensure consistency with intercensal population projections obtained from the U.S. Census Bureau. The adjustments that were made to the basic sampling weights are as follows:

Adjustment 1. Adjustment for dwelling unit nonresponse. The first type of nonresponse encountered in the survey was failure to complete the screening interview for sampled dwellings. Sample weights were adjusted for this type of nonresponse using a logistic regression model. This procedure used logistic regression to model the expected value of a zero-one response indicator, given a set of predictor variables available for both respondents and nonrespondents. The algorithm used to fit the logistic regression response propensity model is a generalization of raking or iterative proportional fitting (Bishop, Fienberg, \& Holland, 1975, pp.83-102). In 1996, the potential predictor variables included: quarter of the year when interviews in the dwelling unit were conducted, sample stratum, region, population density of the sample segment (e.g., segment located in a metropolitan area with 1 million or more persons), and other variables based on 1990 Census block and enumeration district characteristics, including percent Hispanic, percent black, percent owner-occupied households, median housing value, and median rent. After obtaining the final models, the adjustment factor was calculated as the inverse of the estimated response propensity.

Adjustment 2. Dwelling unit roster adjustment. This adjustment was based on a logistic regression model using the same predictor variables used in Adjustment 1 together with age, race/ethnicity, and sex.

Adjustment 3. Adjustment for individual nonresponse (incomplete interviews). This adjustment was based on a logistic regression model using the same predictor variables as Adjustment 2.

Adjustment 4. Post-stratification to ensure consistency with U.S. Census Bureau projections. This adjustment was designed to ensure consistency between the sums of weights within specified demographic subgroups and U.S. Census Bureau projections of the sizes of the subgroups. The post-stratification totals were obtained from the National 
Estimates and Projections Branch of the U.S. Census Bureau and were classified by age, sex, race, and Hispanic origin.

\section{Limitations of the Data}

\section{$\underline{\text { Target Population }}$}

An important limitation of the NHSDA estimates of drug use prevalence is that they are only designed to describe the target population of the survey (i.e., the civilian noninstitutionalized population). Although this includes more than 98 percent of the total U.S. population, it does exclude some important and unique subpopulations who may have very different substance use patterns. For example, the survey excludes active military personnel, who have been shown to have significantly lower rates of illicit drug use. The survey also excludes persons living in institutional group quarters, such as prisons and residential drug treatment centers, who have been shown to have higher rates of illicit drug use. Homeless persons who are not living in a shelter at the time of the survey, another population shown to have higher than average rates of illicit drug use, are also excluded.

\section{Sampling Error and Statistical Significance}

The sampling error of an estimate is the error caused by the selection of a sample instead of conducting a census of the population. Sampling error is reduced by selecting a large sample and by using efficient sample design and estimation strategies such as stratification, optimal allocation, and ratio estimation.

With the use of probability sampling methods in the NHSDA, it is possible to develop estimates of sampling error from the survey data. These estimates, which are presented in Appendix B, have been calculated for all prevalence estimates presented in this report using a software package called SUDAAN that implements a Taylor series linearization approach to take into account the effects of the complex NHSDA design features (Shah, Barnwell, Hunt, \& LaVange, 1994). The sampling errors are used to identify unreliable estimates and to test for the statistical significance of differences between estimates.

Estimates considered to be unreliable due to unacceptably large sampling error are noted by asterisks $\left({ }^{*}\right)$ in the tables in Appendix A. The criterion used for suppressing estimates was based on the relative standard error (RSE), which is defined as the ratio of the standard error over the estimate. The log transformation of the proportion estimate (p) was used to calculate the RSE. Specifically, rates and corresponding estimated number of users were suppressed if:

$$
\begin{array}{ll} 
& \operatorname{RSE}[-\ln (\mathrm{p})]>0.175 \quad \text { when } \mathrm{p}<.5 \\
\text { or } \quad \operatorname{RSE}[-\ln (1-\mathrm{p})]>0.175 \quad \text { when } \mathrm{p} \geq .5 .
\end{array}
$$


Estimates were also suppressed if they rounded to zero or 100 percent. All results described in this report were tested and found to be significant at least at the .05 level, unless otherwise indicated.

When making comparisons of estimates for different population subgroups from the same data year, the covariance term, which is usually small and positive, has typically been ignored. This results in somewhat conservative tests of hypotheses that will sometimes fail to establish statistical significance when in fact it exists.

\section{Nonsampling Error}

Nonsampling errors occur from nonresponse, coding errors, computer processing errors, errors in the sampling frame, reporting errors, and other errors. Nonsampling errors in the NHSDA are reduced through data editing, statistical adjustments for nonresponse, and close monitoring and periodic retraining of interviewers. Although nonsampling errors can often be much larger than sampling errors, measurement of most nonsampling errors is difficult or impossible. However, some indication of the effects of some types of nonsampling errors can be obtained through proxy measures such as response rates and from other research studies.

In the 1996 NHSDA, of the 56,912 eligible households sampled, 52,770 were successfully screened for a screening response rate of 92.7 percent. In these screened households, a total of 23,240 sample persons were selected, and completed interviews were obtained from 18,269 of these sample persons, for an interview response rate of 78.6 percent. Nearly ten percent, or 2,300 of the sample persons were classified as refusals, $1,795(7.7 \%)$ were not available or never at home, and $876(3.8 \%)$ did not participate for various other reasons, such as physical or mental incompetence or language barrier. The response rate was highest among those age $12-17(82 \%)$. Response rates were also higher among Hispanics $(81 \%)$ than among blacks (79\%) and whites (77\%).

Among survey participants, item response rates were above 98 percent for most questionnaire items. However, inconsistent responses for some items, including the drug use items, were common. Estimates of drug use from the NHSDA are based on the responses to multiple questions by respondents, so that the maximum amount of information is used in determining whether a respondent is classified as a drug user. Inconsistencies in responses are resolved through a logical editing process that involves some judgement on the part of survey analysts and is a potential source of nonsampling error. For example, a respondent might report his/her most recent use of a drug as more than a month ago, but in a later question report having used in the past month. This inconsistency could occur because the interviewer may have developed greater rapport with the respondent in the latter stages of the interview, leading to more openness on the part of the respondent. In this example, the respondent would be considered a past-month user. In 1996, 23 percent of the estimate of past-month marijuana use and 40 percent of the past-month cocaine use estimate is based on such cases. 
NHSDA estimates are based on self-reports of drug use, and their value depends on respondents' truthfulness and memory. Although many studies have generally established the validity of self-report data and the NHSDA procedures are designed to encourage honesty and recall, some degree of underreporting is assumed. No adjustment to NHSDA data is made to correct for this. The methodology used in the NHSDA has been shown to produce more valid results than other self-report methods, such as telephone interviews (Turner, Lessler, \& Gfroerer, 1992; Aquilino, 1994). However, comparisons of NHSDA data with data from surveys conducted in classrooms suggest that underreporting of drug use by youth in their homes may be substantial (Gfroerer, Wright, \& Kopstein, 1997).

\section{References}

Aquilino, W.S. (1994). Interview mode effects in surveys of drug and alcohol use: A field experiment. Public Opinion Quarterly, 58, 210-240.

Bishop, Y.M.M., Fienberg, S.E., \& Holland, P.W. (1975). Discrete multivariate analysis: Theory and practice. Cambridge, MA: The MIT Press.

Gfroerer, J., Wright, D., \& Kopstein, A. (1997). Prevalence of youth substance use: The impact of methodological differences between two national surveys. Drug and Alcohol Dependence, 47, 19-30.

Office of Applied Studies, SAMHSA. (1997). 1996 National Household Survey on Drug Abuse methodological resource book. Rockville, MD: SAMHSA.

Shah, B.V., Barnwell, B.G., Hunt, P.N., \& LaVange, L.M. (1994). SUDAAN user's manual: Release 6.4, Research Triangle Park, NC: Research Triangle Institute.

Turner, C. F., Lessler, J.T. \& Gfroerer, J. C. (1992). Survey measurement of drug use: Methodological studies. Rockville, MD: National Institute on Drug Abuse. 


\section{APPENDIX D: ESTIMATION OF BLOOD ALCOHOL CONCENTRATION (BAC) LEVELS}

The analysis of driving behaviors following alcohol use described in Chapter 2 of this report incorporates estimates of blood alcohol concentration (BAC) levels. Estimated BAC levels were calculated using the method described by the National Highway and Traffic Safety Administration (NHTSA) in "Computing a Blood Alcohol Estimate." BAC levels were estimated for each respondent's most recent experience of driving within two hours of alcohol use. The method used to estimate BAC levels is as follows:

1. Calculate the water content of the individual. Each respondent's weight was converted from pounds to kilograms. This weight in kilograms was then multiplied by a conversion factor (.58 for males, .49 for females) to estimate each individual's water content in liters. This number was multiplied by 1,000 to get each individual's estimated water content in milliliters.

2. Calculate the alcohol concentration in $\mathrm{g} / \mathrm{ml}$ of body water. The number of alcoholic drinks each respondent reportedly consumed before driving was multiplied by 23.36 grams (i.e., weight of one ounce of alcohol). This amount was then multiplied by .6 oz., the average of the amount of ethanol found in a $12 \mathrm{oz}$. beer, a $5 \mathrm{oz}$. wine, and $1.5 \mathrm{oz}$. of spirits (.54 oz., $.65 \mathrm{oz} ., .62 \mathrm{oz}$. , respectively). This product, which is an estimate of the total number of grams of alcohol consumed, was divided by the milliliters of body water for each individual.

3. Calculate the alcohol concentration in the blood. The measure of grams of alcohol per milliliter of water obtained in the previous step was multiplied by a conversion factor of $.806(.806 \mathrm{ml}$ of water $/ \mathrm{ml}$ blood $)$. This product was then multiplied by 100 to obtain a measure in grams per deciliter units.

4. Classify individuals by metabolism rate. If a respondent indicated that he/she had consumed 60 or more alcoholic drinks in the past month, he/she was classified as having a high alcohol metabolic rate and was assigned a rate of decline in BAC level of .02 per hour. Individuals who consumed two or fewer drinks in the past month were classified as having a low alcohol metabolic rate. About one-fifth of current drinkers age 16 and older (21 percent) fell into this category and were assigned a rate of decline in BAC level of .012 per hour. Individuals who did not fall within either of these two extremes were categorized as moderate drinkers with an average alcohol metabolic rate, and a corresponding .017 per hour decline in BAC level. 
5. Adjust estimated BAC levels for rate of metabolism. The rate of decline in BAC level determined by each individual's alcohol metabolic rate was multiplied by the amount of time from consumption of the first alcoholic drink to when driving began. This product was then subtracted from the BAC level estimated in step \#3 to produce a BAC level adjusted for metabolic rate. 
APPENDIX E: 1996 NHSDA

DRIVING BEHAVIORS MODULE 
DB-1. Have you driven a car or other motor vehicle during the past 12 months?

YES, I have driven during the past

12 months $\ldots \ldots \square_{1} \longrightarrow$ DB-2. On how many days in the past 12 months have you driven a car or other motor vehicle?

No, I have not driven during the past

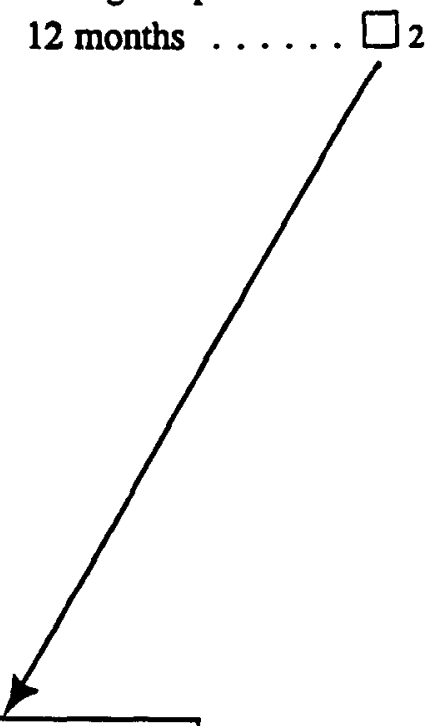

More than 300 days (which is every day or almost every day) ........... $\square_{1}$

201 to 300 days ( 5 to 6 days a week) . . . $\square_{2}$

101 to 200 days ( 3 to 4 days a week) ... $\square_{3}$

51 to 100 days ( 1 to 2 days a week) .... $\square_{4}$

25 to 50 days ( 3 to 4 days a month) .... $\square 5$

12 to 24 days ( 1 to 2 days a month) .... $\square 6$

6 to 11 days (less than 1 day a month) $\ldots \square 7$

3 to 5 days ............ $\square_{8}$

1 to 2 days .............

GO TO BOX A

AT BOTTOM OF

PAGE 17 
DB-3. During the past 12 months, have you driven a car or other motor vehicle within 2 hours after drinking an alcoholic beverage?

YES, during the past 12 months, I have driven a car or other motor vehicle within 2 hours after drinking an alcoholic beverage ..... $\square_{1}$

NO, during the past 12 months, I have not driven a car or other motor vehicle within 2 hours after drinking an alcoholic beverage

GO TO QUESTION. DB-9 AT TOP OF PAGE 4

DB-4. On how many days in the past 12 months have you driven a car or other motor vehicle within 2 hours after drinking an alcoholic beverage? Your best estimate is fine.

More than 300 days (which is every day or almost every day) $\ldots \ldots \ldots \square$,

201 to 300 days $(5$ to 6 days a week) $\ldots \ldots \ldots \ldots \ldots$

101 to 200 days $(3$ to 4 days a week) $\ldots \ldots \ldots \ldots \ldots \ldots$

51 to 100 days $(1$ to 2 days a week) $\ldots \ldots \ldots \ldots \ldots$

25 to 50 days $(3$ to 4 days a month) $\ldots \ldots \ldots \ldots \ldots$ s

12 to 24 days ( 1 to 2 days a month) $\ldots \ldots \ldots \ldots \ldots$

6 to 11 days (less than 1 day a month) $\ldots \ldots \ldots \ldots \ldots$

3 to 5 days $\ldots \ldots \ldots \ldots \ldots \ldots \ldots \ldots \ldots \ldots \ldots$

1 to 2 days $\ldots \ldots \ldots \ldots \ldots \ldots \ldots \ldots \ldots \ldots \ldots \ldots$

DB-5. During the past 30 days, on how many days have you driven a car or other motor vehicle within 2 hours after drinking an alcoholic beverage? Your best estimate is fine.

Number of days during the past 30 days I drove a car or other motor vehicle within 2 hours after drinking an alcoholic beverage

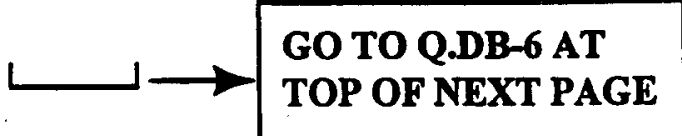

I have not driven a car or other motor vehicle within 2 hours after drinking an alcoholic beverage during the past 30 days GO TO Q.DB-9 AT TOP OF PAGE 4 
DB-6. Think about the most recent time you drove a car or other motor vehicle within 2 hours after drinking an alcoholic beverage. On this most recent occasion, how many drinks did you have? Count as a drink a can or bottle of beer; a wine cooler or a glass of wine, champagne, or sherry; a shot of liquor or a mixed drink or cocktail. Your best estimate is fine.

On this most recent occasion, I had drink(s)

DB-7. On this most recent occasion when you drove a car or other motor vehicle within 2 hours after drinking an alcoholic beverage, how much time passed from when you started your first drink until you finished your last drink? Your best estimate is fine. PLEASE MARK ONLY ONE BOX FOR THE BEST ANSWER.

More than 8 hours $\ldots \ldots \ldots \ldots \ldots \ldots \ldots \ldots$

At least 6 hours but not more than 8 hours . . . . . . . $\square_{2}$

At least 4 hours but not more than 6 hours $\ldots \ldots \ldots \ldots \ldots$

At least 2 hours but not more than 4 hours $\ldots \ldots \ldots \ldots \ldots$

At least 1 hour but not more than 2 hours $\ldots \ldots \ldots \ldots$ s

At least 30 minutes but not more than 1 hour $\ldots \ldots \ldots \ldots$. . . . 6

Less than 30 minutes $\ldots \ldots \ldots \ldots \ldots \ldots \ldots \ldots \ldots \ldots$

I only had one drink on this most recent occasion $\ldots \ldots \ldots \ldots \ldots$

DB-8. Again, think about the most recent time when you drove a car or other motor vehicle within 2 hours after drinking an alcoholic beverage. On this most recent occasion, how much time passed from when you drank your last drink until you began driving? Your best estimate is fine. PLEASE MARK ONLY ONE BOX FOR THE BEST ANSWER.

2 hours $\ldots \ldots \ldots \ldots \ldots \ldots \ldots \ldots \ldots \ldots \ldots$

At least 1 hour but not more than 2 hours $\ldots \ldots \ldots \ldots \ldots \square_{2}$

At least 30 minutes but not more than 1 hour $\ldots \ldots \ldots \ldots \ldots$

At least 15 minutes but not more than 30 minutes $\ldots \ldots \ldots \ldots \ldots \square_{4}$

At least 5 minutes but not more than 15 minutes $\ldots \ldots \ldots \ldots \ldots$ s

Less than 5 minutes $\ldots \ldots \ldots \ldots \ldots \ldots \ldots$

(PLEASE TURN TO THE NEXT PAGE) 
DB-9. Have you used any marijuana or hashish during the past 12 months?

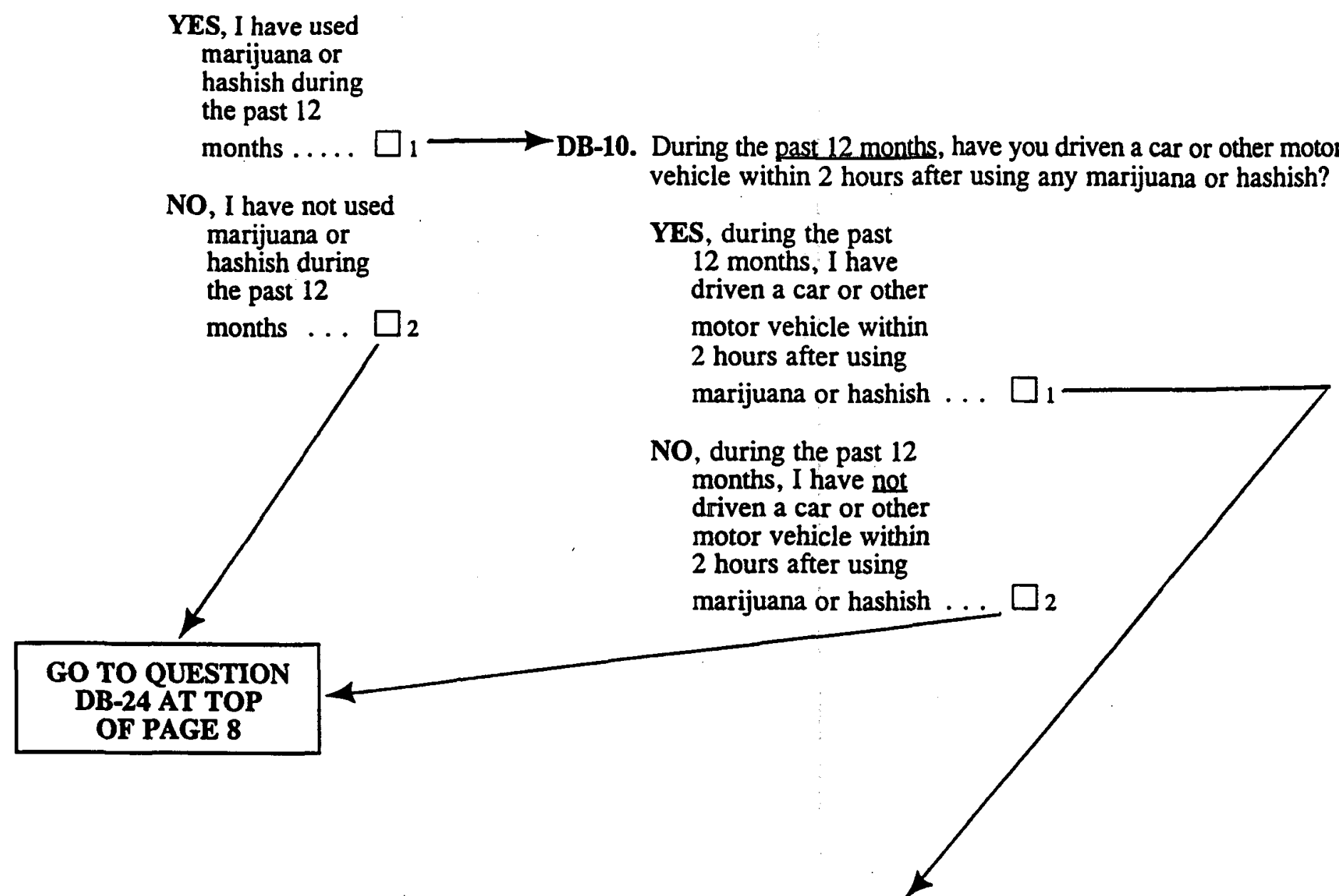

DB-11. Think about those occasions in the past 12 months when you drove a car or other motor vehicle within 2 hours after using any marijuana or hashish. As you read the following list of drugs, please mark one box beside each drug to indicate how often you used that drug along with the marijuana or hashish.

\section{How often used with marijuana or hashish? NEVER RARELY SOMETIMES OFTEN}
a. Alcohol $\ldots \ldots \ldots \ldots \ldots \ldots \square_{1} \ldots \ldots \square_{2} \ldots \ldots \ldots \square_{3} \ldots \ldots \ldots \square_{4}$
b. Cocaine $\ldots \ldots \ldots \ldots \ldots \square_{1} \ldots \ldots \square_{2} \ldots \ldots \ldots \square_{3} \ldots \ldots \ldots \square_{4}$
c. Heroin $\ldots \ldots \ldots \ldots \ldots \ldots \square_{1} \ldots \ldots \square_{2} \ldots \ldots \ldots \square_{3} \ldots \ldots \ldots \square_{4}$
d. Hallucinogens $\ldots \ldots \ldots \ldots \square_{1} \ldots \ldots \square_{2} \ldots \ldots \ldots \square_{3} \ldots \ldots \ldots \square_{4}$
e. Inhalants $\ldots \ldots \ldots \ldots \ldots \square_{1} \ldots \ldots \square_{2} \ldots \ldots \square_{3} \ldots \ldots \ldots \square_{4}$
f. Analgesics ......... $\square_{1} \ldots \ldots \square_{2} \ldots \ldots \ldots \square_{3} \ldots \ldots \ldots \square 4$
g. Tranquilizers $\ldots \ldots \ldots \ldots \square_{1} \ldots \ldots \square_{2} \ldots \ldots \ldots \square_{3} \ldots \ldots \square_{4}$
h. Stimulants $\ldots \ldots \ldots \ldots \ldots \square_{1} \ldots \ldots \square_{2} \ldots \ldots \square_{3} \ldots \ldots \ldots \square_{4}$
i. Sedatives $\ldots \ldots \ldots \ldots \ldots \square_{1} \ldots \ldots \square_{2} \ldots \ldots \ldots \square_{3} \ldots \ldots \ldots \square_{4}$
j. I used some other drug(s) $\ldots \ldots \square_{1} \ldots \ldots \square_{2} \ldots \ldots \square_{3} \ldots \ldots$ PLEASE LIST BELOW THE OTHER DRUG(S):

(PLEASE GO TO THE NEXT PAGE) 
DB-12. During the past 30 days, on how many days have you driven a car or other motor vehicle within 2 hours after using any marijuana or hashish?

Number of days during the past 30 days I drove a car or other motor vehicle within 2 hours after using marijuana or hashish

I have not driven a car or other motor vehicle within 2 hours after using marijuana or hashish during the past 30 days ......... $\square 93$

DB-13. Think about the most recent time you drove a car or other motor vehicle within 2 hours after using any marijuana or hashish. On this most recent occasion, did you use only marijuana or hashish, marijuana or hashish with alcohol, or marijuana or hashish with one or more other drugs? PLEASE MARK ONLY ONE BOX FOR THE BEST ANSWER.

I used only marijuana or hashish $\ldots \ldots \ldots \ldots \ldots \ldots \ldots \ldots$

I used marijuana or hashish with alcohol $\ldots \ldots \ldots \ldots \ldots \ldots$

I used marijuana or hashish with one or more other drugs . . . . . $\square_{3}$ PLEASE LIST BELOW THE OTHER DRUG(S):

DB-14. Again thinking about the most recent occasion you drove a car or other motor vehicle within 2 hours after using any marijuana or hashish, where were you driving from? PLEASE MARK ONLY ONE BOX FOR THE BEST ANSWER.

My home $\ldots \ldots \ldots \ldots \ldots \ldots \ldots \ldots \ldots \ldots \ldots \ldots \ldots \ldots$

A friend or relative's home $\ldots \ldots \ldots \ldots \ldots \ldots \ldots$

A bar or nightclub $\ldots \ldots \ldots \ldots \ldots \ldots \ldots \ldots \ldots$

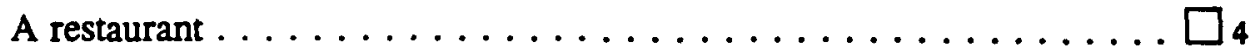

A sporting event $\ldots \ldots \ldots \ldots \ldots \ldots \ldots \ldots$

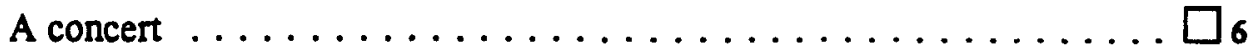

My workplace $\ldots \ldots \ldots \ldots \ldots \ldots \ldots \ldots \ldots$

Somewhere else .................. $\square_{8}$

PLEASE DESCRIBE BELOW THIS OTHER PLACE:

DB-15. On this most recent occasion, when you drove a car or other motor vehicle within 2 hours after using any marijuana or hashish, where was the first place you drove to? PLEASE MARK ONLY ONE BOX FOR THE BEST ANSWER.

My home $\ldots \ldots \ldots \ldots \ldots \ldots \ldots \ldots \ldots \square_{1}$

A friend or relative's home $\ldots \ldots \ldots \ldots \ldots \ldots \ldots$

A bar or nightclub ................... $\square_{3}$

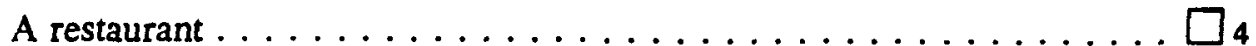

A sporting event $\ldots \ldots \ldots \ldots \ldots \ldots \ldots \ldots \ldots$

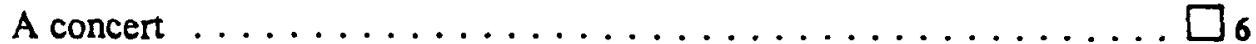

My workplace . ...........................

No place in particular (I was just driving around) $\ldots \ldots \ldots \ldots \ldots$

Somewhere else .....................

PLEASE DESCRIBE BELOW THIS OTHER PLACE:

(PLEASE TURN TO THE NEXT PAGE) 
DB-16. Again, think about the most recent occasion when you drove within 2 hours after using any marijuana or hashish. Did you drive on an interstate, highway, or freeway, or only on smaller roads? PLEASE MARK ONLY ONE BOX FOR THE BEST ANSWER.

I drove on an interstate, highway, or freeway ............ $\square_{1}$

I drove only on smaller roads $\ldots \ldots \ldots \ldots \ldots \ldots \square_{2}$

DB-17. On this most recent occasion when you drove a car or other motor vehicle within 2 hours after using any marijuana or hashish, were you driving primarily in a rural, urban or suburban area? PLEASE MARK ONLY ONE BOX FOR THE BEST ANSWER.

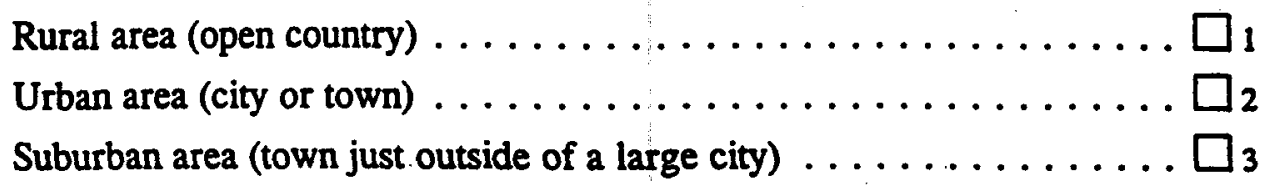

DB-18. On this most recent occasion when you drove a car or other motor vehicle within 2 hours after using any marijuana or hashish, on which day of the week were you driving?

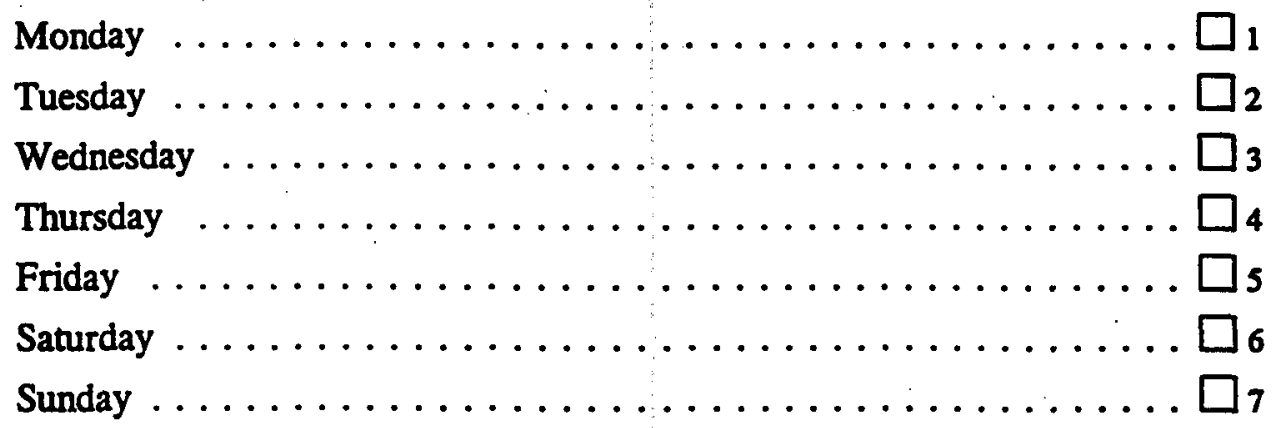

DB-19. On this most recent occasion when you drove a car or other motor vehicle within 2 hours after using any marijuana or hashish, what time of day did you begin driving? PLEASE MARK ONLY ONE BOX FOR THE BEST ANSWER.

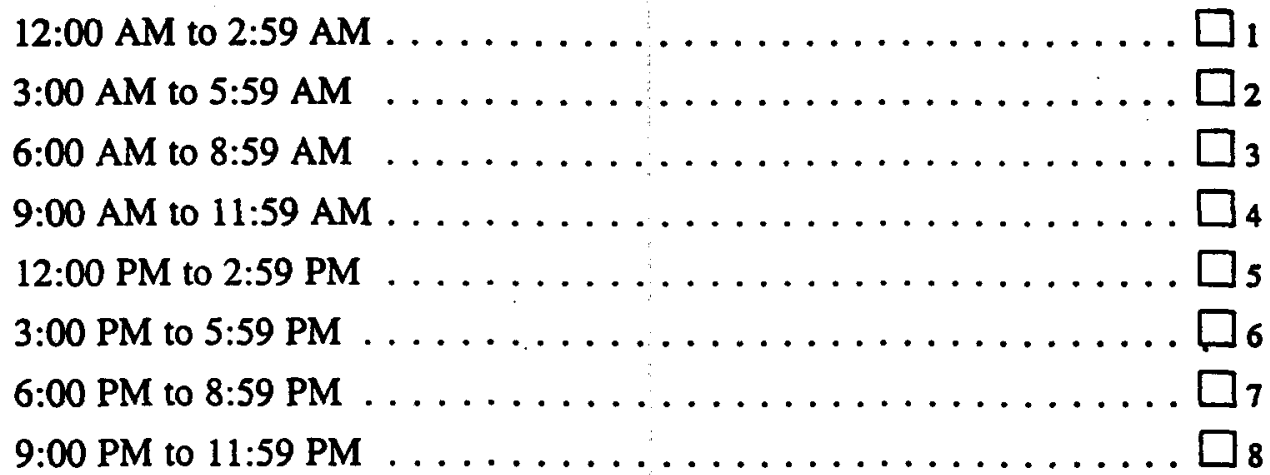

(PLEASE GO TO THE NEXT PAGE) 
DB-20. On this most recent occasion when you drove a car or other motor vehicle within 2 hours after using any marijuana or hashish, how much do you think your use of marijuana or hashish reduced your ability to drive safely?

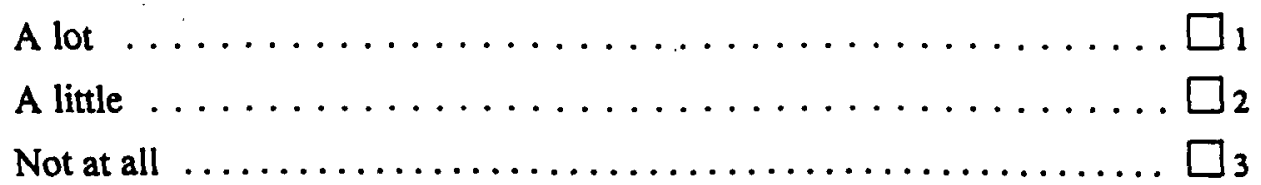

DB-21. Some people drive after using marijuana or hashish because they have an appointment to keep, they have no one else to drive them, or for some other reason. As you read the following list of reasons, please mark one box beside each reason to indicate whether it is a reason why you drove within 2 hours after using any marijuana or hashish on this most recent occasion.

Reason why you drove? YES NO
a. There was no other way to get to where I was going $\square_{1} \quad \ldots . \quad \square_{2}$
b. I wasn't high enough to cause a crash ........ $\square_{1} \ldots \ldots \square_{2}$
c. The police would not be likely to catch me .... $\square_{1} \ldots \square_{2}$
d. No one else was available to drive my motor vehicle $\square_{1} \quad \ldots . \square_{2}$
e. I had an appointment or curfew ......... $\square_{1} \ldots \square_{2}$
f. I drove for some other reason(s) $\ldots \ldots \ldots \ldots \ldots \square_{1} \ldots \ldots \square_{2}$
PLEASE SPECIFY REASON(S) BELOW:

DB-22. In general, when you drive within 2 hours after using any marijuana or hashish, how much more likely do you think it is that you will be stopped by the police than when you drive without using marijuana or hashish?

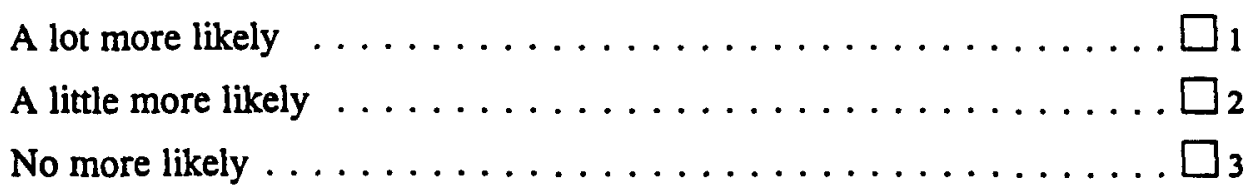

DB-23. In general, how much do you feel using any marijuana or hashish reduces your ability to drive safely?

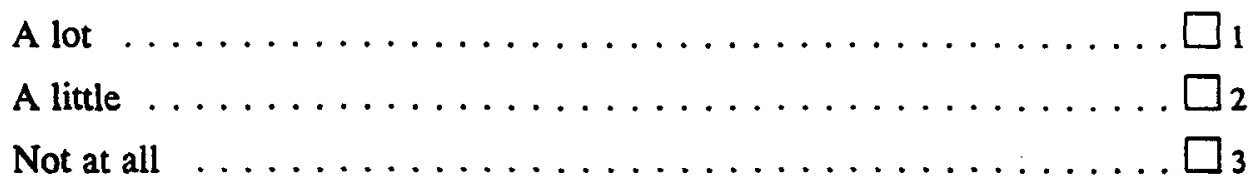

(PLEASE TURN TO THE NEXT PAGE) 
DB-24. Have you used any cocaine during the past 12 months?

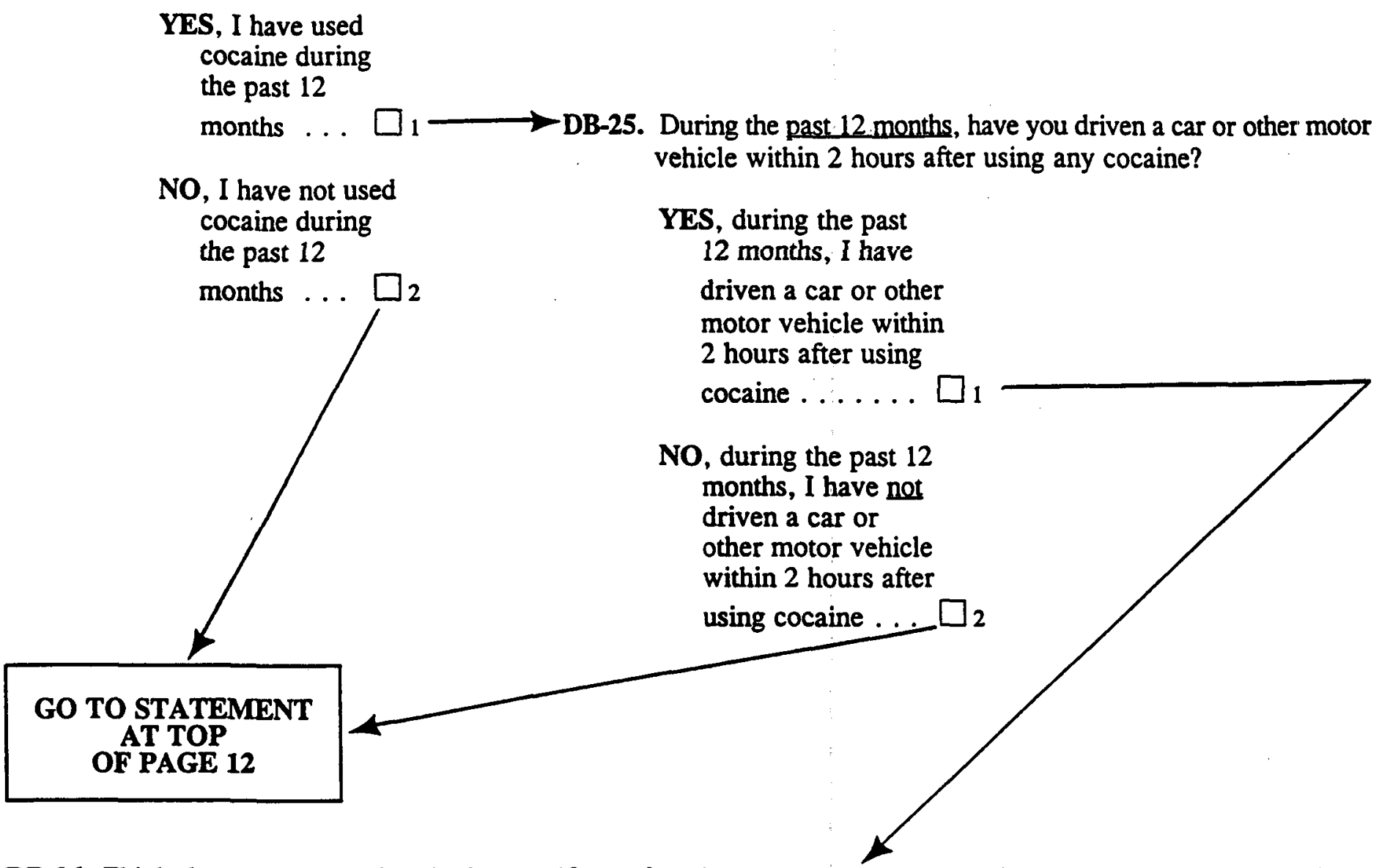

DB-26. Think about those occasions in the past 12 months when you drove a car or other motor vehicle within 2 hours after using any cocaine. As you read the following list of drugs, please mark one box beside each drug to indicate how often you used that drug along with the cocaine.

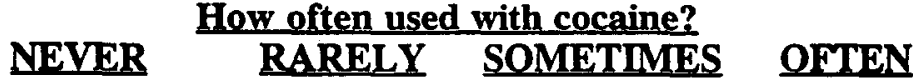
a. Alcohol
$\square_{1} \ldots \ldots \ldots$
.......... $\square_{3}$
........ $\square_{4}$
b. Marijuana or hashish
$\square_{1} \ldots \ldots . \square_{2}$
c. Heroin $\square_{2} \ldots \ldots \ldots \square_{3} \ldots \ldots \ldots \square_{4}$
d. Hallucinogens $\ldots \ldots \ldots \ldots, \square 1 \ldots \ldots \square_{2} \ldots \ldots \ldots \square_{3} \ldots \ldots \ldots \square_{4}$
e. Inhalants ........... $\square \mathrm{i} \ldots \ldots \square_{2} \ldots \ldots \ldots \square_{3} \ldots \ldots \square_{4}$
f. Analgesics .......... $\square_{1} \ldots \ldots \square_{2} \ldots \ldots \ldots \square_{3} \ldots \ldots \ldots \square_{4}$
g. Tranquilizers $\ldots \ldots \ldots \ldots \ldots \square \square_{1} \ldots \ldots \square_{2} \ldots \ldots \ldots \square_{3} \ldots \ldots \square_{4}$
h. Stimulants $\ldots \ldots \ldots \ldots \ldots \square_{1} \ldots \ldots \square_{2} \ldots \ldots \ldots \square_{3} \ldots \ldots \square_{4}$
i. Sedatives ............ $\square_{1} \ldots \ldots \square_{2} \ldots \ldots \ldots \square_{3} \ldots \ldots \square_{4}$
j. I used some other drug(s) .... $\square_{1} \ldots \ldots \square_{2} \ldots \ldots \ldots \square_{3} \ldots \ldots . \square_{4}$ PLEASE LIST BELOW THE OTHER DRUG(S): 
DB-27. During the past 30 days, on how many days have you driven a car or other motor vehicle within 2 hours after using any cocaine?

Number of days during the past 30 days I drove a car or other motor vehicle within 2 hours after using cocaine ...........L.

I have not driven a car or other motor vehicle within 2 hours after using cocaine during the past 30 days $\ldots \ldots \ldots \ldots 93$

DB-28. Think about the most recent time you drove a car or other motor vehicle within 2 hours after using any cocaine. On this most recent occasion, did you use only cocaine, cocaine with alcohol, or cocaine with one or more other drugs? PLEASE MARK ONLY ONE BOX FOR THE BEST ANSWER.

I used only cocaine

I used cocaine with alcohol

I used cocaine with one or more other drugs

PLEASE LIST BELOW THE OTHER DRUG(S):

DB-29. Again thinking about the most recent occasion you drove a car or other motor vehicle within 2 hours after using any cocaine, where were you driving from? PLEASE MARK ONLY ONE BOX FOR THE BEST ANSWER.

My home $\ldots \ldots \ldots \ldots \ldots \ldots \ldots \ldots \ldots \ldots \ldots \ldots \ldots$

A friend or relative's home $\ldots \ldots \ldots \ldots \ldots \ldots \ldots \square_{2}$

A bar or nightclub $\ldots \ldots \ldots \ldots \ldots \ldots \ldots \ldots \ldots \ldots$

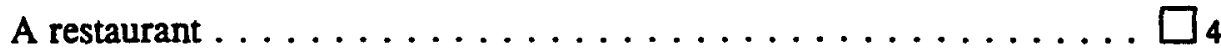

A sporting event $\ldots \ldots \ldots \ldots \ldots \ldots \ldots \ldots \ldots \ldots$

A concert ...................... $\square_{6}$

My workplace $\ldots \ldots \ldots \ldots \ldots \ldots \ldots \ldots \ldots$

Somewhere else ................... $\square_{8}$

PLEASE DESCRIBE BELOW THIS OTHER PLACE:

DB-30. On this most recent occasion when you drove a car or other motor vehicle within 2 hours after using any cocaine, where was the first place you drove to? PLEASE MARK ONLY ONE BOX FOR THE BEST ANSWER.

My home $\ldots \ldots \ldots \ldots \ldots \ldots \ldots \ldots \ldots \ldots \ldots \ldots$

A friend or relative's home $\ldots \ldots \ldots \ldots \ldots \ldots \ldots \ldots$

A bar or nightclub $\ldots \ldots \ldots \ldots \ldots \ldots \ldots \ldots$

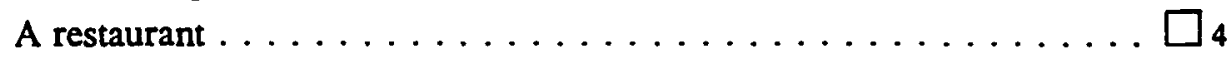

A sporting event $\ldots \ldots \ldots \ldots \ldots \ldots \ldots \ldots \ldots$

A concert ..................... $\square_{6}$

My workplace $\ldots \ldots \ldots \ldots \ldots \ldots \ldots \ldots \ldots$

No place in particular (I was just driving around) $\ldots \ldots \ldots \ldots \square_{8}$

Somewhere else ................... $\square$ g

PLEASE DESCRIBE BELOW THIS OTHER PLACE:

(PLEASE TURN TO THE NEXT PAGE) 
DB-31. Again, think about the most recent occasion when you drove within 2 hours after using any cocaine. Did you drive on an interstate, highway, or freeway, or only on smaller roads? PLEASE MARK ONLY ONE BOX FOR THE BEST ANSWER.

I drove on an interstate, highway, or freeway .......... $\square_{1}$

I drove only on smaller roads

DB-32. On this most recent occasion when you drove a car or other motor vehicle within 2 hours after using any cocaine, were you driving primarily in a rural, urban or suburban area? PLEASE MARK ONLY ONE BOX FOR THE BEST ANSWER.

Rural area (open country) $\ldots \ldots \ldots \ldots \ldots \ldots \ldots \ldots \ldots \ldots$

Urban area (city or town) $\ldots \ldots \ldots \ldots \ldots \ldots \ldots \ldots \ldots \ldots \ldots$

Suburban area (town just outside of a large city) $\ldots \ldots \ldots \ldots \ldots \square_{3}$

DB-33. On this most recent occasion when you drove a car or other motor vehicle within 2 hours after using any cocaine, on which day of the week were you driving?

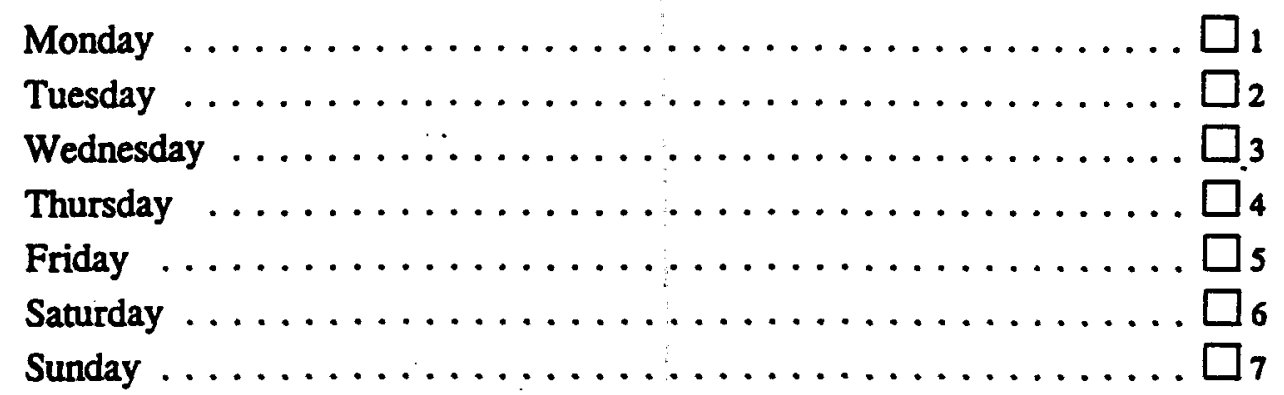

DB-34. On this most recent eccasion when you drove a car or other motor vehicle within 2 hours after using any cocaine, what time of day did you begin driving? PLEASE MARK ONLY ONE BOX FOR THE BEST ANSWER.

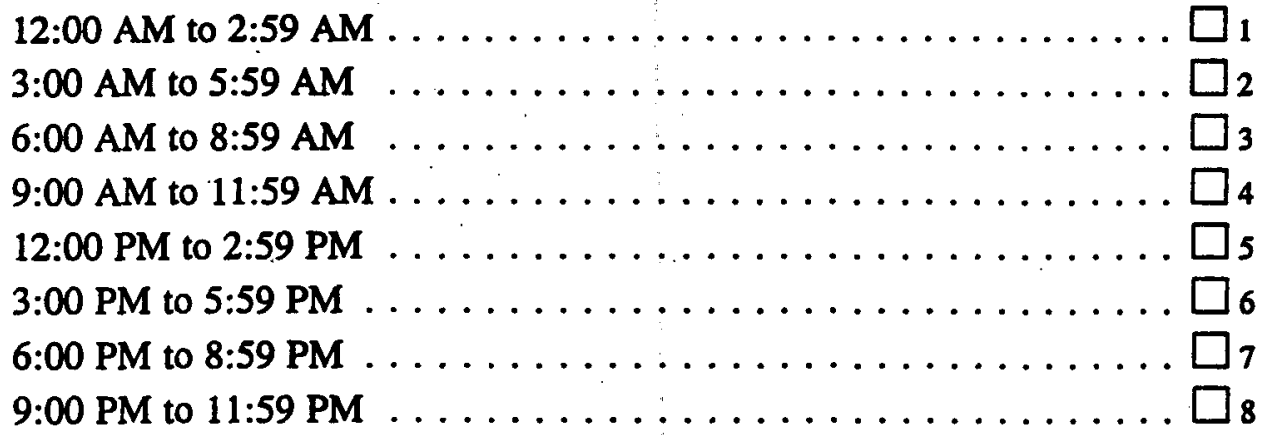

DB-35. On this most recent occasion when you drove a car or other motor vehicle within 2 hours after using any cocaine, how much do you think your use of cocaine reduced your ability to drive safely?

A lot $\ldots \ldots \ldots \ldots \ldots \ldots \ldots \ldots \ldots \ldots \ldots \ldots$

A little $\ldots \ldots \ldots \ldots \ldots \ldots \ldots \ldots \ldots \square_{2}$

Not at all $\ldots \ldots \ldots \ldots \ldots \ldots \ldots \ldots \ldots \ldots \ldots \ldots \ldots \ldots \ldots \ldots \ldots$

(PLEASE GO TO THE NEXT PAGE) 
DB-36. Some people drive after using cocaine because they have an appointment to keep, they have no one else to drive them, or for some other reason. As you read the following list of reasons, please mark one box beside each reason to indicate whether it is a reason why you drove within 2 hours after using any cocaine on this most recent occasion.

Reason why you drove? YES NO

a. There was no other way to get to where I was going $\square_{1} \ldots \ldots \quad \square 2$

b. I wasn't high enough to cause a crash . . . . . $\square_{1} \ldots \ldots \square_{2}$

c. The police would not be likely to catch me ..... $\square_{1} \ldots \square_{2}$

d. No one else was available to drive my motor vehicle $\square_{1} \ldots \square_{2}$

e. I had an appointment or curfew . . . . . ... $\square_{1} \ldots \square_{2}$

f. I drove for some other reason(s) $\ldots \ldots \ldots \ldots \ldots \square_{1} \ldots \ldots \square_{2}$ PLEASE SPECIFY REASON(S) BELOW:

DB-37. In general, when you drive within 2 hours after using any cocaine, how much more likely do you think it is that you will be stopped by the police than when you drive without using cocaine?

A lot more likely $\ldots \ldots \ldots \ldots \ldots \ldots \ldots \ldots$

A little more likely $\ldots \ldots \ldots \ldots \ldots \ldots \ldots \ldots \ldots$

No more likely $\ldots \ldots \ldots \ldots \ldots \ldots \ldots \ldots \ldots$

DB-38. In general, how much do you feel using any cocaine reduces your ability to drive safely?

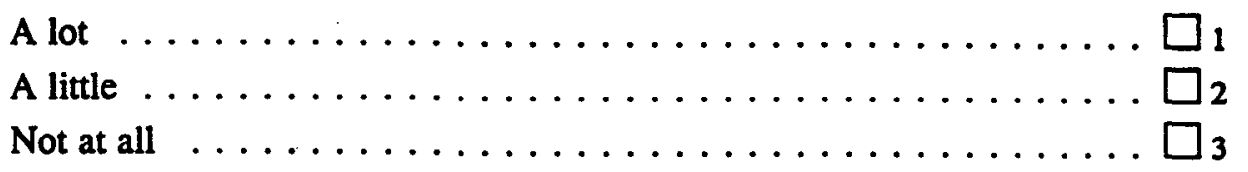

(PLEASE TURN TO THE NEXT PAGE) 
This next set of questions asks about your use of tranquilizers during the past 12 months. For these questions, include any prescription or over-the-counter tranquilizers you used for a medical reason, as well as any you used only for the experience or feeling they caused.

DB-39. Have you used any tranquilizers during the past 12 months?

YES, I have used tranquilizers during the past

12 months.$\square 1 \longrightarrow$ DB-40. During the past 12 months, have you driven a car or other motor vehicle within 2 hours after using any tranquilizers?

NO, I have not used tranquilizers during the past 12

YES, during the past 12 months, I have driven a

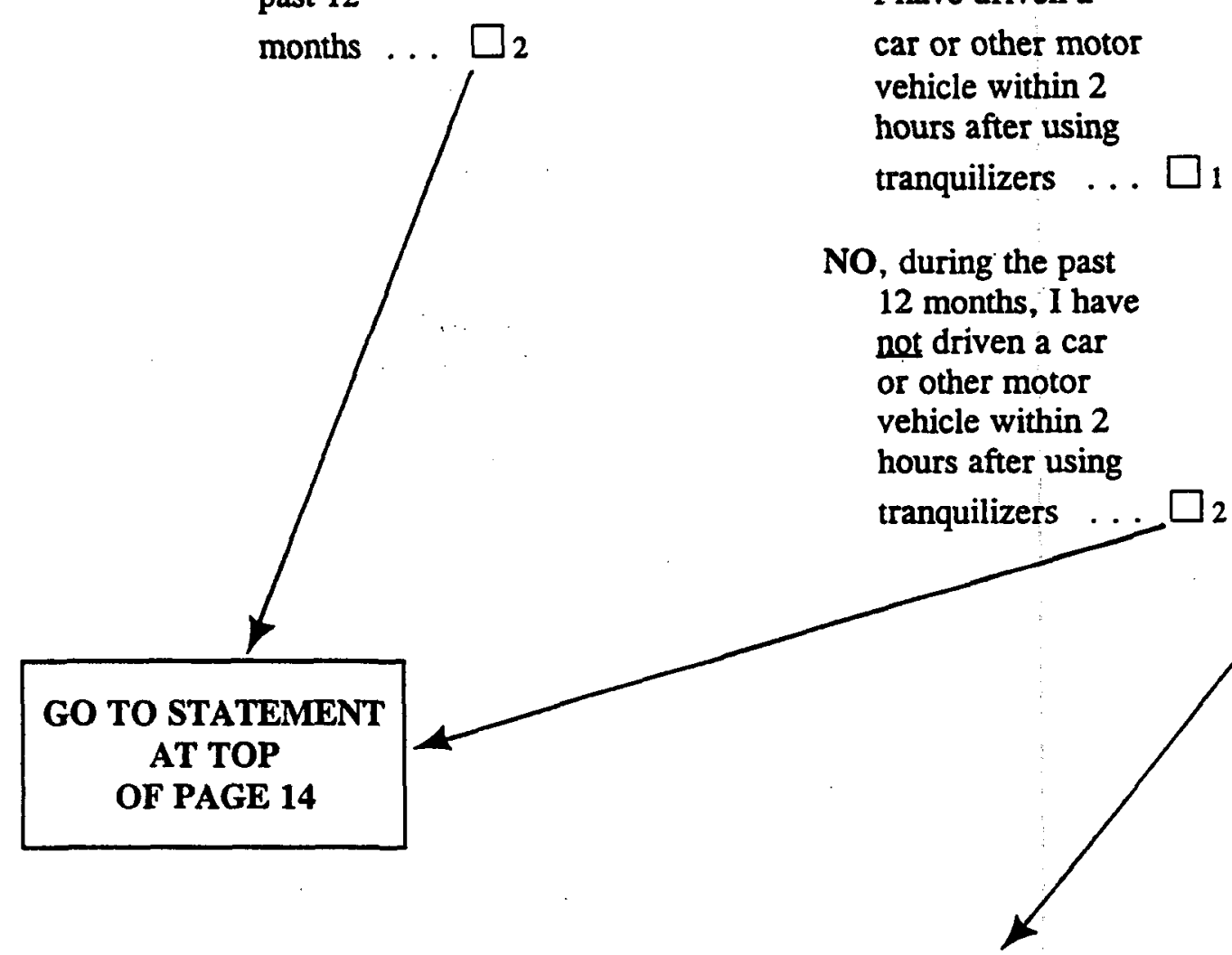

car or other motor vehicle within 2 hours after using tranquilizers $\ldots \square_{1}$

, during the past 12 months, I have not driven a car or other motor vehicle within 2 hours after using

DB-41. During the past 30 days, on how many days have you driven a car or other motor vehicle within 2 hours after using any tranquilizers?

Number of days during the past 30 days I drove a car or other motor vehicle within 2 hours after using tranquilizers $\ldots \ldots \ldots \ldots$

I have not driven a car or other motor vehicle within 2 hours after using tranquilizers during the past 30 days $\ldots \ldots \ldots \ldots 93$

(PLEASE GO TO THE NEXT PAGE) 
DB-42. Think about the most recent time you drove a car or other motor vehicle within 2 hours after using any tranquilizers. On this most recent occasion, did you use tranquilizers for a medical reason, or did you use them only for the experience or feeling they caused? PLEASE MARK ONLY ONE BOX FOR THE BEST ANSWER.

I used tranquilizers for a medical reason $\ldots \ldots \ldots \ldots \ldots \ldots \ldots \ldots \square_{1}$

I used tranquilizers only for the experience or feeling they caused $\ldots \ldots \ldots \ldots \square_{2}$

DB-43. On this most recent occasion when you drove a car or other motor vehicle within 2 hours after using any tranquilizers, did you use only tranquilizers, tranquilizers with alcohol, or tranquilizers with one or more other drugs? PLEASE MARK ONLY ONE BOX FOR THE BEST ANSWER.

I used only tranquilizers $\ldots \ldots \ldots \ldots \ldots \ldots \ldots \ldots \ldots \ldots \square_{1}$

I used tranquilizers with alcohol . . . . . . . . . . . . . . . . $\square_{2}$

I used tranquilizers with one or more other drugs $\ldots \ldots \ldots \ldots \ldots \ldots \ldots$ PLEASE LIST BELOW THE OTHER DRUG(S):

DB-44. On this most recent occasion when you drove a car or other motor vehicle within 2 hours after using any tranquilizers, how much do you think your use of tranquilizers (whether it was alone or along with one or more other drugs) reduced your ability to drive safely?

A lot $\ldots \ldots \ldots \ldots \ldots \ldots \ldots \ldots \ldots \ldots \ldots \ldots \ldots$

A little $\ldots \ldots \ldots \ldots \ldots \ldots \ldots \ldots \ldots \ldots \ldots \ldots \ldots \ldots \ldots \ldots$

Not at all $\ldots \ldots \ldots \ldots \ldots \ldots \ldots \ldots \ldots \ldots \ldots \ldots \ldots$

(PLEASE TURN TO THE NEXT PAGE) 
This next set of questions asks about your use of stimulants during the past 12 months. For these questions, include any prescription or over-the-counterstimulants you used for a medical reason, as well as any you used only for the experience or feeling they caused.

DB-45. Have you used any stimulants during the past 12 months?

YES, I have used

stimulants

during the past

12 months . $\square_{1} \longrightarrow \mathrm{DB}-46$. During the past 12 months, have you driven a car or other motor vehicle within 2 hours after using any stimulants?

NO, I have not used

stimulants

during the

YES, during the

past 12

past 12 months,

I have driven a

months ... $\square_{2}$

car or other motor

vehicle within 2

hours after using

stimulants ..... $\square_{\mathrm{l}}$

No, during the past

12 months, I have

not driven a car

or other motor

vehicle within 2

hours after using

stimulants . . . $\square_{2}$

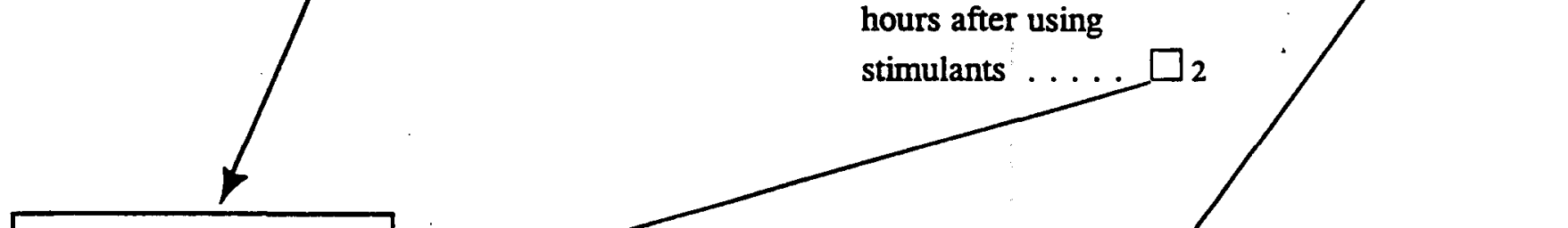

\section{GO TO STATEMENT}

AT TOP

OF PAGE 16

DB-47. During the past 30 days, on how many days have you driven a car or other motor vehicle within 2 hours after using any stimularits?

Number of days during the past 30 days I drove a car or other motor vehicle within 2 hours after using stimulants $\ldots \ldots \ldots \ldots$

I have not driven a car or other motor vehicle within 2 hours after using stimulants during the past 30 days $\ldots \ldots \ldots \ldots \ldots$ 
DB-48. Think about the most recent time you drove a car or other motor vehicle within 2 hours after using any stimulants. On this most recent occasion, did you use stimulants for a medical reason, or did you use them only for the experience or feeling they caused? PLEASE MARK ONLY ONE BOX FOR THE BEST ANSWER.

I used stimulants for a medical reason $\ldots \ldots \ldots \ldots \ldots \ldots \ldots$

I used stimulants only for the experience or feeling they caused $\ldots \ldots \square_{2}$

DB-49. On this most recent occasion when you drove a car or other motor vehicle within 2 hours after using any stimulants, did you use only stimulants, stimulants with alcohol, or stimulants with one or more other drugs? PLEASE MARK ONLY ONE BOX FOR THE BEST ANSWER.

I used only stimulants $\ldots \ldots \ldots \ldots \ldots \ldots \ldots \ldots \ldots \ldots$

I used stimulants with alcohol $\ldots \ldots \ldots \ldots \ldots \square_{2}$

I used stimulants with one or more other drugs $\ldots \ldots \ldots \ldots \ldots \square_{3}$

PLEASE LIST BELOW THE OTHER DRUG(S):

DB-50. On this most recent occasion when you drove a car or other motor vehicle within 2 hours after using any stimulants, how much do you think your use of stimulants (whether it was alone or along with one or more other drugs) reduced your ability to drive safely?

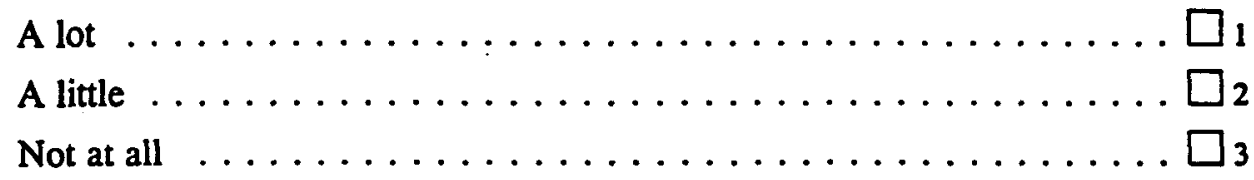

(PLEASE TURN TO THE NEXT PAGE) 
This next set of questions asks about your use of sedatives during the past 12 months. For these questions, include any prescription or over-the-counter sedatives you used for a medical reason, as well as any you used only for the experience or feeling they caused.

DB-51. Have you used any sedatives during the past 12 months?

YES, I have used

sedatives

during the past

12 months.$\square_{1} \longrightarrow$ DB-52. During the past 12 months, have you driven a car or other motor vehicle within 2 hours after using any sedatives?

NO, I have not used

sedatives

during the

past 12

YES, during the

past 12 months,

I have driven a

months ... $\square_{2}$

car or other motor

vehicle within 2

hours after using

sedatives . . . . $\square 1$

No, during the past

12 months, I have

not driven a car

or other motor

vehicle within 2

hours after using

sedatives ..... $\square_{2}$

GO TO BOX A

AT BOTTOM

OF PAGE 17

DB-53. During the past 30 days, on how many days have you driven a car or other motor vehicle within 2 hours after using any sedatives?

Number of days during the past 30 days I drove a car or other motor vehicle within 2 hours after using sedatives $\ldots \ldots \ldots \ldots \ldots$

I have not driven a car or other motor vehicle within 2 hours after using sedatives during the past 30 days . . . . . . . . . . $\square 93$ 
DB-54. Think about the most recent time you drove a car or other motor vehicle within 2 hours after using any sedatives. On this most recent occasion, did you use sedatives for a medical reason, or did you use them only for the experience or feeling they caused? PLEASE MARK ONLY QNE BOX FOR THE BEST ANSWER.

I used sedatives for a medical reason $\ldots \ldots \ldots \ldots \ldots \ldots \ldots$

I used sedatives only for the experience or feeling they caused . . . . . . . $\square 2$

DB-55. On this most recent occasion when you drove a car or other motor vehicle within 2 hours after using any sedatives, did you use only sedatives, sedatives with alcohol, or sedatives with one or more other drugs? PLEASE MARK ONLY ONE BOX FOR THE BEST ANSWER.

I used only sedatives $\ldots \ldots \ldots \ldots \ldots \ldots \ldots \ldots \ldots \ldots$

I used sedatives with alcohol $\ldots \ldots \ldots \ldots \ldots \ldots \ldots \ldots$

I used sedatives with one or more other drugs . . . . . . . . . . $\square_{3}$

PLEASE LIST BELOW THE OTHER DRUG(S):

DB-56. On this most recent occasion when you drove a car or other motor vehicle within 2 hours after using any sedatives, how much do you think your use of sedatives (whether it was alone or along with one or more other drugs) reduced your ability to drive safely?

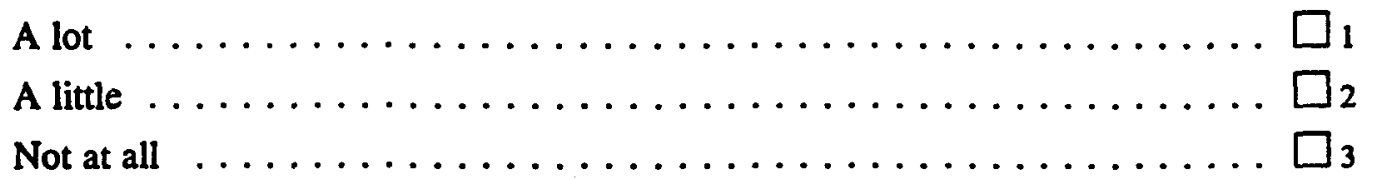

\begin{tabular}{|c|c|}
\hline \multirow{3}{*}{ BOX A } & YOU HAVE FINISHED THE QUESTIONS ABOUT DRIVING BEHAVIORS. \\
& THANK YOU FOR ANSWERING THESE QUESTIONS. \\
TELL THE INTERVIEWER THAT YOU ARE FINISHED WITH THE DRIVING \\
BEHAVIORS QUESTIONS.
\end{tabular}


Place an "X" next to the items you would like to receive and legibly print or type your mailing address below.

\section{National Household Survey on Drug Abuse (NHSDA) Series:}

Preliminary Results from the 1997 National Household Survey on Drug Abuse (BKD275)

1997 NHSDA Population Estimates (BKD273)

1996 NHSDA Main Findings (BKD261)

\section{Drug Abuse Warning Network (DAWN) Series}

Mid-Year 1997 Preliminary Emergency Department Data from the Drug Abuse Warning Network (BKD264)

Year-End Preliminary Estimates from the 1996 Drug Abuse Warning Network (BKD243)

1996 DAWN Annual Medical Examiner Data (BKD263)

1994 DAWN Annual Emergency Department Data (BKD210)

\section{Drug and Alcohol Services Information System (DASIS) Series:}

Uniform Facility Data Set (UFDS): Data for 1996 and 1980-1996 (BKD244)

National Directory of Drug Abuse and Alcoholism Treatment and Prevention Programs, 1997 (BKD283)

National Admissions to Substance Abuse Treatment Services: The Treatment Episode Data Set (TEDS) 1992-1996 (BKD269)

\section{Analytic Series}

\section{Driving After Drug or Alcohol Use: Findings from the 1996 NHSDA (BKD274)}

An Analysis of Worker Drug Use and Workplace Policies and Programs (BKD237)

Substance Use Among Women in the United States (BKD238)

Prevalence of Substance Use Among Racial and Ethnic Subgroups in the United States, 1991-1993 (BKD262)

Services Research Outcomes Study (BKD245)

Analyses of Substance Abuse and Treatment Need Issues (BKD267)

Substance Abuse and Mental Health Statistics Source Book, 1998 (BKD287)

\section{Methodology Series}

Drug Abuse Warning Network Sample Design and Estimation Procedures--Technical Report (BKD249)

Substance Abuse in States and Metropolitan Areas: Model Based Estimates from the 1991-1993 National Household Surveys on Drug Abuse--Methodology Report (BKD233)

Please add my name to the mailing list to receive future issues of the publications that $I$ am requesting. NAME:

ADDRESS:

Office of Applied Studies information materials can be accessed from SAMHSA's Internet Website at: http://www.samhsa.gov. 
NATIONAL CLEARINGHOUSE FOR ALCOHOL AND DRUG INFORMATION P. O. BOX 2345

ROCKVILLE, MD 20847-2345 


\section{Substance Abuse and Mental Health Services Administration (SAMHSA) \\ Office of Applied Studies Publications Series}

\section{National Household Survey on Drug Abuse Series:}

Reports in the Household Survey Series present information from SAMHSA's National Household Survey on Drug Abuse. This representative survey is the primary source of information on the prevalence, patterns, and consequences of drug and alcohol use and abuse in the general U.S. civilian non-institutionalized population, age 12 and older. This survey has been conducted every one to three years since 1971. Standard publications in the Household Survey Series include: Population Estimates, Main Findings, and Preliminary Data Reports.

"H" Series publications currently available:

H-1: National Household Survey on Drug Abuse: Main Findings 1995

H-2: The Prevalence and Correlates of Treatment for Drug Problems

H-3: Preliminary Results from the 1996 National Household Survey on Drug Abuse

H-4: National Household Survey on Drug Abuse: Population Estimates 1996

H-5: National Household Survey on Drug Abuse: Main Findings 1996

H-6: Preliminary Results from the 1997 National Household Survey on Drug Abuse

H-7: National Household Survey on Drug Abuse: Population Estimates 1997

\section{Drug Abuse Warning Network (DAWN) Series:}

Reports in the DAWN Series provide data on the number and characteristics of (1) drug abuse related visits to a national representative sample of hospital emergency departments, and (2) drug abuse related deaths from selected medical examiner offices in the DAWN system. The medical examiner cases are not from a national representative sample. DAWN is an ongoing data system that began in the early 1970 s.

" $\mathrm{D}$ " Series publications currently available:

D-1: Drug Abuse Warning Network Annual Medical Examiner Data 1995

D-2: Mid-Year Preliminary Estimates from the 1996 Drug Abuse Warning Network

D-3: Year-End Preliminary Estimates from the 1996 Drug Abuse Warning Network

D-4: Drug Abuse Warning Network Annual Medical Examiner Data 1996

D-5: Mid-Year 1997 Preliminary Emergency Department Data from the Drug Abuse Warning Network 


\section{Drug and Alcohol Services Information System Series:}

Reports in the Services Series provide national and state level data on (1) the characteristics of specialty treatment facilities providing drug and alcohol services and (2) the number and types of patients treated. The Services Series also includes the National Directory of Drug Abuse and Alcoholism Treatment and Prevention Programs. The publications in this Series are based on SAMHSA's Drug and Alcohol Services Information System (DASIS).

"S" Series publications currently available:

S-1: National Directory of Drug Abuse and Alcoholism Treatment and Prevention Programs 1996

S-2: $\quad$ Uniform Facility Data Set (UFDS): Data for 1995 and 1980-1995

S-3: $\quad$ Uniform Facility Data Set (UFDS): Data for 1996 and 1980-1996

S-4R: National Directory of Drug Abuse and Alcoholism Treatment and Prevention Programs 1997

S-5: $\quad$ National Admissions to Substance Abuse Treatment Services: The Treatment Episode Data Set (TEDS) 1992-1996

\section{Analytic Series:}

Reports in the Analytic Series address special topics relating to alcohol, drug abuse, and mental health. The Analytic Series generally provides data from outcome and other special studies, secondary analysis of multiple data sources, or more in-depth analysis of the data presented in the standard annual reports in the other Office of Applied Studies publication series.

"A" Series publications currently available:

A-1: Employment Outcomes of Indigent Clients Receiving Alcohol and Drug Treatment in Washington State

A-2: $\quad$ An Analysis of Worker Drug Use and Workplace Policies and Programs

A-3: $\quad$ Substance Use Among Women in the United States

A-4: $\quad$ Substance Abuse and Mental Health Statistics Source Book 1998

A-5: $\quad$ Services Research Outcomes Study

A-6: Prevalence of Substance Use Among Racial and Ethnic Subgroups in the United States, 1991-1993

A-7: Analyses of Substance Abuse and Treatment Need Issues

A-8: Driving After Drug or Alcohol Use: Findings from the 1996 NHSDA

\section{Methodology Series:}

Reports in the Methodology Series address methodological issues concerning data collection systems conducted by SAMHSA's Office of Applied Studies. These reports include studies of new statistical techniques and theories, survey methods, sample design, survey instrument design, and objective evaluations of the reliability of collected data.

"M" Series publications currently available:

M-1: Substance Abuse in States and Metropolitan Areas: Model Based Estimates from the 19911993 NHSDA--Methodology Report

M-2: Drug Abuse Warning Network Sample Design and Estimation Procedures--Technical Report 


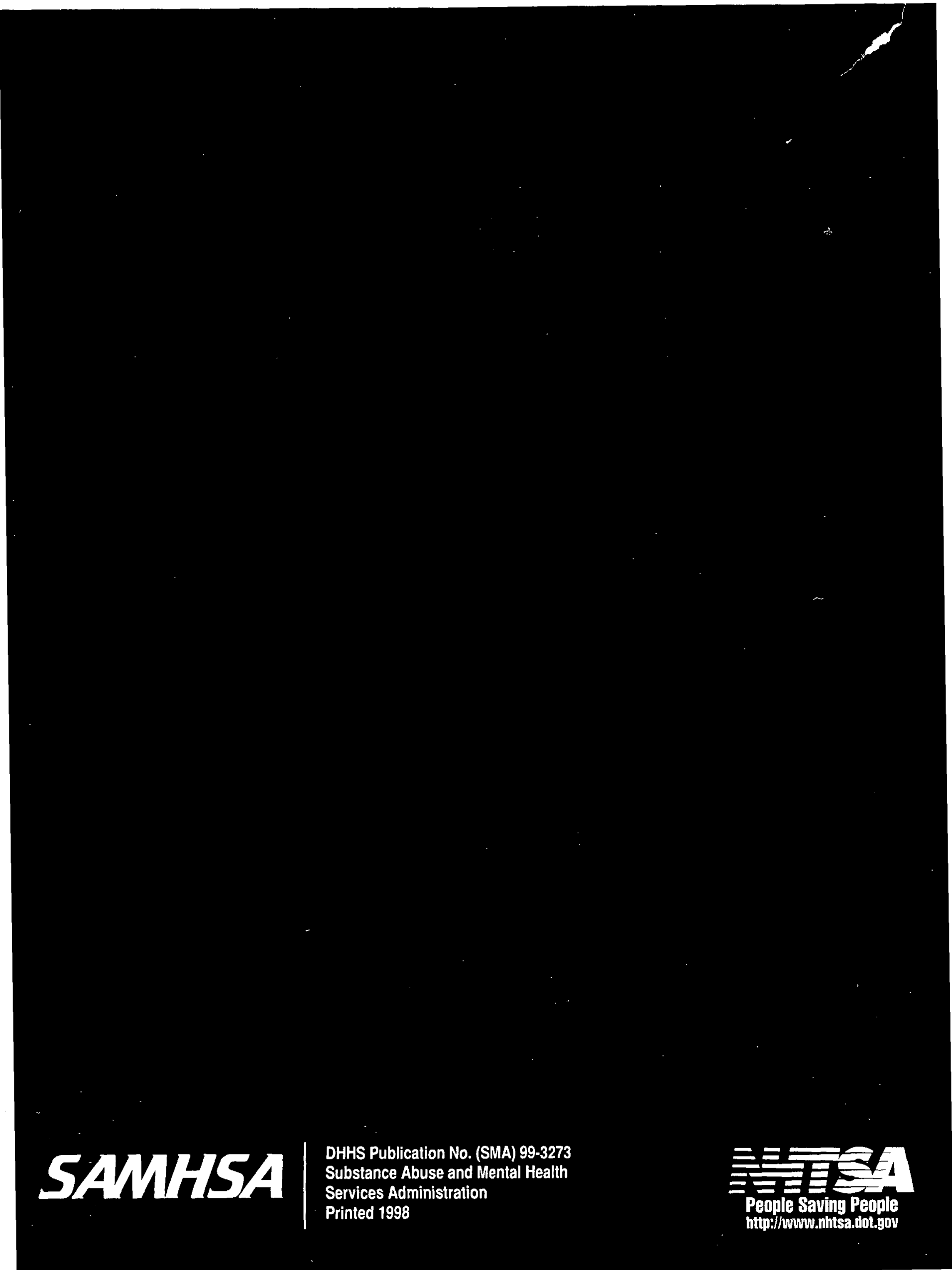

